NBER WORKING PAPER SERIES

\title{
HOW QUANTITATIVE EASING WORKS: EVIDENCE ON THE REFINANCING CHANNEL
}

\author{
Marco Di Maggio \\ Amir Kermani \\ Christopher Palmer \\ Working Paper 22638 \\ http://www.nber.org/papers/w22638 \\ NATIONAL BUREAU OF ECONOMIC RESEARCH \\ 1050 Massachusetts Avenue \\ Cambridge, MA 02138 \\ September 2016
}

A previous version of this paper was circulated under the title, "Unconventional Monetary Policy and the Allocation of Credit." For helpful comments and discussions, we thank our discussants, Florian Heider, Anil Kashyap, Deborah Lucas, Philipp Schnabl, and Felipe Severino; Adam Ashcraft, Charles Calomiris, Andreas Fuster, Robin Greenwood, Sam Hanson, Arvind Krishnamurthy, Michael Johannes, David Romer, David Scharfstein, Jeremy Stein, Johannes Stroebel, Stijn Van Nieuwerburgh, Annette Vissing-Jørgensen, and Paul Willen; workshop participants at Berkeley and Columbia; and seminar participants at NBER Monetary Economics, the Econometric Society 2016 Meetings, the EEA 2016 meetings, Federal Reserve Board, HEC Paris, Northwestern-Kellogg, NYU-Stern, NY Fed/NYU Stern Conference on Financial Intermediation, the Paul Woolley Conference at LSE, Penn State, San Francisco Federal Reserve, Stanford, Stanford GSB, St. Louis Fed Monetary Policy and the Distribution of Income and Wealth Conference, University of Minnesota-Carlson, University of Illinois at UrbanaChampaign, and USC-Price. We also thank Sam Hughes, Sanket Korgaonkar, Christopher Lako, and Jason Lee for excellent research assistance. The views expressed herein are those of the authors and do not necessarily reflect the views of the National Bureau of Economic Research.

NBER working papers are circulated for discussion and comment purposes. They have not been peer-reviewed or been subject to the review by the NBER Board of Directors that accompanies official NBER publications.

(C) 2016 by Marco Di Maggio, Amir Kermani, and Christopher Palmer. All rights reserved. Short sections of text, not to exceed two paragraphs, may be quoted without explicit permission provided that full credit, including $\odot$ notice, is given to the source. 
How Quantitative Easing Works: Evidence on the Refinancing Channel

Marco Di Maggio, Amir Kermani, and Christopher Palmer

NBER Working Paper No. 22638

September 2016, Revised September 2016

JEL No. E21,E58,E65,G01,G18,G21,R28

\begin{abstract}
Despite massive large-scale asset purchases (LSAPs) by central banks around the world since the global financial crisis, there is a lack of empirical evidence on whether and how these programs affect the real economy. Using rich borrower-linked mortgage-market data, we document that there is a "flypaper effect" of LSAPs, where the transmission of unconventional monetary policy to interest rates and (more importantly) origination volumes depends crucially on the assets purchased and degree of segmentation in the market. For example, QE1, which involved significant purchases of GSE-guaranteed mortgages, increased GSE-eligible mortgage originations significantly more than the origination of GSE-ineligible mortgages. In contrast, QE2's focus on purchasing Treasuries did not have such differential effects. We find that the Fed's purchase of MBS (rather than exclusively Treasuries) during QE1 resulted in an additional $\$ 600$ billion of refinancing, substantially reducing interest payments for refinancing households, leading to a boom in equity extraction, and increasing consumption by an additional $\$ 76$ billion. This de facto allocation of credit across mortgage market segments, combined with sharp bunching around GSE eligibility cutoffs, establishes an important complementarity between monetary policy and macroprudential housing policy. Our counterfactual simulations estimate that relaxing GSE eligibility requirements would have significantly increased refinancing activity in response to QE1, including a $20 \%$ increase in equity extraction by households. Overall, our results imply that central banks could most effectively provide unconventional monetary stimulus by supporting the origination of debt that would not be originated otherwise.
\end{abstract}

\author{
Marco Di Maggio \\ Harvard Business School \\ Baker Library 265 \\ Soldiers Field \\ Boston, MA 02163 \\ and NBER \\ mdimaggio@hbs.edu \\ Amir Kermani \\ Haas School of Business \\ University of California, Berkeley \\ 545 Student Services Building \#1900 \\ Berkeley, CA 94720 \\ and NBER \\ kermani@berkeley.edu
}

\author{
Christopher Palmer \\ Haas School of Business \\ University of California, Berkeley \\ 545 Student Services Building \#1900 \\ Berkeley, CA 94720 \\ cjpalmer@berkeley.edu
}




\section{Introduction}

In recent years, many central banks have undertaken unconventional monetary policy to stimulate their economies, mainly through long-duration large-scale asset purchase programs (LSAPs). A common feature of these programs is their significant size; the Federal Reserve, for example, has increased the size of its balance sheet more than fivefold (\$3.6 trillion) since 2008 (see Figure 1). However, LSAPs have varied significantly in the type of assets purchased by central banks, e.g., from Treasuries and Agency debt in the U.S. to ETFs and corporate bonds in Japan. Despite the newfound popularity of LSAPs worldwide, their effectiveness and the channels through which they affect the real economy have been at the center of a vigorous policy and academic debate. We contribute to this debate by investigating the channels through which LSAPs impact the real economy and, in particular, household debt issuance. ${ }^{1}$

There is no clear consensus on whether LSAPs do benefit an economy or on potential transmission mechanisms. Non-standard open-market operations are inconsequential in a frictionless world, as shown by Wallace (1981) and Eggertsson and Woodford (2003). Moving away from a frictionless world, the literature on unconventional monetary policy has suggested multiple explanations for why LSAPs may have real effects. We highlight three of these pathways - see Krishnamurthy and Vissing-Jorgensen (2011) for a comprehensive treatment of such channels along with empirical evidence from asset yields on the relative importance of each. First, under the portfolio-balancing channel, the central bank affects the return of different assets by affecting their relative supply. ${ }^{2}$ Second, the segmentation channel posits that LSAPs are effective when capital-constrained intermediaries in the secondary market are unable to arbitrage in the short run across different market segments (e.g., Vayanos and Vila, 2009, He and Krishnamurthy, 2013 and Greenwood et al., 2015). ${ }^{3}$ Third, the capital-constraints channel highlights how LSAPs can offset the decline in private lend-

\footnotetext{
${ }^{1}$ As discussed below, the "what you buy matters" point was first made by Krishnamurthy and Vissing-Jørgensen (2011) using asset prices and credit spreads.

${ }^{2}$ LSAPs could have real effects by taking safe assets out of the market and therefore inducing cautious investors to take more risk. For related arguments, see Gurley and Shaw (1960), Tobin and Brainard (1963), Tobin (1969), and Brunner et al. (1973).

${ }^{3}$ We refer to this channel as the duration-segmentation channel if the inhibiting segmentation is along asset duration. The key assumption in these models is that most investors in the asset market specialize in trading a specific asset class-or have strong preferences for a specific asset class-while there are few capital-constrained intermediaries who arbitrage between different markets. Thus, by directly purchasing specific assets, the Fed increases the price of that asset class more than others in the short run. The more constrained the arbitrageurs are, the longer it will take other asset class prices to be affected by the LSAPs.
} 
ing from disruptions in financial intermediation (see Gertler and Karadi, 2011 and Curdia and Woodford, 2011). ${ }^{4}$

Under the portfolio-balancing and duration-segmentation channels, only the duration (or riskiness) of assets purchased drives their effectiveness because investors will reallocate their resources to other similar assets not purchased by the central bank. However, if investors specialize in trading a specific asset class, or if the financial intermediation sector is constrained, there will be only limited spillovers of central-bank purchases to other asset classes, and the effectiveness and allocative effects of LSAPs will depend on not only the duration but also the specific type of assets purchased. In other words, to the extent that portfolio rebalancing or duration-segmentation is driving the effectiveness of LSAPs, we should observe spillovers from central-bank purchases to other assets with similar duration. An absence of such spillovers would support the view that LSAPs stimulate real activity through the capital constraints channel/narrow-segmentation channel. This paper provides new empirical evidence for this narrow segmentation channel.

Identifying the effects of aggregate policies is particularly challenging given that such policies intentionally respond to current and anticipated aggregate shocks. For traction, most of the literature has used event studies of short-run asset-price changes immediately surrounding central bank policy announcements. We supplement such before/after comparisons with an identification strategy that exploits the segmentation of the U.S. mortgage market and the legal restriction that the Fed can only purchase mortgages guaranteed by the Government Sponsored Enterprises (GSEs). The outstanding balance on GSE-guaranteed mortgages must be less than so-called conforming loan limits and must have loan-to-value ratios at or below 80 percent. ${ }^{5}$ This allows us to estimate the effects of quantitative easing by contrasting how each LSAP campaign affected refinancing activities in the conforming and non-conforming segments. Specifically, finding spillovers between these two segments supports the portfolio-rebalancing channel or duration-segmentation channels of unconventional monetary policy, while rejecting spillovers would be more consistent with the

\footnotetext{
${ }^{4}$ In contrast to the segmentation channel, the capital constraint channel highlights the role of loan originators, rather than investors in the secondary market, being constrained. It posits that disruptions in private lending might be alleviated by the Fed's financing of loans to the most affected sectors, i.e. Fed supporting mortgage originations in response to the housing market crash.

${ }^{5}$ An important exception to the $80 \%$ LTV cutoff was made possible by the Home Affordable Refinancing Program (HARP), a policy we show had visible effects on the effectiveness of Fed MBS purchases. Additionally, mortgages with (often expensive) private mortgage insurance (PMI) are exempt from the $80 \%$ LTV requirement, although the PMI industry was virtually nonexistent in 2009.
} 
capital-constraints or narrow segmentation channels.

We start our analysis by considering the changes in mortgage interest rates. Consistent with existing work, we find that interest rates decreased by more than 100 basis points on average in response to the beginning of QE1. However, we show that interest rates on jumbo loans decreased significantly less, increasing the jumbo-conforming spread by 40-50 basis points. By contrast, QE2, the Maturity Extension Program (MEP or "Operation Twist") enacted in September 2011, and QE3 led to overall mortgage rate reductions of 20-40 basis points without detectable differential effects across conforming and non-conforming segments. We also investigate the effects of the Fed's decision to taper its MBS purchases starting in June 2013, finding that rates increased in response by about 25 basis points more for the conforming segment than the non-conforming segment.

We then turn to examining the main question of the paper, how unconventional monetary policy affected the volume of new mortgages issued. We find that financial institutions more than tripled their monthly origination of mortgages that were eligible for purchase by the Fed around the announcement of QE1, while the origination of loans above the conforming loan limits increased only modestly. Next, we verify that this heterogeneity in the mortgage market response to QE1 was a function of the type of debt the central bank purchased, by contrasting the effect of various $\mathrm{QE}$ episodes. As shown in Figure 3 and discussed in more detail in Section 3, QE1 and QE3 involved MBS and Treasury purchases, while QE2 purchases consisted exclusively of Treasuries. We show that MBS purchases had a relatively immediate and economically significant effect on refinancing activity. QE1 in particular, which occurred at a time when the banking sector was much less healthy than in QE3, had a much stronger impact on the origination of mortgages that were eligible to be bundled into the type of MBS that the Fed was purchasing, with more modest effects on other types of mortgages. We estimate that QE1 increased refinance-mortgage origination by over $\$ 600$ billion, substantially reducing interest payments for refinancing households and resulting in larger average annual savings than the one-time stimulus checks. Our back-of-the-envelope calculations suggest that these savings and the corresponding boom in equity extraction increased mortgagors' consumption by $\$ 76$ billion. Importantly, we find that the QE1-induced reduction in interest rates can only explain about $25-45 \%$ of the observed increase in the refinancing volume, meaning that most of the increase in the origination of refinance loans was directly attributable to the Fed purchasing MBS rather than an indirect effect of lowering long-maturity yields market-wide. 
Our focus on quantities has several advantages over studies that rely on high-frequency event studies of asset prices. Asset prices respond immediately to central bank announcements, making it unlikely that other shocks hit market prices in narrow windows around QE announcements. However, market price reactions in the immediate short run might be very different from the programs' effects in the longer run. ${ }^{6}$ Second, event-study papers investigate secondary-market yields. ${ }^{7}$ To the extent that the pass-through of mortgage-backed securities (MBS) yields to primary-market mortgage interest rates is imperfect during this period (as documented in Fuster et al., 2013 and Scharfstein and Sunderam, 2013), these studies may overstate the real effect of LSAPs. More importantly, interest rates are observed conditional on origination, meaning that inferring the effects of unconventional monetary policy by merely looking at interest rate changes will be an overstatement by assuming perfect availability of credit. ${ }^{8}$ This motivates our focus on the detection of "real effects," specifically the effects of credit easing on the primary mortgage market induced by LSAPs as distinct from effects on financial variables like asset prices and interest rates.

To identify the causal impacts of LSAPs, we account for time-varying credit demand and supply shocks that might otherwise confound our results. First, our loan-level dataset combines agency and non-agency mortgages, allowing us, for example, to compare observationally similar loans above and below the conforming loan limit that are plausibly exposed to the same shocks to funding and fundamentals. Event studies support this parallel trends assumption, particularly with our specifications' tight windows around policy dates. Further steps to address demand shocks include focusing on refinance mortgages, which are mainly driven by changes in interest rates as opposed to changes in the demand for housing (purchase mortgages), and controlling for regional shocks to fundamentals (income, house prices, expectations, etc.) by controlling for county $\times$ month effects. Several additional measures suggest that our results are not driven by segment-specific credit supply shocks. We focus our analysis on the post-2008 period to avoid making inferences off of the asset-backed securities market disruptions that differentially affected the jumbo-lending market as it transitioned away from being heavily reliant on private securitization (Chernenko,

\footnotetext{
${ }^{6}$ This can be either because of partial segmentation of different asset classes as in Greenwood et al. (2015) or because investors' understanding of the effectiveness of LSAPs changes over time.

${ }^{7} \mathrm{~A}$ notable exception is Hancock and Passmore (2011), who look for effects on primary-market mortgage rates.

${ }^{8}$ The preponderance of fixed-rate mortgages in the United States means that most households need to qualify for a new refinance mortgage to benefit from monetary stimulus, excluding underwater fixed-rate borrowers (and fixed-rate borrowers who cannot qualify for new refinance mortgages) from the direct benefits of QE.
} 
Hanson, and Sunderam, 2014). We also show that our results are robust to the inclusion of timeseries controls proxying for segment-specific shocks to funding availability (BBB-AAA credit spreads, GSE guarantee fee changes, and premia on bank credit default swaps).

Finally, we complement this mortgage-level evidence with borrower-level evidence using a novel dataset linking mortgages to borrowers and their credit bureau information to track borrowers before and after they take out a new mortgage to study how households responded to the differential improvement of the GSE-eligible segment of the mortgage market. Theoretically, refinancing can affect consumption through three different channels. First, savings from lower monthly payments result in immediately higher disposable income (Di Maggio et al., 2014 and Keys et al., 2014). Second, the present value of lower interest payments functions as a positive (albeit illiquid) wealth shock for borrowers even absent any change in monthly payments. While both these channels support increased consumption by refinancers, a third channel might amplify or mitigate the strength of such a response in aggregate. When borrowers have insufficient equity to refinance, they may cash-in refinance by bringing cash to closing to take out a smaller loan than their previous one, decreasing their stock of liquid wealth but also decreasing the present value of their mortgage liability. Conversely, borrowers with sufficient equity may choose to cash-out refinance, with the opposite implication for cash-on-hand and possibly with a different impact on consumption (Kaplan and Violante, 2014 and Greenwald, 2016).

This effect is indeed sizable; over 35\% of jumbo borrowers who refinanced from 2008-2013 took out a GSE-eligible loan, on average paying down their original mortgages by $\$ 73,000 .{ }^{9}$ A similar fraction of borrowers who refinance loans with current LTVs over 80 percent engage in cash-in refinancing, on average paying down $\$ 9,000$ of mortgage principal. Importantly, we also find that the Home Affordable Refinancing Program (HARP) alleviated this deleveraging behavior significantly by allowing eligible high-LTV borrowers refinancing opportunities, highlighting the complementarity between unconventional monetary policy and other interventions in the mortgage market. However, our counterfactual exercise finds that a simple countercyclical macroprudential policy lever raising the GSE LTV eligibility cutoff from $80 \%$ to $90 \%$ would have resulted in a $16 \%$ increase in refinanced loans and a $20 \%$ increase in equity cashed out, further supporting aggregate

\footnotetext{
${ }^{9}$ Note that this cashing-in is not driven by splitting the mortgages into a GSE-eligible first lien and a second lien.
} 
demand. ${ }^{10}$

Quantitative Easing works through a refinancing channel by improving credit availability and lowering interest rates for affected households. Aggregate demand increases from refinancing households consuming much of their cashed-out equity and monthly mortgage payment savings. The targeted nature of the Fed's MBS purchase program coupled with its lack of spillovers during QE1 means that Fed purchases de facto allocated credit within the mortgage market towards GSE-eligible borrowers. An immediate implication of this lack of reallocation is that the borrowers who benefitted the most from monetary stimulus during the recession had relatively high levels of home equity or cash-on-hand and disproportionately lived in the least hard-hit areas.

The paper proceeds as follows. Section 2 reviews the relevant academic literature on monetary policy transmission. Section 3 provides further background on the Federal Reserve's Quantitative Easing program as well as institutional details about the credit markets we study in this paper. Sections 4 and 5 detail the data sources used in our analysis and our research design, respectively. Section 6 presents our results on debt origination, household behavior, along with several alternative specifications and robustness checks to address threats to validity. Section 7 uses our empirical model to simulate the amount of refinancing that would have occurred under a counterfactual macroprudential policy of countercyclical LTV caps. Finally, Section 8 summarizes and concludes with a discussion of policy implications.

\section{Related Literature}

The main contribution of this paper is to provide evidence that the Fed de facto allocated credit through LSAPs and to show that these programs had limited spillovers to other assets. It contributes to the empirical literature on LSAPs which generally finds that targeted asset purchases and/or direct extensions of credit to private borrowers by the Fed and other central banks have affected equilibrium rates of return, including Ashcraft et al. (2011), Baba et al. (2006), Gagnon et al. (2010), Hancock and Passmore (2011), Sarkar and Shrader (2010), Stroebel and Taylor (2012)

\footnotetext{
${ }^{10}$ This increase would have been more than HARP achieved its first year. As discussed below, HARP's effectiveness was limited relative to increasing the LTV cap because HARP did not allow borrowers to cash-out. We find that cash-out refinances can play a large role in supporting aggregate demand.
} 
and Swanson (2015). ${ }^{11}$ The key studies we build on are Krishnamurthy and Vissing-Jorgensen (2011, 2013), who, among other things, illustrate that QE1 MBS purchases affected MBS yields more than QE2 Treasury purchases. In addition to providing corroborating evidence on the effects of QE on asset returns as highlighted by these papers, we complement this literature by documenting how LSAPs shaped the refinancing activities in the aftermath of the crisis, finding that the previously documented yield curve changes explain some of the change in debt issuance but ultimately underpredict the effectiveness (and heterogenous effects of) QE.

Our results also inform the growing theoretical literature studying the effects of unconventional monetary policy. Until the financial crisis, the benchmark theory for many macroeconomists has always been that non-standard open market operations in private assets are irrelevant as shown first by Wallace (1981), and extended to models with nominal frictions, money in the utility function and zero nominal interest rate by Eggertsson and Woodford (2003). The idea in these papers is that once the nominal interest rate reaches its lower bound, liquidity has no further role in this class of economies, or in most other standard models with various types of frictions, such as Rotemberg and Woodford (1997) or Christiano et al. (2005).

In the aftermath of the crisis, other studies have highlighted the mechanisms through which unconventional monetary policy can have a significant impact. For instance, Curdia and Woodford (2011) provide a model with heterogeneous agents and imperfections in private financial intermediation to demonstrate that quantitative easing will affect the economy provided either 1) the increase in reserves increases central-bank lending to the private sector or 2) the policy changes expectations about how future interest-rate policy will be conducted, both of which seem to be satisfied by QE1. Brunnermeier and Sannikov (2015) show that monetary policy can work against the adverse feedback loops that precipitate crises by affecting the prices of assets held by constrained agents and redistributing wealth. Drechsler et al. (2014) point out the role played by large-scale asset purchases, equity injections, and asset guarantees in supporting risky asset prices. Del Negro et al. (2011) investigate the effects of interventions in which the government provides liquidity in exchange for illiquid private paper once the nominal interest rate reaches the zero bound. Similarly, Gertler and Karadi (2011) show in the context of a DSGE model of unconventional monetary pol-

\footnotetext{
${ }^{11}$ See also Chodorow-Reich (2014) and Di Maggio and Kacperczyk (2015), who study the impact of unconventional monetary policy on different sectors of the financial markets, such as pension funds, insurance companies, and money market funds.
} 
icy that during a crisis, the balance sheet constraints on private intermediaries tighten, raising the net benefits from central bank intermediation. These benefits may be substantial when the zero lower bound constraint binds. Greenwood et al. (2015) demonstrate that understanding market segmentation is important in designing and evaluating LSAPs.

Our paper is also related to a broader strand of the literature that investigates the channels through which monetary policy impacts banks' lending decisions. In a seminal paper, Kashyap and Stein (2000) provide evidence of the bank lending channel of the transmission of (conventional) monetary policy. More recently, Jimenez et al. (2014) show that a lower overnight interest rate induces less capitalized banks to lend to riskier firms, while Jimenez et al. (2012) show that for distressed banks, tighter monetary policy and worse economic conditions substantially reduce lending. Agarwal et al. (2015b) estimate banks' marginal propensity to lend out of a decrease in their cost of funds to show that banks were reluctant to lend to riskier borrowers in the aftermath of the crisis. Maddaloni and Peydro (2011) find that low short-term interest rates for an extended period eventually soften lending standards for household and corporate loans. ${ }^{12}$ Finally, Chakraborty, Goldstein and MacKinlay (2016) and Rodnyansky and Darmouni (2016) look explicitly at the effect of QE on bank lending, with the former showing that the banks that are more active in the MBS market increased their mortgage origination market share following the LSAPs, and the latter finding that MBS purchases have important implications for which banks are able to increase credit supply in response to QE3. We add to these studies by uncovering the impact of unconventional monetary policy on individual household refinancing decisions, highlighting the heterogenous allocation of unconventional monetary stimulus. ${ }^{13}$

Finally, we also contribute to the literature investigating the redistributional consequences of monetary policy, e.g., Doepke and Schneider (2006), Fuster and Willen (2010), Coibion et al. (2012), Sterk and Tenreyro (2014). Particularly related to our study is Beraja et al. (2015), who use the same borrower-linked refinance data we do to show that the heterogeneous regional effects of QE1 covary with regional economic conditions and amplify existing regional disparities.

\footnotetext{
${ }^{12}$ See also Bernanke and Blinder (1988), Christiano and Eichenbaum (1992), Landier et al. (2013), Stein (2012) and Williamson (2012).

${ }^{13}$ For the international channel of unconventional monetary policy transmission, see Bauer and Neely (2014) and Caballero et al. (2015).
} 


\section{Background}

In this section, we provide a brief summary of the Federal Reserve's Quantitative Easing program and discuss how its MBS purchases were conducted on the secondary mortgage market. For reference, Figure 2 provides a timeline of the various Fed LSAP programs. ${ }^{14}$ QE1 lasted from late November 2008 until March 2010, and QE2 was first announced in mid-August 2010 and ran from November 2010 to June 2011. We consider QE2 to have begun in September 2010 when the Fed signaled that it was considering a second round of monetary stimulus. ${ }^{15}$ In September 2011, the Fed began a program known as the Maturity Extension Program (MEP) or Operation Twist. Under the MEP, the Federal Reserve reduced the supply of longer-term Treasury securities in the market by selling and redeeming about $\$ 600$ billion in shorter-term Treasury securities and using the proceeds to buy longer-term Treasuries. ${ }^{16}$ QE3 was announced in September 2012 and we treat the beginning of the Fed's tapering its MBS purchases as June 2013, following Bernanke's tapering announcement on May 22, 2013.

In late November 2008, the Fed announced its mortgage-buying program with the intent to purchase about $\$ 500$ billion in mortgage-backed securities, consisting of mortgages guaranteed by Fannie Mae, Freddie Mac, and to a lesser extent, Ginnie Mae. In March 2009, the Fed announced an expansion to this program, subsequently purchasing an additional $\$ 750$ billion in mortgagebacked securities with 50-70\% of agency originations each month ending up on the Fed's balance sheet (Appendix Figure 1). The first quantitative easing program ended in the first quarter of 2010 , with a total of $\$ 1.25$ trillion in purchases of mortgage-backed securities and $\$ 175$ billion of agency debt purchases. ${ }^{17}$ Figure 3 depicts the gross amount of MBS purchased and sold by the Fed since beginning LSAPs. During QE1, the Fed purchased both MBS and Treasuries with a greater emphasis on MBS purchases. QE2, on the other hand, was exclusively focused on Treasuries, and QE3 was roughly equally weighted between Treasuries and MBS. The Maturity Extension Program

\footnotetext{
${ }^{14}$ As detailed in Appendix Table 1, where possible, we have relied on the dates provided by Krishnamurthy and Vissing-Jorgensen (2013).

${ }^{15}$ Krishnamurthy and Vissing-Jorgensen (2013) found that most of the market reaction to QE2 was when it was first signaled in September 2010. Interest rates actually increased after the official announcement in November 2010 as it failed to live up to market expectations.

${ }^{16}$ See Foley-Fisher, Ramcharan, and Yu (2014) for a recent paper on the effect of this program on firms' financing constraints.

${ }^{17}$ Notably, the Fed was effectively able to purchase $\$ 1.85$ trillion (about $40 \%$ more than the usually reported $\$ 1.25$ trillion amount of net purchases) by contemporaneously reselling a substantial fraction of these securities, perhaps enhancing market liquidity without further expanding the Fed balance sheet.
} 
led to roughly equally sized purchases and sales of Treasuries, as well as the reinvestment of prepaid MBS principal into new Agency purchases. As Figure 3 shows, a greater fraction of each QE campaign's MBS purchases have occurred at the beginning of each program, with purchases slowly declining over the course of each LSAP campaign. ${ }^{18}$ Figure 4 shows the relative magnitude of GSE MBS net purchases compared with the total size of the GSE-guaranteed mortgage market. During QE1, the volume of Fed purchases was similar in magnitude to the volume of new issuance of GSE-guaranteed MBS. During QE3, Fed net GSE MBS purchases were roughly half of the GSE market.

To comply with the Federal Reserve Act, Fed MBS purchases had to consist of governmentguaranteed debt. Contrary to popular perception, Fed MBS purchases did not involve buying legacy (and underperforming) MBS from banks. Instead, Fed MBS purchases were on the TBA (To-be Announced) mortgage market. ${ }^{19}$ A key feature of the Agency MBS market is the existence of this highly liquid forward market, through which more than 90\% of Agency MBS trading volume occurs and which consists predominantly of newly originated mortgages (Vickery and Wright, 2013), with trading volumes on the order of $\$ 200$ billion per day and around $\$ 100$ billion delivered each month. $^{20}$ Appendix Figure 1 confirms this by plotting the percentage of GSE-guaranteed MBS issued in each quarter that are ultimately owned by the Fed. Less than $10 \%$ of pre-2008 GSE issuance is owned by the Fed (and less than $20 \%$ of 2008 issuance) in contrast to more than half of GSE MBS created during QE1. See Appendix A for additional details on the TBA market. ${ }^{21}$

The characteristics of the TBA market matter both for conceptually understanding the channels through which Fed MBS purchases affect the economy and also for econometric identification. The eligibility requirements for mortgages to be included in TBAs provide sharp cross-sectional predictions on the effect of MBS purchases on loan originations. Because TBA delivery must be accomplished with Agency-eligible mortgages that are usually recent originations, the strict eligibility

\footnotetext{
${ }^{18}$ Note that the policy of the Fed to reinvest principal prepaid on its MBS holdings into new MBS purchases results in non-zero MBS purchases even after QE3 officially ends.

${ }^{19} \mathrm{~A}$ limited number of the TBA securities purchased by the Fed at the beginning of QE1 included MBS CUSIPs that had been originated in early 2008 instead of roughly contemporaneous with Fed purchases. Still, these were GSE-eligible mortgages originated in 2008 and not the types of legacy MBS that were troubling banks, having been filled with mortgages originated under questionable underwriting standards that were deeply underwater by 2009 .

${ }^{20}$ Note that the scale of the Fed MBS purchases could only be executed on a market with the unrivaled size and liquidity of the TBA market.

${ }^{21}$ The de facto restriction of QE purchases to newly originated debt contrasts with the emphasis on legacy assets of the Troubled Asset Relief Program (TARP), signed into law on October 3, 2008.
} 
rules for GSE guarantees allow us to compare origination volumes by loan size. Specifically, GSE guarantees require loan sizes to be beneath published conforming loan limits (CLLs). ${ }^{22}$ Mortgages with a loan size exceeding geographically and time-varying CLLs (known as jumbo mortgages) are essentially ineligible for inclusion in GSE MBS. Many of our results below will test for a deviation in mortgage origination volume for loans just below the CLL, which should be directly affected by Fed purchases because of their TBA eligibility, and loans just above the CLL, which should only be indirectly affected by Fed MBS purchases.

\section{Data}

Our workhorse data source is the Equifax's Credit Risk Insight Servicing McDash (CRISM) dataset, which covers roughly 65 percent of the mortgage market during our sample period (2008-2013), first used to examine the effects of QE by Beraja et al. (2015). One of the features of this dataset is that it merges McDash Analytics mortgage-servicing records (from Lender Processing Services) with credit bureau data (from Equifax). This provides us with information about the characteristics of each mortgage at origination, such as the mortgage type, the size of the loan, the monthly payments, the interest rate, the borrower's FICO, as well as their behavior over time. We also observe borrowers' other liabilities, such as their auto loans, HELOCs, and credit cards. Panels I and II of Table 1 report loan-level summary statistics on conforming and jumbo loans from the CRISM database. Our sample includes more than seven million loans below the conforming loan limit and about 170,000 jumbo loans. On average, non-jumbo (jumbo) borrowers in our sample have a 750 (760) FICO score and an LTV of $67 \%$ (65\%). The average balance of conforming and jumbo loans in our data are $\$ 211,000$ and $\$ 960,000$, respectively. Panel III reports summary statistics for time series controls used in robustness checks, including guarantee fees from Fuster et al. (2013) and bond yields from Federal Reserve Economic Data (FRED) at the Federal Reserve Bank of St. Louis. The guarantee fees, BBB-AAA bond spreads, and bank CDS spreads average 34, 134, and 177 basis points, respectively, over our sample period.

The unique advantage of this data is that it enables us to link multiple loans by the same borrower together, allowing us to gather more complete information about a borrower's refinancing decision.

\footnotetext{
${ }^{22}$ See Adelino et al. (2013) and DeFusco and Paciorek (2015) for studies of the consequences of the sharp change in GSE eligibility at the conforming loan limit.
} 
In addition to following individual mortgages over time,we can match borrowers to mortgages, observe each borrower in the credit bureau data six months before any mortgage origination, and track the borrower as they refinance into a new mortgage. Appendix Table 2 demonstrates the usefulness of this linkage, reporting a refinancing transition matrix of mortgage product types for each year from 2006-2013. This dimension of the dataset (linking refinance mortgages to prior mortgages) allows us to study cash-in/cash-out refinancing much more accurately. For example, by observing the outstanding amount of the old loan and the principal amount of the new loan, we can measure the dollar amount of equity that is added to the borrower's position during the refinancing process.

\section{$5 \quad$ Empirical Strategy}

In this section we present our main empirical strategy to identify the effects of LSAPs on both interest rates and refinancing volumes.

\subsection{Quantifying the Effect of QE on Interest Rates}

In the spirit of the empirical QE literature's focus on debt yields, we begin by comparing the interestrate reaction to LSAPs for loans above and below the conforming loan limit. To form a comparable jumbo/conforming interest-rate sample, we only consider loans that are 30-year fixed-rate first-lien mortgages secured by owner-occupied single-family houses with an initial LTV of less than $80 \%$ and without any prepayment penalty or balloon-payment or interest-only deferred amortization features. ${ }^{23}$ We also drop FHA mortgages for this exercise, which require mortgage insurance and have more flexible lending requirements than those for conventional loans.

Changes in borrower composition over time limit the usefulness of simple time-series comparisons of interest rates. Instead, we take into account that rates change in response to changing mortgageborrower characteristics. For example, some of the decrease in interest rates that we observe is due to stricter credit standards at the end of our sample - later mortgages feature both higher average FICO scores and lower LTVs.

\footnotetext{
${ }^{23}$ Appendix Table 2 shows that a third of all refinance mortgages are transitions from one 30-year fixed-rate mortgage to another.
} 
To facilitate graphical comparisons of composition-adjusted interest rates over time, we estimate the following regression (separately) for loans above and below the conforming loan limit

$$
r_{i t}=\alpha_{t}+\beta_{1}\left(F I C O_{i}-720\right)+\beta_{2}\left(L T V_{i}-0.75\right)+\varepsilon_{i t},
$$

where $r_{i t}$ is the interest rate of loan $i$ at time $t$ measured in basis points. We control for the difference between the FICO score and loan-to-value ratio of loan $i$ and benchmark FICO and LTV ratios such that estimated time effects $\alpha_{t}$ capture "rate-sheet-adjusted" interest rates - interest rates for a representative borrower with a FICO score of 720 and an LTV ratio of $75 \%$.

To quantify the differential reaction of jumbo and conforming interest rates to purchase program events, we pool jumbo and non-jumbo mortgages together and estimate the following loan-level specification around the beginning of each monetary policy event separately

$$
r_{i c t}=X_{i}^{\prime} \beta+\theta_{0} \text { Jumbo }_{s}+\theta_{1} \text { Program }_{t}+\theta_{2} \text { Program }_{t} \cdot \text { Jumbo }_{s}+\eta_{c t}+\varepsilon_{i c t}
$$

where Program is an indicator for month $t$ being after the institution of a specific monetary policy program (e.g., QE1), Jumbo is an indicator variable for whether loan $i$ was a jumbo mortgage, and $X_{i}$ is a vector of flexible loan-level controls consisting of 5-point LTV bins (we drop loans with less than 25\% LTV), 20-point FICO bins, and an indicator for missing FICO scores. We also control for county $\times$ month fixed effects $\eta_{c t}$ to purge interest rates in both segments of static and time-varying regional shocks to credit demand or supply, including differences in house price growth and changes in expectations. We consider the three quantitative easing programs as well as the Maturity Extension Program in September 2011 and the beginning of tapering in June 2013.

The coefficient $\theta_{1}$ reports the number of basis points by which interest rates for non-jumbo mortgages fell on average in the three (or six) months immediately following the beginning of each QE campaign relative to the period immediately prior. The coefficient $\theta_{2}$ captures changes in the jumbo-conforming spread in response to each QE campaign's commencement, in other words by how much more or less interest rates in the jumbo segment responded. We interpret $\theta_{1}$ as causal only with some degree of caution because it will combine the effect of LSAPs with any contemporaneous national shock to mortgage rates, even those effects not caused by the monetary policy events in question. The identifying assumption behind our causal interpretation of $\theta_{2}$ is that, conditional on borrower and loan characteristics and county-month fixed effects, time-varying shocks do not 
affect the jumbo and conforming segments differently. In other words, our ability to identify the effect of unconventional monetary policy on mortgage-market segments relies on a parallel-trends assumption, which, as we discuss below, seems to be satisfied, especially over the short time horizons used to estimate equation (1). Finally, we cluster our standard errors at the month level to account for the correlation between contemporaneous shocks across loans and geographies.

\subsection{Quantifying the Effect of QE on Mortgage Origination Volumes}

As discussed in Section 1, inferring the impact of unconventional monetary policy from changes in interest rates tends to overstate policy effectiveness by assuming perfect availability of credit. In particular, interest rates are observed conditional on origination, but as not all mortgages are eligible for purchase by the Fed, the relative size and composition of each segment may change substantially. Considering the volume of debt issuance in response to the LSAPs is an essential consideration in estimating the response of households financial markets to new measures of monetary policy adopted after the crisis. Furthermore, we can test for the presence of spillovers from the conforming segment (directly affected by the LSAPs) to the jumbo segment.

To form a comparable jumbo/conforming sample for an analysis of quantities, we drop FHA mortgages and consider first-lien refinance loans for single-family houses (note that this sample restriction is more inclusive than the interest-rate sample restrictions needed to compare interest rates on equal footing). We quantify these effects on refinance origination volumes $Q_{s c t}$ at the county $c \times$ month $t \times$ mortgage-market segment $s \in\{J u m b o$, non-Jumbo $\}$ level by estimating

$$
\log Q_{s c t}=\beta_{0} \text { Jumbo }_{s}+\beta_{1} \text { Program }_{t}+\beta_{2} \operatorname{Program}_{t} \cdot \text { Jumbo }_{s}+X_{s c t}^{\prime} \gamma+\alpha_{c t}+\varepsilon_{s c t} .
$$

For each policy event, we provide baseline results and subsequent robustness checks containing a more restrictive specification in which we allow for county $\times$ month fixed effects $\alpha_{c t}$ and control for measures of the local composition of each segment's borrowers in each month $X_{\text {sct }}$ (average FICO scores and average LTV ratios for a county $\times$ month $\times$ segment). We also restrict attention to counties where we observe an active jumbo market by restricting the sample to counties that have at least one jumbo refinance origination each month. Again, we conservatively cluster our standard errors at the month level.

The coefficient $\beta_{1}$ tells us by how many log points conforming origination volumes increased 
in the average county in the months following an LSAP event relative to the months immediately preceding that event. We focus our attention on $\beta_{2}$, which is an estimate of whether jumbo origination volumes responded differently than conforming origination volumes. Again, the identifying assumption required for $\beta_{2}$ to be an unbiased estimate of differential allocation of LSAP credit across mortgage market segments is that there were no other shocks, say $\zeta_{s t}$, occurring coincident with QE events that affected the jumbo market more (or less) than the conforming market. While our interest in refinance origination volumes instead of purchase originations helps us abstract away from local shocks to credit demand including beliefs about future house prices, county $\times$ month fixed effects $\alpha_{c t}$ absorb any remaining local shocks to credit demand or supply. The requirement for parallel trends across conforming and non-conforming segments motivates using tight three- and six-month windows around each event, as well as our focus on the conforming loan limit since underwriting standards in the conforming and prime jumbo market are similar. The graphical evidence discussed below also supports this parallel-trends assumption, as do several subsequent robustness

checks, including specifications that control for macroeconomic factors $W_{t}$ interacted with the jumbo indicator to allow for several potential segment-specific shocks.

\subsection{Estimating Changes in the Propensity to Refinance}

A complementary way to examine the impact of QE uses the individual-level panel structure of our data to test whether each QE campaign altered the likelihood that a given individual refinanced. A given loan's segment as used in equations (1) and (2) is actually an outcome that is potentially affected by QE itself. Individual-level hazard regressions solve this selection problem by looking at results based on the original loan segment and characteristics. Moreover, because our sample each month in a mortgage-termination regression only consists of loans that have not yet failed, a hazard model is needed to correct for this dynamically selected sample. Analyzing how individual access to refinancing changed during QE1 with respect to characteristics of the original mortgage is an input into understanding the degree to which the quantity results are explained by the change in interest rates or how credit might have been allocated in counterfactual scenarios with, for example, higher 
GSE LTV caps. We estimate a hazard model of the form

$$
\begin{aligned}
\lambda_{i t} & =\exp \left(X_{i t}^{\prime} \beta\right) \lambda_{0}\left(t-t_{0}(i)\right) \\
X_{i t}^{\prime} \beta & =\theta_{L}^{\prime} W_{i t}^{\text {loan }}+\theta_{B}^{\prime} W_{i}^{\text {borrower }}+\sum_{k} \sum_{\tau=D e c 2008}^{F e b 2008} \beta_{k \tau} \cdot Q E 1_{t} \times S_{k, i t}
\end{aligned}
$$

where $\lambda_{i t}$ is the instantaneous probability that loan $i$ will refinance in calendar month $t$, conditional on not yet having refinanced by month $t$. The baseline hazard function $\lambda_{0}(\cdot)$ is a cubic function of loan age (current month $t$ minus loan $i$ 's origination month $t_{0}(i)$ ) and nonparametrically captures the standard life-cycle of mortgage prepayment, while covariates scale the baseline hazard depending on their contribution to prepayment risk. The covariates in $X_{i t}$ consist of loan- and borrower-level

controls. Loan-level controls $W_{i t}^{\text {loan }}$ include current LTV (imputed using CoreLogic repeat-sales home-price indices), original balance, and an indicator for whether the loan size is currently above the conforming loan limit. Borrower-level controls $W_{i t}^{\text {borrower }}$ include FICO bins, DTI ratio, and an indicator for whether the DTI is missing. The coefficients of interest are $\beta_{k \tau}$, which are coefficients for each of the three months following the beginning of QE1 on the QE1 indicator variable interacted with two separate indicators for whether loan $i$ is currently GSE ineligible (whether loan $i$ 's current LTV exceeds .9 and whether its loan size exceeds the CLL). We take for our sample all loans that were outstanding as of September 2008, and use the continuous-time maximum-likelihood estimator described in Palmer (2015). Estimated coefficients report partial effects on the log refinancing hazard. We limit the sample to fixed-rate first-liens secured by owner-occupied single-family homes originated before January 2008 and outstanding as of January 2008.

\section{$6 \quad$ Results}

We present three main sets of results. First, we examine the response of mortgage rates to the LSAPs. We then turn to the changes in refinancing volume in the mortgage market. Finally, we turn to the household-level analysis to shed further lights on how LSAPs affected households' refinancing decisions. 


\subsection{The Effect of LSAPs on the Primary Mortgage Market}

\subsubsection{Interest Rate Results}

In Figure 5, we plot the estimated interest rates for loans above and below the conforming loan limit. There is a visible change in interest rates as QE1 begins, when mortgage interest rates declined markedly, from $6.5 \%$ to about $5.5 \%$ and $5 \%$ for loans just above and just below the conforming loan limit, respectively. While rates for the two types of loans follow each other quite closely, conformingloan rates declined almost $50 \%$ more than prime jumbo mortgage rates. ${ }^{24}$

To quantify the average magnitude of these effects over each monetary policy event, Table 2 reports the estimates for the interest-rate response to the announcements of the different LSAPs within a three-month window (panel I) and a six-month window (panel II) around the event, both for jumbo and non-jumbo loans. We find that the most significant reaction is to the announcement of QE1 with an interest-rate reduction of more than 100 basis points. Consistent with Figure 5, jumbo-mortgage interest rates also decline after QE1, but the conforming rate falls by an additional 40 basis points. Rates declined by around 35 basis points in response to QE2, without any differential effect across segments, consistent with our interpretation that the reason QE1 had differential effects is because the Fed purchased MBS at a time of strong segmentation in the mortgage market. ${ }^{25}$ The Maturity Extension Program resulted in a reduction of about 46 basis points, but we observe little, if any, differential effect for the conforming and non-conforming segments. QE3, instead, led to a reduction of about 18 basis points in the three months after the beginning of the program. Finally, the beginning of the Fed tapering led to an increase in interest rates concentrated in the conforming loan segment. ${ }^{26}$ The results are qualitatively similar when we consider a longer window around the announcement in panel II to build up a longer pre-period, with the estimated economic magnitude of each event generally larger in the six-month window specifications.

\footnotetext{
${ }^{24}$ For context, the increase in the jumbo-conforming spread from the announcement of QE1 is on par with the spread increase observed in the second half of 2007, when the securitization market.

${ }^{25}$ This comparatively lower reduction in overall interest rates might also be indicative that, while QE1 was a significant surprise, the second quantitative easing program was largely anticipated by market participants.

${ }^{26}$ One potential reason for the asymmetry of the QE3 and Tapering coefficients is the asymmetric effects of interest rate decreases and increases to MBS investors. A reduction in interest rates increases the value of fixed-income investments and relaxes investors' capital constraints, supporting an overall lending expansion (provided markets aren't too segmented). An (expected) increase in interest rates, on the other hand, tightens intermediaries' capital constraints, reducing lending differentially to that segment whose interest rates are likely to rise significantly. For example, mortgage REITs - an important buyer of GSE MBS - reduced their holdings of MBS by more than $30 \%$ in the two months following the Tapering announcement.
} 
Our identification approach is particularly well-suited to control for demand shocks affecting both segments at the same time. For each event, even columns control for county-month fixed effects and loan characteristics, including flexibly specified loan-to-value ratios and FICO scores, to ensure that the differential response of jumbo and conforming mortgages is not driven by time-varying borrower composition. Geography $\times$ time fixed effects absorb time-varying regional heterogeneity to account for any local shocks, unrelated to monetary policy, to fundamentals or beliefs that affect credit demand or supply. Comparing even and odd columns, we find that our results on the jumboconforming spread are not driven by changes in borrower composition or the local lending market.

\subsubsection{Mortgage Origination Results}

Figure 6 plots the origination amount of refinance mortgages recorded by LPS for mortgages with loan sizes above and below the GSE conforming loan limit (CLL). The jumbo and non-jumbo segments trend very similarly in origination counts (panel I) and total volume (panel II) prior to the beginning of QE1, bolstering our identifying assumption of parallel trends. Right at the commencement of QE1, the amount of below-CLL refinance origination increases by a factor of three (counts) or four (dollar volume). The sudden increase and subsequent fading of below-CLL refinance originations coincides quite closely with the dynamics of Fed MBS purchases, as shown in Figure 7. By contrast, refinance origination above the conforming loan limit is fairly flat until a modest increase in April 2009. In other words, while the increase in the conforming spread indicates a differential response of rates depending on GSE eligibility, loan origination suggests an even deeper relationship between the allocation of credit supply and QE1 MBS purchases.

Table 3 reports results from estimating equation (2) for a three-month window (panel I) and a six-month window (panel II). ${ }^{27}$ The dependent variable is the log of the total dollar amount of monthly loan origination. Focusing on the conservative three-month window specification in panel I, column 1 shows that overall mortgage refinancing activity increased by $100 \log$ points (170\%) during QE1, with almost all of the effect concentrated in the conforming loan segment. In contrast, during both QE2 and the MEP, both conforming and jumbo originations increased by

\footnotetext{
${ }^{27}$ As discussed in Section 5, our identifying assumption (supported graphically and by the robustness checks below) of no mortgage segment-specific shocks allows us to interpret the coefficient on the program $\times$ jumbo indicator as reflective of the differential impact of each LSAP program on origination volumes. We acknowledge, however, that contemporaneous aggregate shocks can confound our estimates of the main effect of each LSAP event.
} 
about $65 \%$ (50 log points), with no detectable differential effect across loan segments. Column 8 shows that mortgage refinancing volumes responded very similarly across segments in the months immediately following the beginning of QE3, increasing by 15-30\%. Finally, refinancing activities in the conforming segment fell around 30\% in the aftermath of the Fed's tapering announcement. Note that the total effect of tapering on jumbo originations in column 9 of Table 3 is close to zero, suggesting that jumbo originations were relatively unaffected by the tapering. Results using a sixmonth bandwidth around QE event dates are generally stronger, although each of the qualitative patterns remains the same.

In sum, Fed asset purchases were effective at inducing new debt origination and cheaper monthly payments for households. Purchasing mortgage-backed securities was particularly effective during QE1, when monetary stimulus was needed the most and LSAP spillovers to other market segments were limited. These results shed lights on the channels through which LSAPs might have real effects. In fact, the limited spillovers support the view that distressed markets are acutely segmented, causing LSAPs to have effects primarily in the segments in which purchases occurred. Contrasting the segment-specific effects of QE1 and QE3, the results of Table 3 are also consistent with Krishnamurthy and Vissing-Jørgensen (2013) and Gertler and Karadi (2011): since financial intermediaries were in greater distress during the first program, we should expect much more reallocation of the Fed's funds across segments during the third program. Finally, the small main effects that we estimate for QE2 and QE3 are consistent with results on yields in Krishnamurthy and Vissing-Jørgensen (2013) suggesting that the size of those programs (and market expectations about them) muted their overall effects.

\subsubsection{Robustness Checks}

Our identification strategy takes advantage of the natural segmentation in the mortgage market and effectively employs a differences-in-differences approach in an event-study framework by comparing the refinancing activities in the conforming (the treated group) and non-conforming (the control group) segment in a narrow window around the policy events. This allows us to limit the role of other common shocks affecting both segments at the same time and control for changes in credit demand. However, one potential limitation of this approach is the possibility that unobserved aggregate credit supply shocks, occurring at about the same time of the policy announcements and 
differentially impacting the conforming and jumbo loan segments, might confound our results. For example, because jumbo mortgage investors bear default risk that GSE mortgage investors do not, lenders might face different shocks to funding constraints in the two segments of the market.

We propose three such factors (credit-spread shocks, guarantee fees, and average premia on bank credit default swaps), demonstrate that they explain a significant amount of variation in differential movements in the jumbo and conforming segments, and verify that our results are robust to the inclusion of these three factors as time-series controls measuring aggregate shocks to funding availability in these two segments. We measure credit spreads as the difference in yields between BBB and AAA rated bonds. Second, the guarantee fee ("g-fee") originators must pay to the GSEs to insure a loan's default risk has varied over time from just 20 basis points before the crisis to the 50 basis points in 2015, naturally affecting non-GSE and GSE-eligible loans differentially. Third, we collect data on the credit-default swaps for all major financial institutions in the U.S. and construct an index by value weighting the corresponding six-month contract premia. Intuitively, the credit spread captures the price of risk, and the g-fee reflects the price to avoid default risk, both of which might influence (and be correlated with) the relative market supply of jumbo-mortgage credit, whereas the CDS index captures the overall financial health of the banking sector. When g-fees increase, we expect the jumbo-conforming spread to decrease, and when credit spreads or CDS premia rise, we expect the jumbo segment to be hit harder than the conforming segment. These factors do play an important role in the mortgage market, together explaining $80 \%$ of the variation in the jumbo-conforming spread (see Appendix Table 4).

In order to have a stable and uncontaminated estimate of the contribution of these three factors to interest rates and quantities, we adopt the following abnormal-returns event-study procedure using data on bond-yield spreads from the St. Louis Fed, g-fees from Fuster et al. (2013), and CDS spreads from Markit. First, for each QE event, we use the 2008-2013 sample period excepting the six months surrounding the QE event in question to estimate the coefficients on the spread, g-fee, and CDS index in a linear regression with county $\times$ month fixed effects and a jumbo indicator. These coefficients are reported in Appendix Table 4-we note the relative stability of the coefficients across sample periods, finding that these three factors alone explain a significant portion of the overall variation in interest rates and quantities, as evidenced from the $R^{2}$ statistics in Appendix Table 4. We then partial out these three factors, by subtracting the contribution of contemporaneous 
credit spreads, g-fees, and CDS index from current interest rates and quantities to reestimate the specifications in Tables 2 and 3 controlling for time-varying credit spreads, g-fees and CDS premia.

Table 4 and Appendix Table 3 report these results for three- and six-month windows, respectively. We find that the effects highlighted in Tables 2 and 3 are still economically and statistically significant, but as expected the magnitude of the differential behavior between jumbo and conforming segments is reduced since the controls pick up some of the effect we were attributing to QE. For instance, the top panel shows that the jumbo mortgage rates experience a lower reduction as the jumbo-conforming spread widens by 30 basis points in the post-QE1 period conditional on credit spreads, g-fees, and CDS premia, in contrast to the 42 basis point widening reported in Table 2. No economically significant differential effect is found for QE2, the MEP, or QE3.We also find that the Fed tapering spread narrowing is robust to these added controls.

The bottom panel of Table 4 reports the results for the refinance origination volume. The economic magnitude of the coefficients is reduced by at most 15 percent from Table 3, which indicates that, while there may have been other factors affecting intermediaries' willingness to lend in these two segments, the conclusions remain qualitatively and economically the same.

A related concern is that these differences among loans below and above the conforming loan limit could be an artifact of the January 2008 change in the limit itself. The relevant chronology is not consistent of this particular explanation - this initial increase in conforming loan limits happened much too early to explain the differential response of mortgage market segments to QE1, and the eventual decrease in conforming loan limits (September 2011) did not coincide with any particular LSAP window (see Appendix Figure 2 and 3). For completeness, the analysis in Appendix B addresses this threat to validity, confirming that the differential origination pattern holds even in those areas that did not see an increase in the conforming loan limit. Overall, the evidence in this section is suggestive that our results are not driven by time-series variation in credit supply. ${ }^{28}$

We also investigate whether our results are confounded by differences in the sensitivity of jumbo and conforming mortgage rates to short and long interest rates. For example, it might be that jumbo mortgages are more sensitive to the short end of the yield curve, which might make them less

\footnotetext{
${ }^{28}$ Our findings are likely unrelated to TARP. The majority of lending to banks through TARP occurred in October and November of 2008, which, if supportive of mortgage origination, would work against our finding a strong reaction to the beginning of QE1. Likewise, improvement in bank health would likely encourage jumbo origination more than conforming loans, as the latter rely more heavily on market liquidity.
} 
responsive to policies that aim to decrease the long end of the yield curve. As reported in Appendix Table 5, we find that this is not the case. We perform univariate regressions relating mortgage rates to 5-year and 10-year Treasury rates in columns 1-4, and then we regress mortgage rates on both Treasury rates in columns 5 and 6 . The univariate regressions show a very similar sensitivity of both types of mortgage rates to Treasury rates, as highlighted by the similar coefficients in columns 1-4. If anything, columns 5 and 6 show that the conforming rates seem to be more sensitive to the short end of the yield curve, ruling out this alternative explanation for our findings.

Finally, one potential concern is that borrowers might endogenously choose to be on one side or the other of the conforming loan limit, which might affect our definition of treatment and control groups. This is less of an issue in our specific case because in 2009 the average loan size in our data was about $\$ 220,000$, which is significantly below the limit, and suggests that the fraction of borrowers around the limit is small relative to the size of the whole sample. However, to show that the results are robust to this modification, we report in Appendix Figure 4 the refinancing volume and counts as in Figure 6 in the text, but excluding all loans that are in the [90\%, 140\%] interval around the conforming loan limit. We find that the results are quite similar in this restricted sample. ${ }^{29}$

\subsubsection{Aggregate Effects: Refinance Volume and Consumption}

In this section, we estimate the stimulative effects of QE purchases by computing the aggregate volume of loans that were refinanced in response to QE1 and estimating the resulting increase in additional consumption using MPC estimates from the literature.

While the regression specifications above imposed several sample restrictions to ensure that composition was not driving our main findings, we now relax these restrictions to estimate the aggregate effects of these policies. In particular, for this exercise, we also consider non-first liens, nonsingle family houses, FHA loans, and loans with LTV outside the [25\%, 120\%] interval. Furthermore, to obtain average effects across all months, we extend the time window to include six months before

\footnotetext{
${ }^{29} \mathrm{~A}$ related compositional concern is that loose QE credit might have led to mortgage origination to riskier borrowers. Appendix Figure 5 plots the percent of loans delinquent within one year (panel I) and within four years (panel II) from refinancing for different types of refinances: GSE, FHA, cash-out and non-GSE. While rising overall property values and tighter credit are improving successive cohorts' loan performance (consistent with Palmer, 2015), this trend is smooth and unabated throughout throughout the QE1 campaign, suggesting that increasing refinancing origination (including cash-out refinances) did not materially affect credit quality.
} 
QE1 through March 2010. These changes end up being conservative our point estimates are smaller on the more universal sample than used in the regression tables above. We re-estimate our specification (2) on this new sample and turn off the coefficient on the interaction term between QE1 and the non-jumbo segment to estimate the volume of refinances that is due to QE1 (\$291 billion). ${ }^{30}$ As our data cover about $48 \%$ of the refinance market (using HMDA data as a national benchmark), our results suggest that QE1 was responsible for $\$ 607$ billion increase in aggregate refinance volume.

This increase in refinances might lead to an increase in consumption through multiple channels. First, many borrowers cash out equity while refinancing, providing cash on hand to support new expenditures. Second, by refinancing their loans, borrowers are able to secure lower interest rates, and increase their monthly disposable income. On average, the amount of equity cashed out is about $11 \%$ of the total volume of refis. As commonly assumed in the MPC literature (see, e.g., Mian and Sufi, 2011), we assume the marginal propensity to consume out of cashed-out equity is 1 (the assumption being that borrowers cash-out equity to spend it). This translates into an increase in borrowers' consumption of about $\$ 67$ billion. We also compute the increase in consumption due to interest rate savings. Specifically, households refinancing in 2009 saved on average $\$ 250$ per month or $\$ 3,000$ per year due to the lower interest rates (see discussion of Appendix Figure 7 below). As found by Di Maggio et al. (2015), the average marginal propensity to consume out of a decrease in monthly interest payments is about 0.75 . This implies that the additional increase in consumption due to the purchase of MBS rather than Treasuries is about $\$ 6$ billion ( $\$ 607$ billion divided by the average loan size of $\$ 220,000 \times \$ 3,000 \times 0.7)$ due to interest rate savings. Moreover, our results show that the purchase of MBS instead of Treasuries resulted in at least 40 bps lower rates for those who refinanced to a conforming mortgage during QE1. This means that for the inframarginal $\$ 1.2$ trillion of GSE refinancing, borrowers realized $\$ 1.2$ trillion $\times 40$ bps $=\$ 4.8$ billion of marginal savings on their annual interest payments, resulting in an additional $\$ 3.6$ billion of consumption. ${ }^{31}$ Putting these channels together, we estimate that the decision to purchase MBS instead of exclusively Treasuries during QE1 increased aggregate consumption through the

\footnotetext{
${ }^{30}$ In re-estimating equation (2), we replace the jumbo indicators with non-jumbo indicators to simulate that it was this extra QE1 $\times$ non-Jumbo effect that would be lost if the Fed had not purchased MBS.

${ }^{31}$ There was $\$ 1.8$ trillion of GSE refinancing during QE1, of which we estimate $\$ 607$ billion was caused by QE1 MBS purchases (instead of an equivalent amount of Treasuries), meaning approximately $\$ 1.2$ trillion of refinancing would have happened irrespective of the assets purchased during QE1.
} 
refinancing channel by approximately $\$ 76$ billion.

To provide further evidence that refinancing results in an increase in borrowers' consumption, we also plot event studies around the origination of a refinance mortgage in Appendix Figure 7. Specifically, we examine the relationship between refinancing and durable goods purchases during QE1, measured using borrower-level credit-bureau data on auto loans linked with data on mortgage refinancing. We restrict our attention to those borrowers who refinanced their mortgage during QE1 (December 2008 to March 2010) and leverage the panel structure of our data by following each borrower 12 months before and after refinancing and estimate event studies of the form

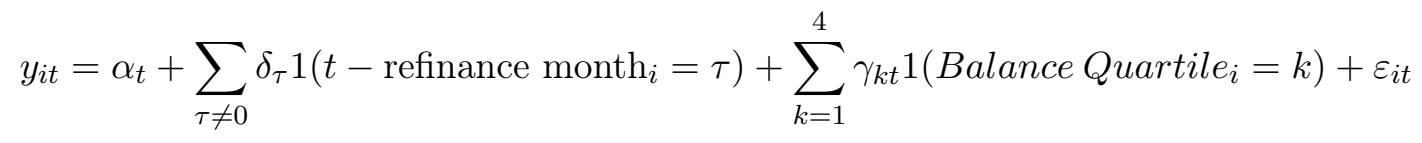

where $y_{i t}$ is either the monthly interest payment or an indicator for whether borrower $i$ in calendarmonth $t$ purchased a (new or used) car (and financed at least some of that purchase to be observed by Equifax) and Balance Quartile $i$ is the quartile of the loan size of borrower $i$ 's new refinance mortgage (which allows for income-segment specific shocks and eliminates pre-trends). The parameters of interest are the event study coefficients $\delta_{\tau}$, which range from $\tau=-12$ to $\tau=12$ and turn on in the months during which borrower $i$ was $\tau$ months away from refinancing. The omitted category is borrowers in the same month their refinance mortgage was originated $(\tau=0)$, meaning that $\delta_{2}$, for example, is the estimated average change in $y$ for borrowers that refinanced two months ago compared with the level of $y$ in the month they refinanced. Calendar-month fixed effects $\alpha_{t}$ capture any time-varying aggregate shocks to outcomes. ${ }^{32}$ An important consideration in interpreting these results is that the timing of interest-rate savings is not random, in contrast to the setting of Di Maggio et al. (2015) and Keys et al. (2015), whose consumption response functions are identified by exogenous interest rate changes that do not require refinancing. To the extent that the borrowers refinance in response to (or in anticipation of) idiosyncratic shocks correlated with their demand for auto loans, our estimates of $\delta_{\tau}$ are biased. The presence of $\alpha_{t}$, however, should account for common shocks to credit demand.

Appendix Figure 7 plots estimated $\hat{\delta}_{\tau}$ for the effect of refinancing on monthly mortgage interest payments (panel I) and the probability of taking on a new auto loan (panel II, measured as an

\footnotetext{
${ }^{32}$ We do not include individual-level fixed effects in these regressions. As car purchases are relatively infrequent and the sample period for each borrower is relatively short (24 months), borrower fixed effects would absorb all variation in car purchase behavior for the majority of individuals who do not purchase a car.
} 
increase in outstanding auto-loan debt of more than $\$ 5,000)$. Immediately after refinancing, there is a large and persistent decline in monthly mortgage interest payments, averaging $\$ 250 /$ month over the first year after refinancing. This interest savings appears in part to be spent on durable consumption. The coefficients plotted in panel II show an increase in the monthly probability of purchasing a car (a fairly rare event at baseline) starting two months after refinancing and staying statistically significant with no signs of intertemporal substitution/reversal over the following year.

Overall, these results show that the composition of Fed asset purchases has a tremendous causal effect on both refinancing volume and aggregate consumption when markets are segmented.

\subsubsection{Allocation of Credit Across Regions}

Given that unconventional monetary stimulus from QE1 was not distributed evenly across the mortgage market, what implications did this have for the geography of credit allocation? We investigate this by analyzing where 2009 refinancing activity was concentrated (see Beraja et al., 2015 for a full treatment of regional heterogeneity in the effects of QE). To ensure full coverage of the mortgage market, we use Home Mortgage Disclosure Act data, which reports the universe of mortgage originations by institutions large enough to be regulated by the act. In Figure 8, we plot the state-level percentage of outstanding mortgage balance refinanced in 2009 against two lagged measures of state-level economic health: 2006-2008 home price appreciation (top panel) and 2006-2008 real GDP growth (bottom panel).

Panel I shows that even though a clear objective of QE1 was to stimulate distressed housing markets, there is a strong positive relationship between past home price appreciation and new refinancing activity, suggesting that the QE1-induced increased availability of refinancing credit may not have reached the areas that arguably needed it the most. In particular, note that the states most affected by the housing bust (the so-called "sand states" of California, Florida, Arizona and Nevada) were the states with the lowest refinancing activity. ${ }^{33}$ Panel II of Figure 8 repeats this exercise, relating refinancing activity to state-level growth in real GDP from 2006-2008. Again, there is a clear positive relationship with contracting states benefiting less from QE1. Taken together, these figures provide evidence that time-invariant mortgage market segmentation combined with contempora-

\footnotetext{
${ }^{33}$ Note that while the correlation between purchase mortgage credit growth could also be driven by shocks to fundamentals that simultaneously reduced demand for mortgage credit and lowered home prices, this is less of a concern for the refinancing activity measure shown here.
} 
neous banking sector stress to allocate credit to the regions with the most potential GSE-eligible refinances, i.e., areas with smaller underwater borrower shares and with correspondingly stronger local economies. While clearly less well identified than the across-segment results presented in Section 6.1.2, these across-region results highlight the important interplay between GSE mortgage-market policy and the effectiveness of monetary stimulus at reaching the local economies that would benefit the most.

\subsection{Household-level Analysis}

\subsubsection{Refinancing Propensity Hazard Regressions}

In Table 5, we report results from estimating hazard models of refinancing, as described in Section 5.3. These models address potential sample-selection and segment-sorting biases and are the basis for our counterfactual simulations in Section 7. Column 1 shows that each of the three months following the announcement and beginning of Fed MBS purchases saw an increase of individual refinancing likelihood. For example, the January 2009 coefficient implies that individuals holding observationally equivalent loans were $125 \%$ (81 log points) more likely to refinance in January 2009 than in the three months preceding December 2008. Column 2 shows that borrowers whose outstanding mortgages were GSE ineligible were significantly less likely to prepay their mortgages. Mortgages with current loan-to-value ratios exceeding $90 \%$ were $36 \%$ (45 log points) less likely to prepay their mortgage in January 2009 than those borrowers with LTVs under 90\%. Similarly, jumbo borrowers - borrowers of mortgages whose size exceeded the local conforming loan limit-were $17 \%$ (19 log points) less likely to prepay in January 2009 than borrowers with mortgages under the CLL. Column 3 demonstrates that these findings are quite similar even when focusing on observationally identical borrowers taking out mortgages with similar characteristics.

These estimates can be used to show that the increase in the origination of conforming loans

cannot be entirely explained by the decline in interest rates. Specifically, we estimate the effect of the segment-specific coupon gap (the difference between the current mortgage rate and the one at which the borrower could refinance, imputed using the segment-specific estimates of equation 1) on the refinancing hazard out of sample. Then, we can use these estimated coupon-gap coefficients and the actual change in the interest rate to predict how many borrowers would have refinanced given 
the actual reduction in market interest rates, augmenting the hazard model in equation (3) with a coupon-gap covariate and constraining its coefficient to be its out-of-sample estimate. Table 6 reports these results. Comparing the QE1 $\times$ Jumbo coefficients in columns 1-3 that do not control for the coupon gap with estimates in columns 4-6 that do, we find that the reduction in interest rates can only explain about $25-45 \%$ of the observed increase in the refinancing volume for the conforming segment. Contrasting columns 1 and 4, we conclude that QE1 affected the mortgage market above and beyond its effects on the yield curve and the natural refinancing response to yield curve changes. Similarly, columns 2 and 5 and columns 3 and 6 show that differential response of the conforming segment to QE1 is much larger than could be explained by the additional 40 bp fall in interest rates in the conforming segment.

\subsubsection{The Intensive-Margin Response of Household Mortgage Debt}

Having shown the differential increase in origination of conforming loans and likelihood of refinancing, we next exploit the granularity of our data to study the borrower's refinancing decision in more detail. This allows us to investigate segmentation and is an input to understanding the effects of the LSAPs on real economic activity.

There are three types of refinancing: cash-in, in which borrowers use cash to lower their loanto-value ratio; cash-out, in which borrowers extract equity from their homes; and rate or term refinancing in which the balance does not change. In principle, different types of refinancing can have different effects on consumption as they might work through three distinct channels. First, lower monthly payments lead to higher disposable income, which might boost aggregate consumption to the extent that borrowers' marginal propensity to consume (MPC) out of this additional income exceeds lenders' MPCs. Lowering interest payments is equivalent to a positive wealth shock for borrowers, which should lead to an increase in consumption as long as borrowers are not liquidity constrained. Finally, cash-in/cash-out decisions increase the borrower's stock of liquid wealth, which the literature has generally asserted is done to finance consumption or various forms of investment.

We are interested in assessing the extent to which the heterogeneous decline in interest rates and change in credit availability induced by QE MBS purchases influenced aggregate household borrowing and savings. We measure cash-in refinancing by linking each new refinance loan to the unpaid balance on the borrower's prior loan. We allow for $\$ 3,000$ closing costs to be rolled into the 
new loan without being classified as cash-in refinancing. ${ }^{34}$ One key advantage of our panel data is that it allows us to observe loan amounts before refinancing and to estimate the LTV prior to the refinance. To account for the introduction of the Home Affordable Refinance Program (HARP) by the Federal Housing Finance Agency in March 2009, which aimed to help underwater homeowners to refinance their mortgages, we will distinguish between the pre- and post-HARP period.

Panel I of Figure 9 plots three kernel densities: the LTV distribution of all outstanding loans with an LTV between $80 \%$ and $90 \%$, the LTV distribution for loans with an LTV between $80 \%$ and $90 \%$ that will be refinanced during the period, and the LTV distribution of the new refinance mortgages for borrowers who started with an original loan with an 80-90\% LTV. Comparing the three curves, we find strong evidence that the differential availability and price of GSE eligible vs. GSE ineligible mortgages resulted in significant deleveraging. Whereas the LTV distribution for all outstanding mortgages in this LTV range is relatively uniform, those that are able to refinance are much more likely to start near $80 \%$, evidence of the frictions associated with non-GSE-eligible refinancing during this time period. Comparing the original LTV distribution and subsequent LTV distribution for refinancers, it is clear that the GSE cutoffs were very important during this time period. Around $34 \%$ of households who prepay from a mortgage that is initially $80-90 \%$ LTV (and thus ineligible for a GSE-guaranteed refinance) deleverage and take out an 80\% LTV mortgage, increasing their equity position via their liquid wealth. ${ }^{35}$ The effect is economically meaningful: conditional on deleveraging to $80 \%$ or below, borrowers cashed-in about $\$ 12,300$; conditional on deleveraging to $80 \%$, borrowers cashed-in about $\$ 9,000$. These results highlight the tightness of credit for a mortgage market segment that was not directly stimulated by Fed MBS purchases.

We can also measure the expansionary effects of LSAPs by looking at cash-out refinancing. panel II of Figure 9 shows a bunching rate of about $22 \%$ with the average borrower cashing out $\$ 4,000$. That is, about $22 \%$ of the refinances with a LTV between 70 and 80 percent before refinancing decide to cash out from their mortgages by refinancing to a loan with an $80 \%$ LTV. This household balance-sheet response to interest rate changes and its dependence on current home equity highlights how accommodative monetary policy may at best not help distressed regions, with less equity to

\footnotetext{
${ }^{34}$ See http://www.bankrate.com/finance/mortgages/closing-costs/closing-costs-by-state.aspx for data on average closing costs by state.

${ }^{35}$ For other studies of mortgage-market bunching, see Adelino et al. (2013), DeFusco and Paciorek (2015), and Best et al. (2015).
} 
extract, as much as areas with lower LTVs outstanding on average.

Figure 10 performs a similar exercise for HARP-eligible loans. Panel I clearly shows that this program alleviated deleveraging behavior significantly, with bunching declining from $34 \%$ to $11 \%$, while panel II shows that cash-out refinances were not significantly affected. This result highlights that GSE eligibility was a limiting factor in the effectiveness of Fed MBS purchases and that there is scope for GSE policies such as HARP to amplify the effectiveness of MBS purchases by relaxing eligibility requirements.

To isolate a setting where credit conditions are similarly high (and thus contrast more comparable market segments), we next return to the prime jumbo segment and perform similar analysis around

the conforming loan limit (CLL). Panel I of Figure 11 estimates bunching from the fraction of borrowers with a mortgage size above the CLL that originate a new mortgage at or below the CLL. Consistent with the results on bunching to the $80 \%$ LTV, we find that about $43 \%$ of households who prepay a GSE-ineligible jumbo mortgage deleverage to the CLL (with 35\% bunching around 99.5$100.5 \%$ ), with an average cash-in amount of about $\$ 31,000$ (corresponding to $\$ 81,000$ on average for deleveraging mortgagors and $\$ 73,000$ for mortgagors bunching around 100\%). Panel II shows significantly less bunching from the left of the CLL, with only about $10 \%$ of the borrowers bunching at the CLL using the new mortgage to cash out an average of $\$ 2,000$. These results suggest that the LTV results above are not driven by unobserved heterogeneity in local economic conditions or borrower creditworthiness.

Overall, these findings highlight that the interactions between LSAPs and GSE policy have profound amplifying or attenuating effects on Fed LSAPs.

\section{Counterfactual Simulation}

Using our statistical model of the relationship between the LSAPs, debt origination, and equity extraction, we can evaluate the effectiveness of an oft-proposed macroprudential tool: countercyclical leverage caps. Specifically, we analyze the complementarity between the maximum loan-to-value ratio allowed by the GSEs (that is, the maximum allowable without credit enhancements such as PMI) and the Fed's LSAP efforts by investigating what would have been the effects of an increase in the LTV cap from $80 \%$ to $90 \%$. This exercise also serves to highlight the degree to which 
seemingly unrelated policy (GSE) is a major factor in modulating the effectiveness of LSAPs. While low-downpayment loans are frequently maligned as an contributor to the housing crisis, ideally leverage ratios would be tight during credit expansions and loose during contractions to smooth macroeconomic shocks. Our bunching and hazard model results highlight the importance of this LTV cap in determining the effectiveness of MBS purchases.

Adopting a countercyclical LTV might have several effects. First, it might allow borrowers with LTV higher than $80 \%$ that would not have been able to qualify for a new mortgage to refinance their current mortgages. Second, it might enable borrowers with lower LTV to cash-out additional equity, supporting their spending behavior during the downturn. This policy intervention is substantially different from HARP; whereas HARP relaxed the requirements to qualify for a refinance loans, it prohibited borrowers from extracting any equity out of their homes (see Amromin and Kearns, 2014 and Agarwal et al. 2015a). Third, borrowers with LTV higher than $80 \%$ that were going to liquidate accumulated wealth to cash-in refinance to do so without deleveraging as much.

Table 7 reports the results of this exercise. For each of several LTV binds, we measure in our data the number of loans, the fraction of borrowers that refinanced, and the average amount cashedout (or cashed-in) again, allowing for $\$ 3,000$ in closing costs in columns $1-3$. Then, we estimate a hazard regression similar to that presented in Table 5 to simulate what would have happened if the maximum allowable LTV were 90\% instead of 80\% (see also Appendix Tables 6 and 8). To do so, we shift the coefficients for the LTV bins between 70-100\% LTV up by one bin, effectively assuming that with a maximum LTV of $90 \%$ instead of $80 \%$, it would be as easy for an $85 \%$ current LTV loan to refinance as it had been for a $75 \%$ loan to refinance in the factual world of an $80 \%$ LTV cap. We do not shift the coefficients for borrowers in the lowest (current LTV below 70\%) and highest (current LTV above 100\%) bins, assuming that such a change in policy would be unlikely to have an effect on the very unconstrained or very constrained households' propensity to refinance. Likewise, we perform a similar exercise for the counterfactual amount of equity cashed out by estimating an OLS regression of the actual amount cashed out on a similar set of controls (detailed in Appendix Tables 7 and 9). In addition to shifting the LTV bin coefficients in the counterfactual, we also replace the amount of available equity to be cashed out (actual equity minus $20 \%$ of property value) with actual equity minus $10 \%$ of the property value. Columns 4 and 5 of Table 7 report the predicted fraction of borrowers who would be able to refinance and the predicted average cash out 
under the counterfactual policy. Columns 6 and 7 report the increase in the number of refinances and the increase in aggregate equity cashed-out as the difference between the actual number and the predicted ones.

We find that the biggest increase in the number of refinances come from the $80 \%$ to $90 \%$ bin, as these borrowers were not able to refinance before without deleveraging to get their current LTV ratio under $80 \%$. However, we also find that there is a significant increase in the aggregate amount cashed out, a result that is mainly driven by the borrowers below $60 \%$ and in the $70 \%$ to $80 \%$ LTV bins, as these borrowers are now able to extract equity in their houses and still be able to refinance. Are such borrowers with substantial equity actually likely to be affected by a change in the maximum allowable LTV from $80 \%$ to $90 \%$ ? Appendix Figure 6 shows that the $80 \%$ cutoff is quite relevant, even for those with very low LTVs that are refinancing. The effects from the below $60 \%$ LTV bin are particularly important because, although only a small fraction of these borrowers cash out, it is the group with the largest number of borrowers. We find in our data that about 5.6\% of borrowers in the below $60 \%$ LTV cash out by bunching at the $80 \%$ threshold, so it is plausible that we would see an increase of a comparable magnitude for people refinancing to $90 \%$ LTV. Notice that this an effect that is not present with other policy interventions such as HARP. Can this policy have large effects? Yes. Accounting for the $48 \%$ coverage ratio of our data (that is, it seems to cover $48 \%$ of nationwide 2009 mortgage origination as measured by HMDA), our estimates show that this simple policy would have increased the number of refinancing households by over 410,000. If we multiply this number by the average mortgage size (i.e., $\$ 224,262$ ), this policy would have resulted in a $\$ 92$ billion increase in refinance mortgage origination. Notably, this policy would have also resulted in an almost $20 \%$ increase in equity cashed-out ( $\$ 10$ billion) with potentially important effects on aggregate demand. One way to benchmark the magnitude of these numbers is to contrast them with estimated effects in the literature of the effect of the HARP program that explicitly supported the refinancing of high LTV mortgages owned by the GSE. We find that the change in the LTV requirement would have been more effective in terms of refinances and aggregate volume than HARP, partly because our policy experiment would have had a significant impact on cash-out activities, and thus on the consumption expenditures, of these borrowers.

Overall, an important implication of our findings is the complementarity between unconventional monetary policy and housing policies which might play a key role in supporting aggregate demand 
through their effects on borrowers' ability to cash out equity from their houses.

\section{Conclusion}

Prior to the fall of 2007, the Fed had largely held Treasury securities on its balance sheet. However, in response to the financial crisis, the Fed started several new programs - liquidity facilities (under which the Fed lent directly to certain sectors of the economy) and targeted purchases of trillions of dollars of long-term Treasuries and GSE-guaranteed mortgage-backed securities. The impacts of these unconventional monetary policies - whether and how they affect the real economy - have been the subject of ongoing debate.

In this paper, we focus on demonstrating and quantifying the pass-through of unconventional monetary policy to the real economy through the mortgage market. We show that Quantitative Easing works through a refinancing channel by improving credit availability and lowering interest rates for affected households. Specifically, we show that QE1 increased refinance origination by over $\$ 600$ billion, which also led to a boom in equity extraction and substantially reduced interest payments, and a resulting significant increase in consumption by $\$ 76$ billion. Our analysis also sheds light on the different transmission channels through which QE has been posited to affect the real economy. Under the portfolio-rebalancing channel (where investors have a desired duration mix), central-bank purchases of long-duration assets will have spillover effects, easing credit to other sectors of the economy as capital is reallocated across the economy. In contrast to this view, using rich loan-level microdata, we find strong evidence of a "flypaper effect" of unconventional monetary policy during QE1, which passed through to borrowers who were able to refinance into mortgages bundled into MBS purchased by the Fed but significantly less to borrowers who couldn't qualify for a GSE-eligible mortgage, consistent with a burgeoning theoretical and empirical literature on debt yields in segmented markets and is supported by results showing how important GSE eligibility cutoffs are for individual borrowers. This de facto allocation of credit highlights a main takeaway from our analysis: the real effects of unconventional monetary policy on the household sector depend crucially on the composition of central-bank asset purchases.

Finally, exploiting the ability of our data to link mortgages across borrowers, we document an important complementarity between GSE policy and Fed purchases. Because banks during QE1 
did not reallocate capital to non-conforming segments of the mortgage market, many households initially ineligible for a conforming mortgage (current loan-to-value ratios exceeding $80 \%$ or loan balances over the conforming loan limit) did not benefit from QE MBS purchases, to the extent that those who did benefit often delevered by bringing cash to closing ("cash-in refinancing") to take advantage of low interest rates during the height of QE1 MBS purchases. Overall, tight GSEeligibility requirements and the lack of spillovers from LSAPs likely dampened the multiplier effects of lower interest rates and suggests that countercyclical macroprudential policy could enhance the effectiveness of MBS purchases. In particular, our counterfactual simulations show that relaxing LTV caps during the crisis would have benefitted economically distressed areas proportionally more by enabling more households to refinance and by reducing household deleveraging.

There are several implications of these findings for designing effective unconventional monetary policy. First, given the limited spillover of Fed purchases, Federal Reserve Act provisions that restrict Fed purchases to government-guaranteed debt have real consequences in allocating credit to certain sectors (i.e., housing) and particular segments within those sectors (i.e., conforming mortgages). Even operating within the legal constraints that govern Federal Reserve purchases, it appears preferable for LSAPs to purchase MBS directly instead of Treasuries during times when banks are reluctant to lend on their own. Related, central-bank interventions could be more effective by providing more direct funding to banks for lending to small business and households. ${ }^{36}$ Finally, we demonstrate a strong interaction between GSE policy and the effectiveness of MBS purchases. Programs like HARP had a role in extending credit to the households who needed it most, as did the significant expansion in the market share of low-downpayment FHA loans during the crisis.

\footnotetext{
${ }^{36}$ While U.S. programs such as TALF and CPFF ostensibly encouraged lending to businesses and households, their main focus was providing liquidity to (and preventing a further collapse of) securitization markets. The high cost of credit under those programs limited their scope as market confidence returned (Ashcraft et al., 2012). For another example of such a program, see also the Bank of England's "Lending for Funding Scheme."
} 


\section{References}

Adelino, M., A. Schoar, and F. Severino (2013). Credit Supply and House Prices: Evidence from Mortgage Market Segmentation. NBER Working Paper No. 17832.

Agarwal, S., G. Amromin, S. Chomsisengphet, T. Piskorski, A. Seru, and V. Yao (2015). Mortgage refinancing, consumer spending, and competition: Evidence from the home affordable refinancing program. NBER Working Paper No. 21512.

Agarwal, S., S. Chomsisengphet, N. Mahoney, and J. Stroebel (2015). Do Banks Pass Through Credit Expansions? The Marginal Profitability of Consumer Lending During the Great Recession. NBER Working Paper No. 21567.

Amromin, G. and C. Kearns (2014). Access to refinancing and mortgage interest rates: Harping on the importance of competition. FRB of Chicago Working Paper.

Ashcraft, A., N. Garleanu, and L. H. Pedersen (2011). Two monetary tools: Interest rates and haircuts. NBER Macroeconomics Annual 25, 143-180.

Ashcraft, A., A. Malz, and Z. Pozsar (2012). The federal reserve's term asset-backed securities loan facility. The New York Fed Economic Policy Review 18(3), 29-66.

Baba, N., M. Nakashima, Y. Shigemi, and K. Ueda (2006). The Bank of Japan's Monetary Policy and Bank Risk Premiums in the Money Market. International Journal of Central Banking.

Bauer, M. D. and C. J. Neely (2014). International channels of the fed's unconventional monetary policy. Journal of International Money and Finance 44, $24-46$.

Beraja, M., A. Fuster, E. Hurst, and J. Vavra (2015). Regional heterogeneity and monetary policy. Staff Report, Federal Reserve Bank of New York.

Bernanke, B. S. and A. S. Blinder (1988). Credit, Money, and Aggregate Demand. American Economic Review 78(2), 435-39.

Best, M. C., J. Cloyne, E. Ilzetzki, and H. J. Kleven (2015). Interest Rates, Debt and Intertemporal Allocation: Evidence From Notched Mortgage Contracts in the UK. Bank of England Working Paper.

Brunner, K., M. Fratianni, J. L. Jordan, A. H. Meltzer, and M. J. Neumann (1973). Fiscal and Monetary Policies in Moderate Inflation: Case Studies of Three Countries. Journal of Money, Credit and Banking, 313-353.

Brunnermeier, M. K. and Y. Sannikov (2015). The I theory of money. Working Paper.

Caballero, R. J., E. Farhi, and P.-O. Gourinchas (2015). Global imbalances and currency wars at the zlb. NBER Working Paper No. 21670.

Calomiris, C. W. and U. Khan (2015). An assessment of tarp assistance to financial institutions. The Journal of Economic Perspectives 29(2), 53-80. 
Chakraborty, I., I. Goldstein, and A. MacKinlay (2016). Monetary stimulus and bank lending. Working Paper.

Chernenko, S., S. G. Hanson, and A. Sunderam (2014). The rise and fall of demand for securitizations. NBER Working Paper No. 20777.

Chodorow-Reich, G. (2014). Effects of Unconventional Monetary Policy on Financial Institutions. Brookings Papers on Economic Activity, 155.

Christiano, L. J. and M. Eichenbaum (1992). Liquidity Effects and the Monetary Transmission Mechanism. American Economic Review, 346-353.

Christiano, L. J., M. Eichenbaum, and C. L. Evans (2005). Nominal rigidities and the dynamic effects of a shock to monetary policy. Journal of Political Economy 113(1), 1-45.

Coibion, O., Y. Gorodnichenko, L. Kueng, and J. Silvia (2012). Innocent bystanders? monetary policy and inequality in the U.S. NBER Working Paper No. 18170.

Curdia, V. and M. Woodford (2011). The Central Bank's Balance Sheet as an Instrument of Monetary Policy. Journal of Monetary Economics 58.1(136), 54-79.

DeFusco, A. and A. Paciorek (2015). The interest rate elasticity of mortgage demand: Evidence from bunching at the conforming loan limit. FEDS Working Paper 2014-11.

Del Negro, M., G. B. Eggertsson, A. Ferrero, and N. Kiyotaki (2011). The great escape? A quantitative evaluation of the Fed's liquidity facilities. FRB of New York Staff Report 520.

Di Maggio, M. and M. Kacperczyk (2014). The Unintended Consequences of the Zero Lower Bound Policy. Columbia Business School Research Paper 14-25.

Di Maggio, M., A. Kermani, and R. Ramcharan (2014). Monetary Policy Pass-Through: Household Consumption and Voluntary Deleveraging. Columbia Business School Research Paper $14-24$.

Doepke, M. and M. Schneider (2006). Inflation and the redistribution of nominal wealth. Journal of Political Economy 114(6), 1069-1097.

Downing, C., D. Jaffee, and N. Wallace (2009). Is the market for mortgage-backed securities a market for lemons? Review of Financial Studies 22(7), 2457-2494.

Drechsler, I., A. Savov, and P. Schnabl (2014). The Deposits Channel of Monetary Policy. Unpublished manuscript.

Eggertsson, G. and M. Woodford (2003). The Zero Bound on Interest Rates and Optimal Monetary Policy. Brookings Papers on Economic Activity 34(1), 139-235.

Foley-Fisher, N., R. Ramcharan, and E. G. Yu (2014). The Impact of Unconventional Monetary Policy on Firm Financing Constraints: Evidence from the Maturity Extension Program. Working Paper.

Fuster, A., L. Goodman, D. O. Lucca, L. Madar, L. Molloy, and P. Willen (2013). The rising gap between primary and secondary mortgage rates. Economic Policy Review 19(2). 
Fuster, A. and P. Willen (2010). \$1.25 trillion is still real money: Some facts about the effects of the federal reserve's mortgage market investments. FRB of Boston Public Policy Discussion Paper 10-4.

Gagnon, J., M. Raskin, J. Remache, and B. P. Sack (2010). Large-scale asset purchases by the Federal Reserve: did they work? FRB of New York Staff Report 441.

Gertler, M. and P. Karadi (2011). A model of unconventional monetary policy. Journal of Monetary Economics 58(1), 17-34.

Glaeser, E. L. and H. D. Kallal (1997). Thin markets, asymmetric information, and mortgagebacked securities. Journal of Financial Intermediation 6(1), 64-86.

Greenwald, D. L. (2016). The mortgage credit channel of macroeconomic transmission. Working Paper.

Greenwood, R., S. G. Hanson, and G. Y. Liao (2015). Price Dynamics in Partially Segmented Markets. HBS Working Paper.

Gurley, J. and E. Shaw (1960). Money in a Theory of Finance. Technical report, The Brookings Institution.

Hancock, D. and W. Passmore (2011). Did the Federal Reserve's MBS purchase program lower mortgage rates? Journal of Monetary Economics 58(5), 498-514.

He, Z. and A. Krishnamurthy (2013). Intermediary asset pricing. The American Economic Review $103(2), 732-770$.

Jimenez, G., S. Ongena, and J.-L. Peydro (2012). Credit supply and monetary policy: Identifying the bank balance-sheet channel with loan applications. American Economic Review 102(5), $2301-2326$.

Jimenez, G., S. Ongena, J.-L. Peydro, and J. Saurina (2014). Hazardous Times for Monetary Policy: What Do Twenty-Three Million Bank Loans Say About the Effects of Monetary Policy on Credit Risk-Taking? Econometrica 82(2), 463-505.

Kaplan, G. and G. L. Violante (2014). A model of the consumption response to fiscal stimulus payments. Econometrica 82(4), 1199-1239.

Kashyap, A. K. and J. C. Stein (2000). What do a million observations on banks say about the transmission of monetary policy? American Economic Review, 407-428.

Keys, B. J., T. Piskorski, A. Seru, and V. Yao (2014). Mortgage Rates, Household Balance Sheets, and the Real Economy. NBER Working Paper No. 20561.

Krishnamurthy, A. and A. Vissing-Jorgensen (2011). The Effects of Quantitative Easing on Interest Rates: Channels and Implications for Policy. Brookings Papers on Economic Activity, 215.

Krishnamurthy, A. and A. Vissing-Jorgensen (2013). The ins and outs of LSAPs. In Economic Symposium Conference Proceedings. Jackson Hole, WY: Federal Reserve Bank of Kansas City. 
Landier, A., D. Sraer, and D. Thesmar (2013). Banks' Exposure to Interest Rate Risk and The Transmission of Monetary Policy. NBER Working Paper No. 18857.

Maddaloni, A. and J.-L. Peydró (2011). Bank risk-taking, securitization, supervision, and low interest rates: Evidence from the Euro-area and the US lending standards. Review of Financial Studies 24 (6), 2121-2165.

Mian, A. and A. Sufi (2011). House prices, home equity-based borrowing, and the us household leverage crisis. The American Economic Review 101(5), 2132-2156.

Palmer, C. (2015). Why Did So Many Subprime Borrowers Default During the Crisis: Loose Credit or Plummeting Prices? Working Paper.

Rodnyansky, A. and O. Darmouni (2016). The Effects of Quantitative Easing on Bank Lending Behavior. Working Paper.

Rotemberg, J. and M. Woodford (1997). An optimization-based econometric framework for the evaluation of monetary policy. NBER Macroeconomics Annual 12, 297-361.

Sarkar, A. and J. Shrader (2010). Financial amplification mechanisms and the Federal Reserve's supply of liquidity during the crisis. Economic Policy Review 16(1), 55.

Scharfstein, D. S. and A. Sunderam (2013). Concentration in Mortgage Lending, Refinancing Activity and Mortgage Rates. NBER Working Paper No. 19156.

Stein, J. C. (2012). Monetary Policy as Financial Stability Regulation. The Quarterly Journal of Economics 127(1), 57-95.

Sterk, V. and S. Tenreyro (2014). The Transmission of Monetary Policy Operations through Redistributions and Durable Purchases. Working Paper.

Stroebel, J. and J. B. Taylor (2012). Estimated Impact of the Federal Reserve's Mortgage-Backed Securities Purchase Program. International Journal of Central Banking.

Swanson, E. T. (2015). Measuring the Effects of Unconventional Monetary Policy on Asset Prices. NBER Working Paper No. 21816.

Tobin, J. (1969). A general equilibrium approach to monetary theory. Journal of money, credit and banking 1(1), 15-29.

Tobin, J. and W. C. Brainard (1963). Financial intermediaries and the effectiveness of monetary controls. American Economic Review 53(2), 383-400.

Vanasco, V. M. (2014). Information Acquisition vs. Liquidity in Financial Markets. Working Paper.

Vayanos, D. and J.-L. Vila (2009). A Preferred-Habitat Model of the Term Structure of Interest Rates. NBER Working Paper No. 15487.

Vickery, J. I. and J. Wright (2013). TBA trading and liquidity in the agency MBS market. Economic Policy Review 19(1), 1-18. 
Wallace, N. (1981). A Modigliani-Miller theorem for open-market operations. American Economic Review, 267-274.

Williamson, S. D. (2012). Liquidity, monetary policy, and the financial crisis: A new monetarist approach. American Economic Review 102(6), 2570-2605. 
Figure 1. Federal Reserve Balance Sheet: Assets

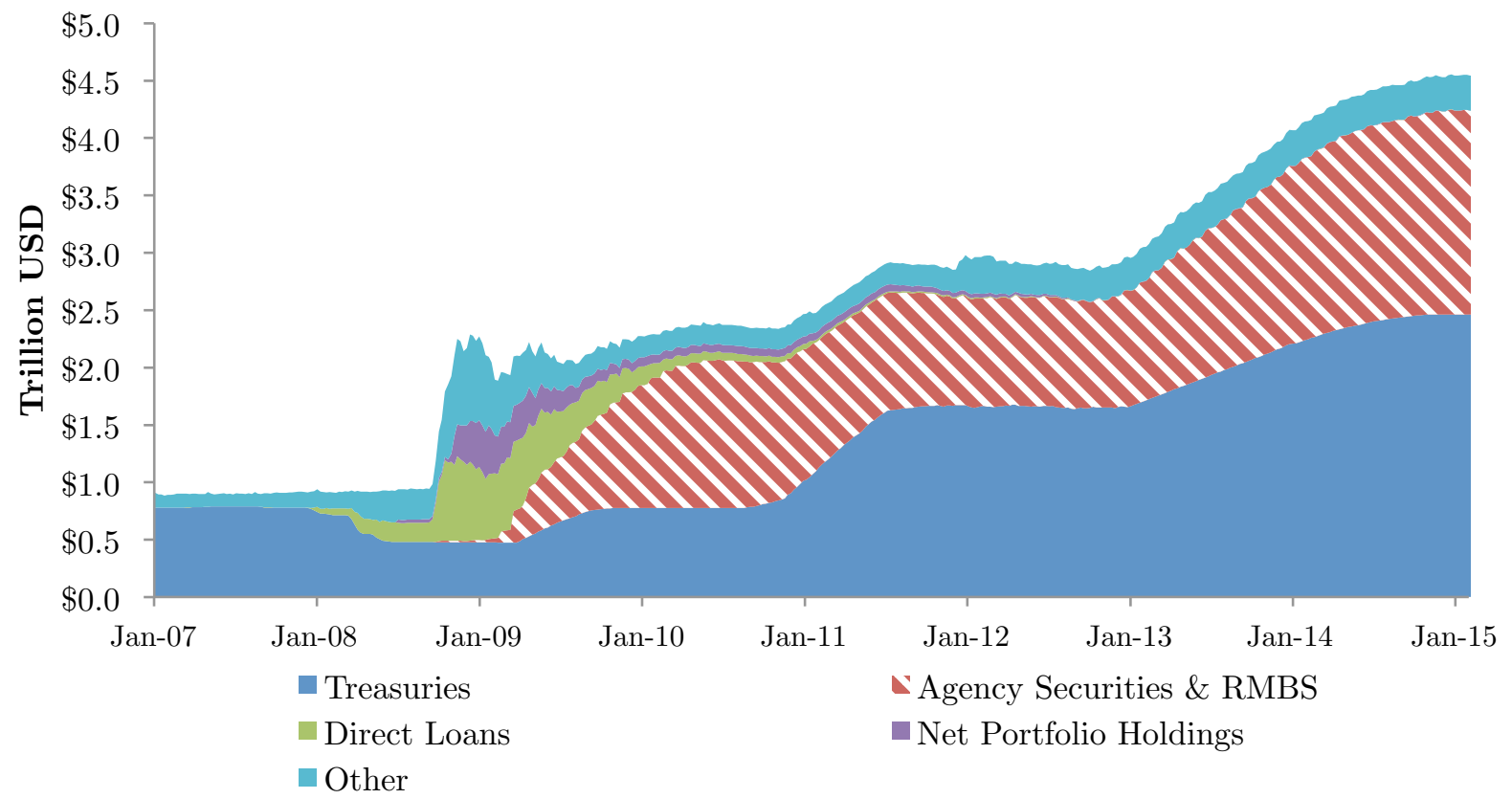

Notes: Graph shows the size and the composition of assets on the Fed Balance sheet from 2007-2015. Source: Fed H4.1 weekly reports. 
Figure 2. Quantitative Easing Timeline

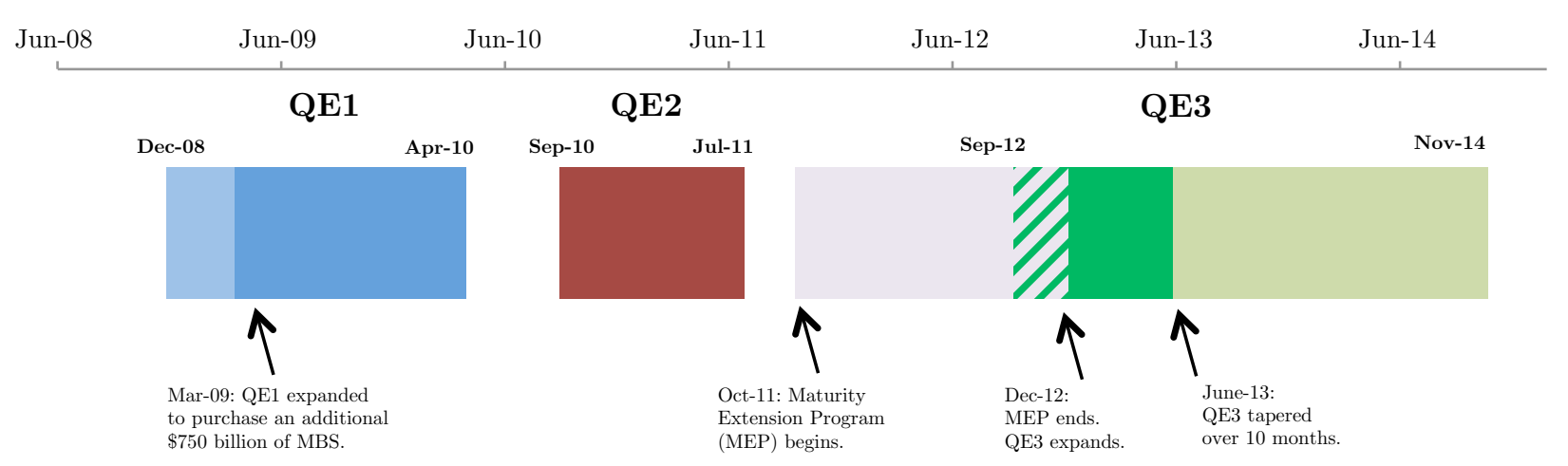


Figure 3. Federal Reserve Asset Purchases \& Sales (Gross)

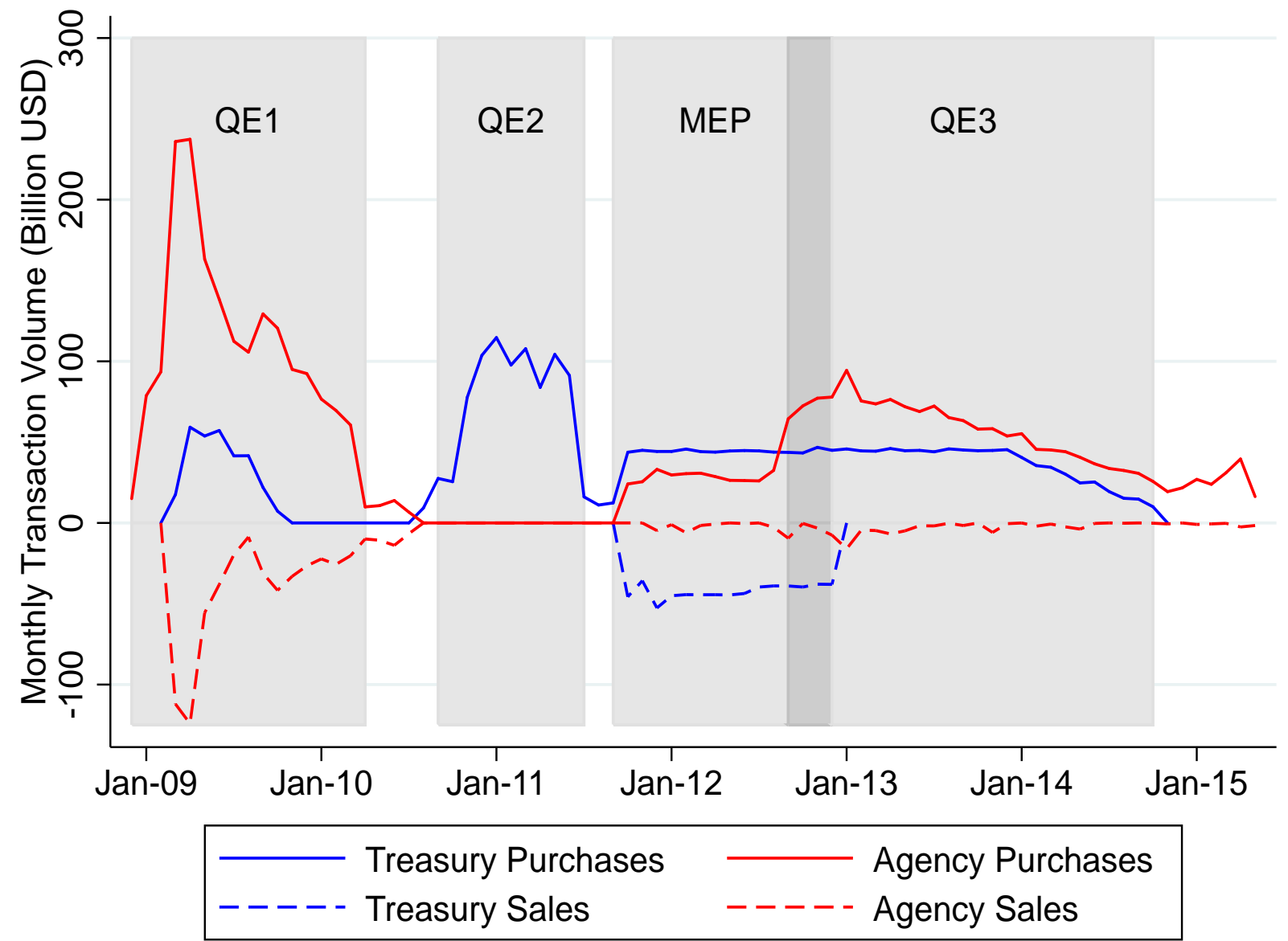

Notes: Figure plots monthly gross transaction amounts for the purchase and sale of mortgage-backed securities (in red) and Treasuries (in blue) by the Fed during the each quantitative easing operation. MEP shading represents the period of the Matury Extension Program, also known as Operation Twist, that involved the swapping of short- and long-term Treasuries. Source: NY Fed Open Market Operations Data. 
Figure 4. Fed GSE MBS Net Purchases vs. Monthly GSE Issuance

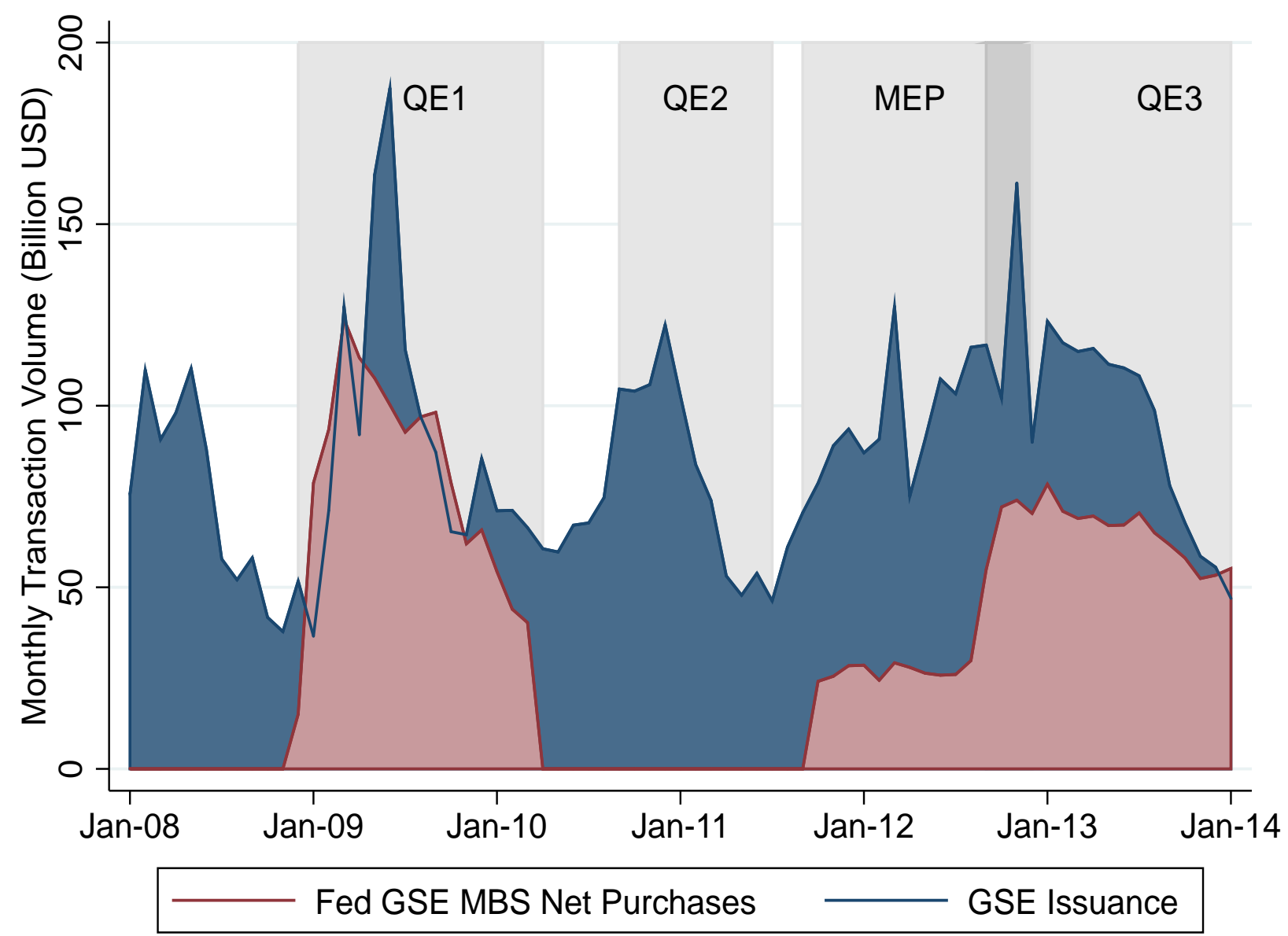

Notes: Figure plots the transaction amounts for the purchase of mortgage-backed securities by the Fed and the issuance of GSE securities during the three quantitative easing operations. Source: NY Fed Open Market Operations Data, Fannie Mae, and Freddie Mac. 
$\underline{\text { Figure 5. Interest Rates for Conforming and Jumbo Refinance Loans }}$

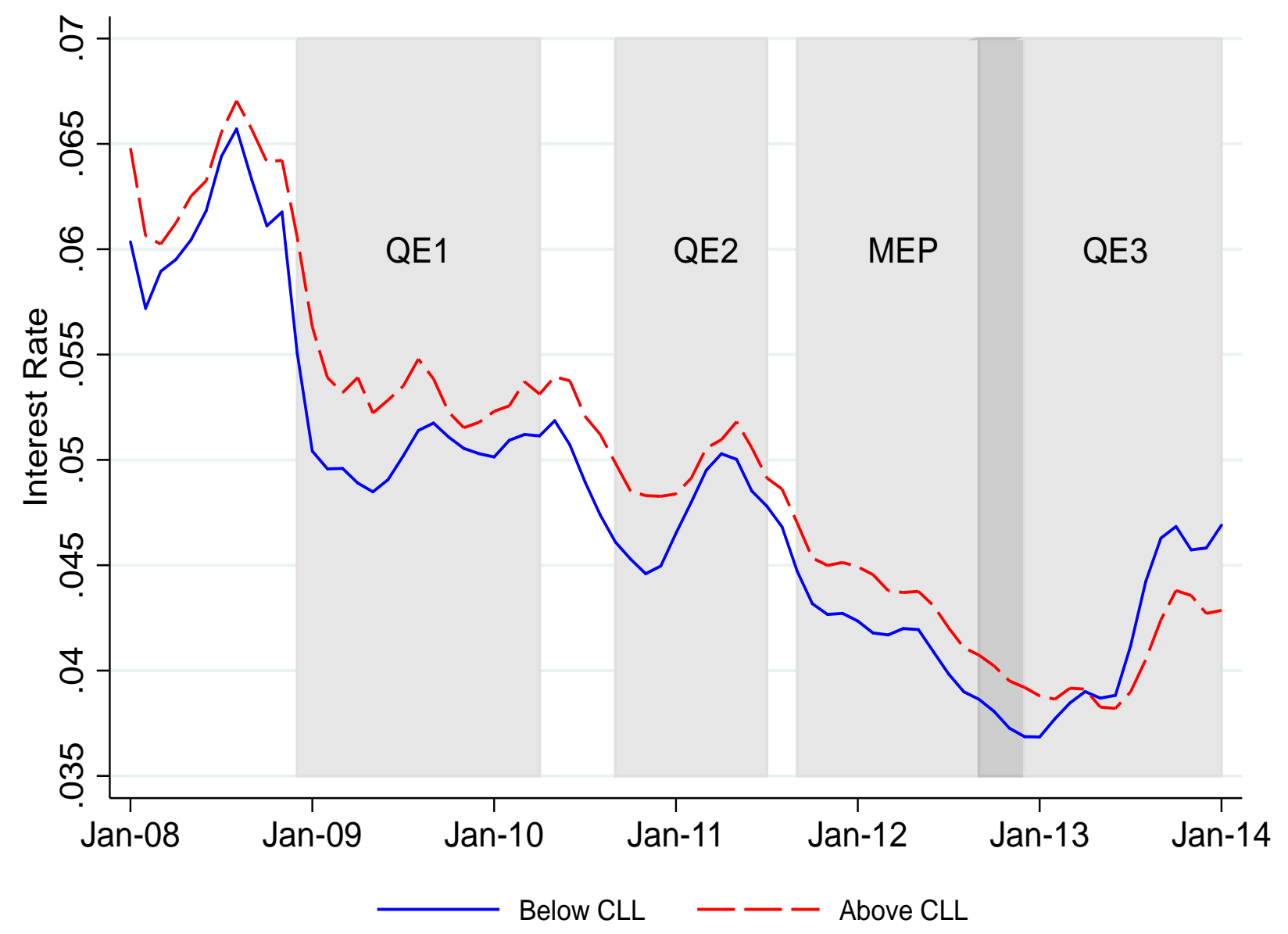

Notes: Figure plots the estimated monthly interest rates for refinance loans above and below the confoming loan limit with a loan-to-value ratio of $75 \%$ and a FICO score of 760 and 30 year fixed rate mortgage. The estimates are based on all non-FHA first-lien refinance loans in LPS with LTV less or equal to $80 \%$ and adjusted for the LTV and credit score of the borrower. See Section 5.1 for more details. 
Figure 6. Refinance Origination Volume

\section{Panel I. Number of Originations}

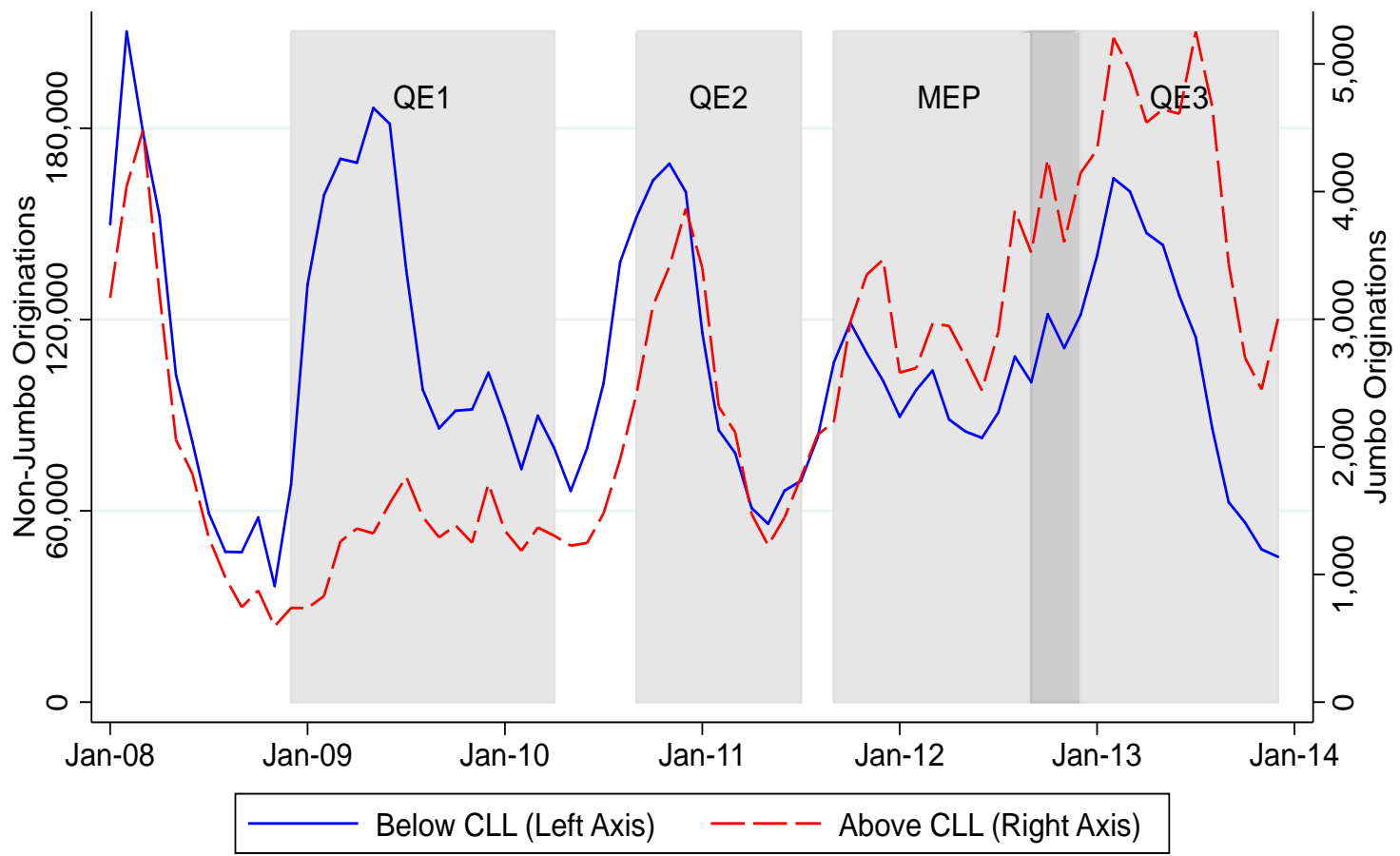

Panel II. Origination Volume

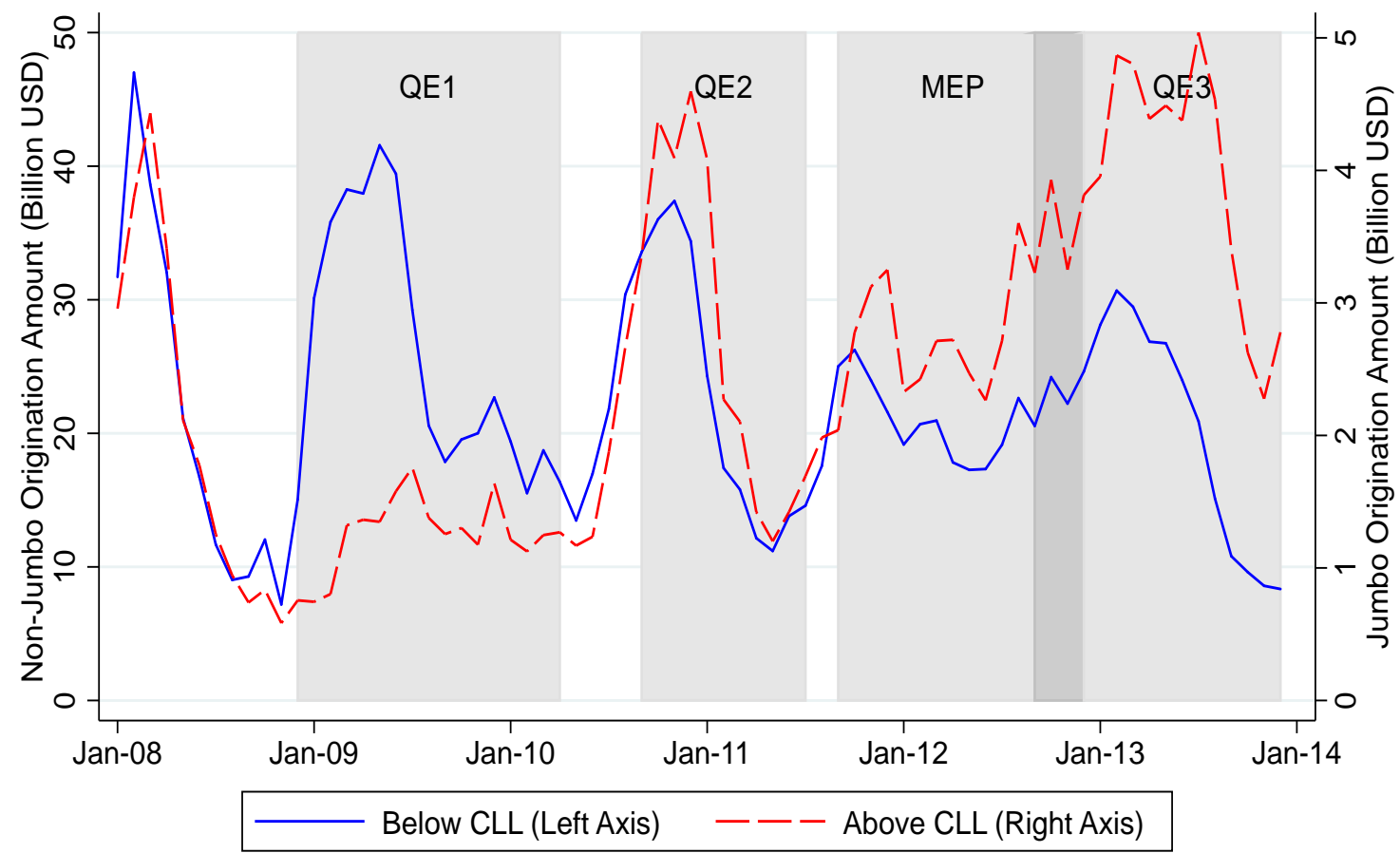

Notes: Figure plots the number of originations (top panel) and the origination volume (bottom panel) of refinance mortgages below the conforming loan limit and above the conforming loan limit as recorded by LPS. FHA loans are excluded from the data. 
Figure 7. Fed Gross MBS Purchases vs. Conforming Origination Volume

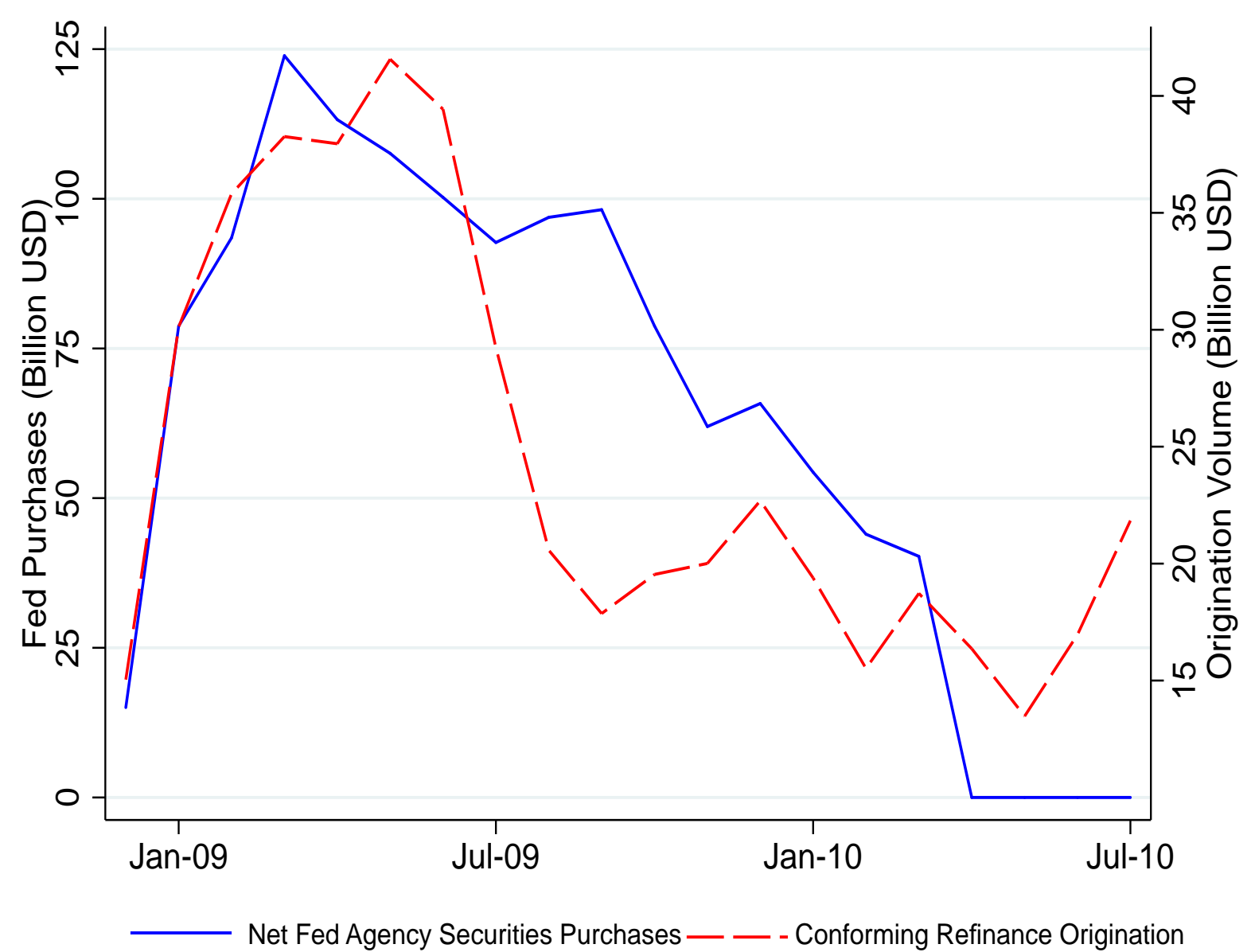

Notes: Figure plots the monthly origination amount of refinance mortgages below the conforming loan limit (right axis) recorded by LPS against the net monthly amount of Fed purchases of Agency securities observed in NY Fed Open Market Operations data (left axis). 
Figure 8. State-level Refinancing Activity vs. Lagged HPI and GDP Growth Panel I. Refinancing Activity and House-Price Growth

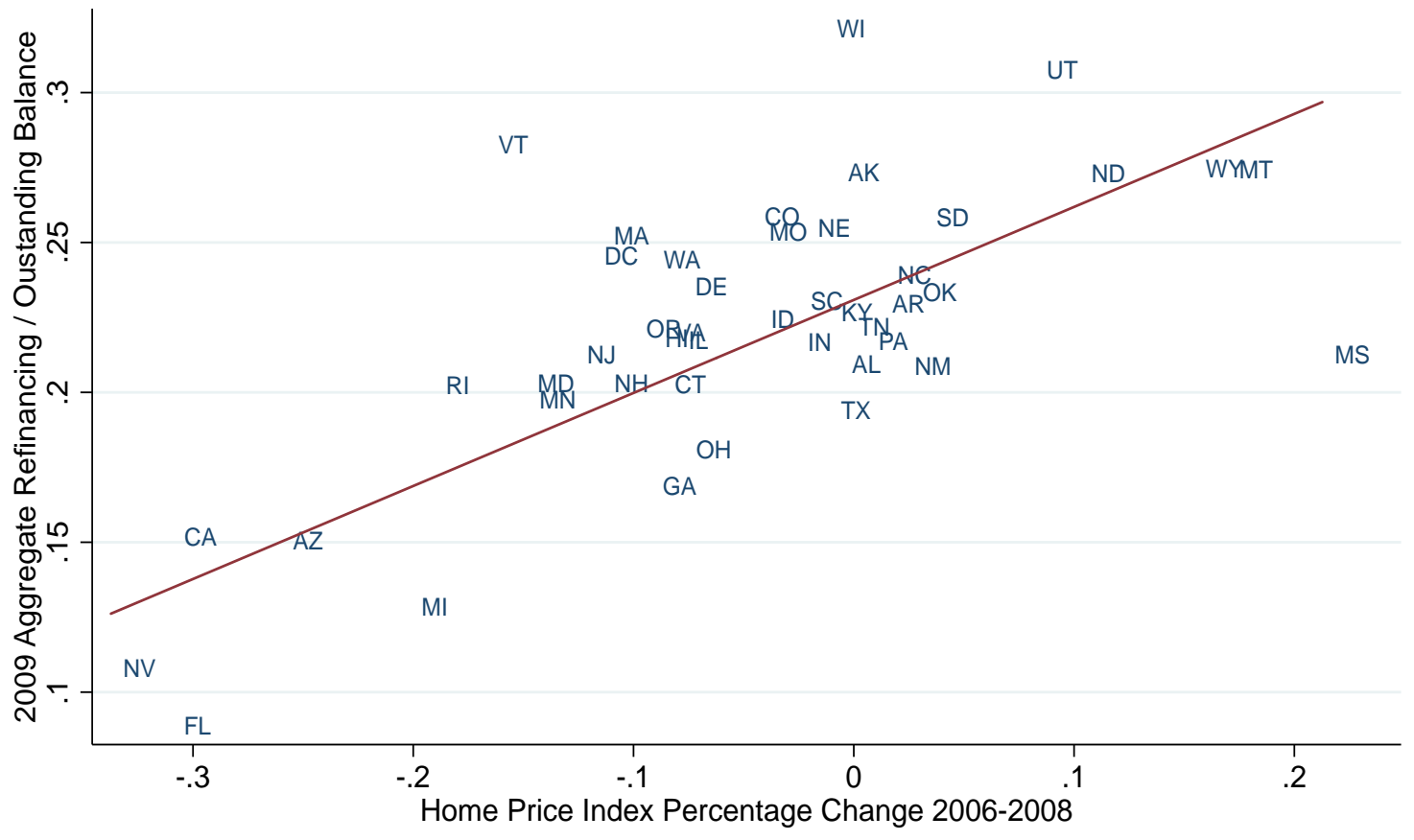

Panel II. Refinancing Activity and Real GDP Growth

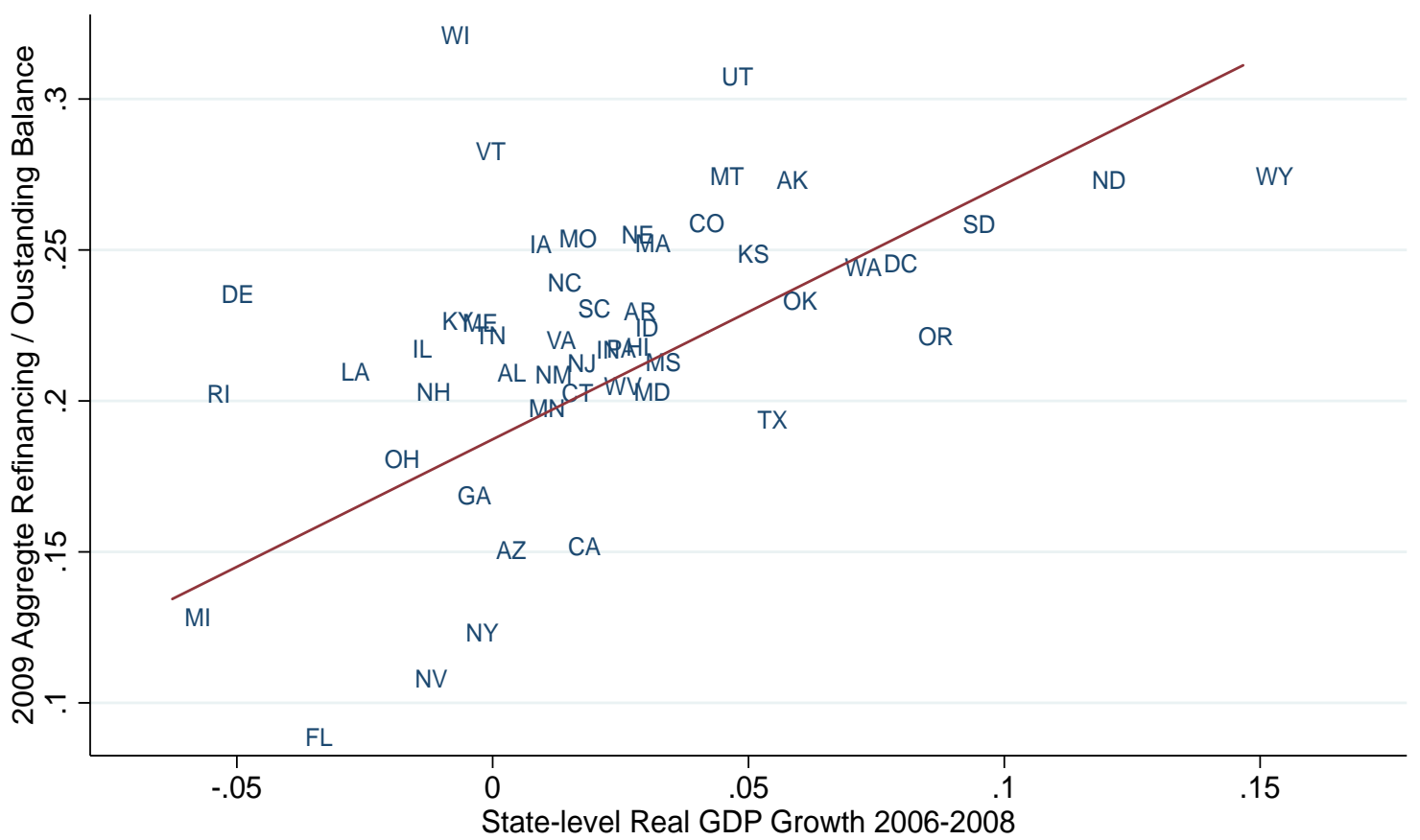

Notes: Figures plot the state-level percentage of 2009 outstanding mortgage balances that were refinanced in 2009 against state-level 2006-2008 Zillow Home Price Index percentage changes (Panel I) and 2006-2008 state-level real GDP growth (Panel II) from the BEA, along with the corresponding bivariate regression line. The robust t-stats are 4.7 for panel I and 4.2 for panel II. 
Figure 9. Loan-to-Value Ratio Bunching Pre-HARP

Panel I. Distribution of LTV for Original LTVs 80-90\%

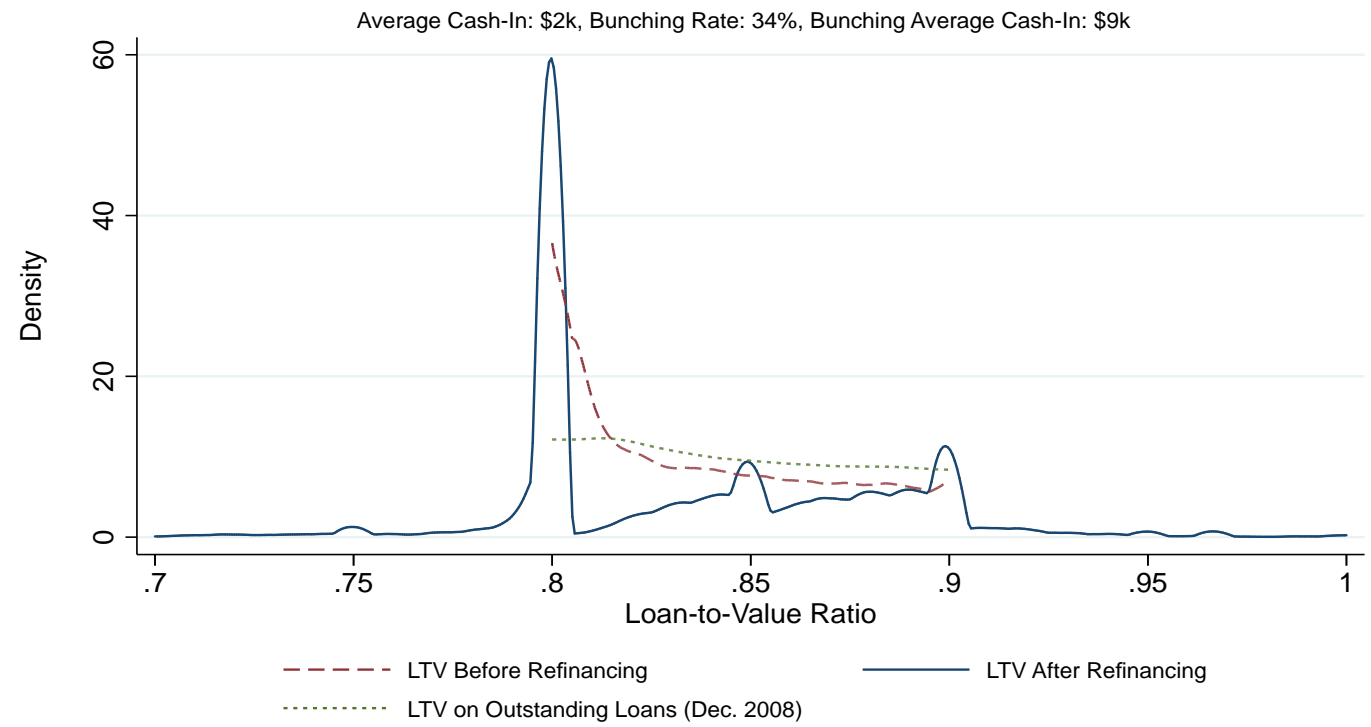

Panel II. Distribution of LTV for Original LTVs 70-80\%

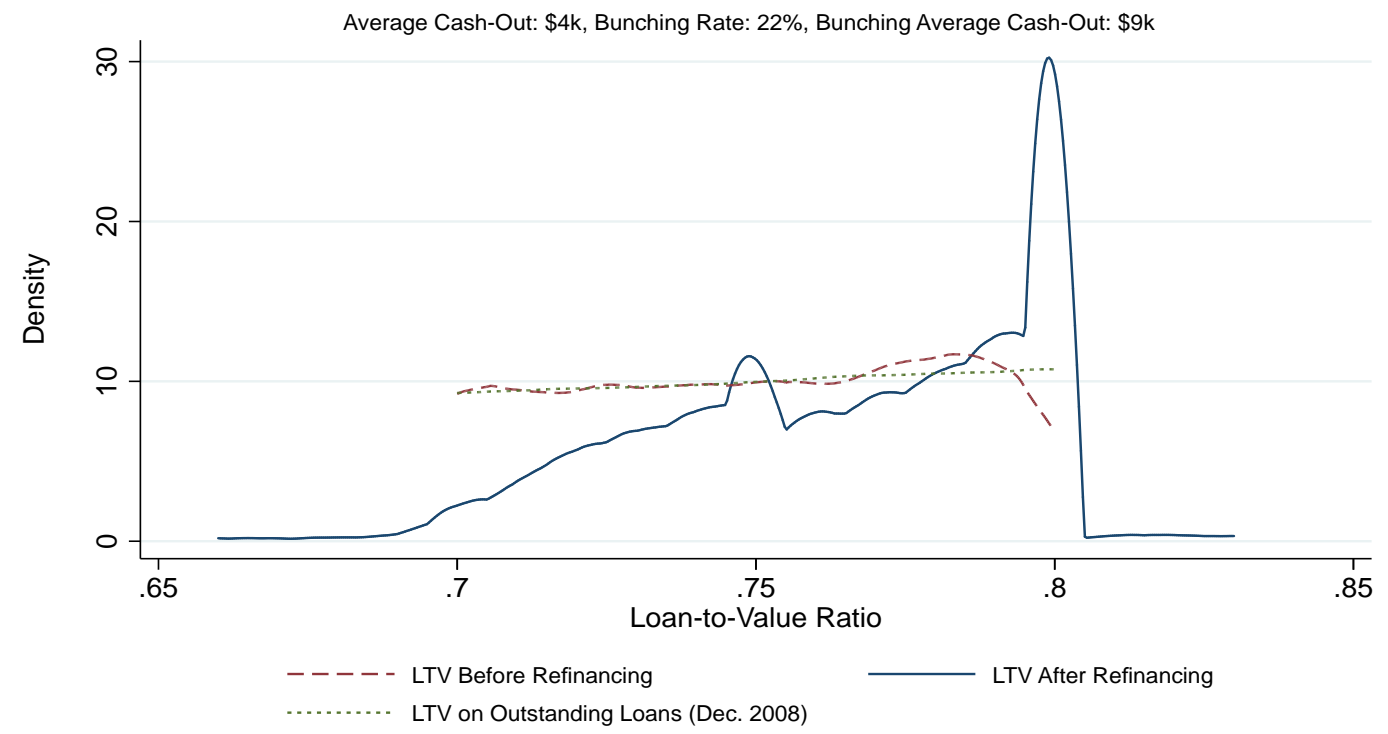

Notes: Figures report the distribution of borrower LTV ratios for various groups during QE1 but before the start of the Home Affordable Refinance Program (HARP) (Dec. 2008-May 2009). Panel I includes loans for which we observe the predecessor loan with imputed LTV 80-90\%. Panel II includes loans with predecessor loan imputed LTV between 70-80\%. Dotted lines plot the LTV distribution of all outstanding loans in the indicated LTV range (i.e. not conditional on refinancing). Dashed lines represent the imputed LTV distribution for mortgages that will be refinanced during the time period. To account for rolling closing costs into the balance of the new loan, we add average refinancing costs $(\$ 3,000)$ to the loan balance before the refinance. The solid blue lines report the distribution of actual LTV ratios for originated refinance mortgages. The bunching rate is the number of refinance mortgages with an LTV ratio between $79.5 \%$ and $80.5 \%$ at origination divided by the total number of loans with an imputed LTV ratio exceeding (below) $80 \%$ that refinance. Reported average cash-in (cash-out) is the average amount borrowers refinancing an above (below) 80\%-LTV ratio mortgage provide at the closing of their new refinance mortgage. See text for average cash-in amounts conditional on deleveraging. 


\section{$\underline{\text { Figure 10. Loan-to-Value Ratio Bunching Post-HARP }}$}

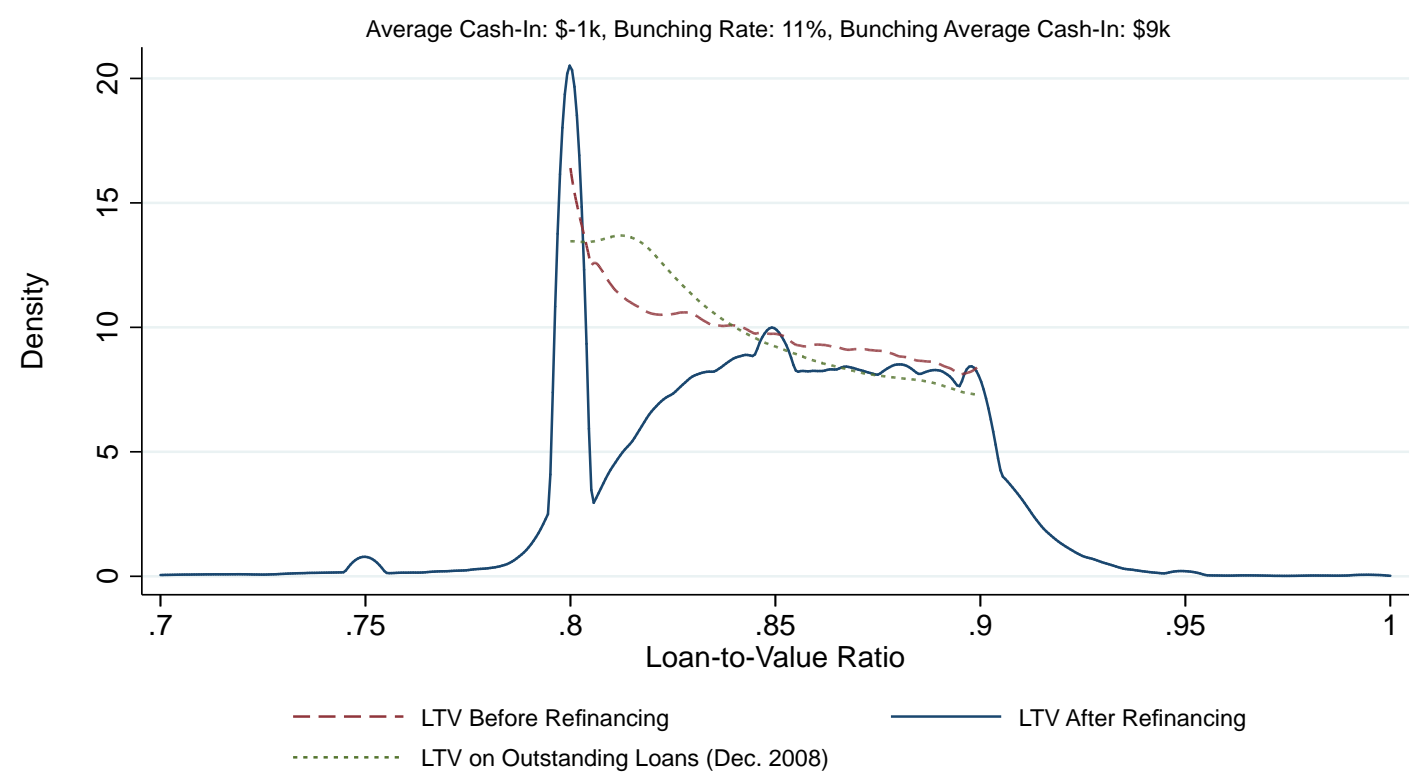

Notes: Figures report the distribution of LTV ratios for HARP eligible loans during QE1 and after the introduction of HARP (June 2009 - Mar. 2010) for loans for which we observe a predecessor loan with an imputed LTV of $80-90 \%$. Dotted lines plot the LTV distribution of all outstanding loans in the indicated LTV range (i.e. not conditional on refinancing). Dashed lines represent the LTV distribution for mortgages that will be refinanced during the time period. To account for rolling closing costs into the balance of the new loan, we add average refinancing costs $(\$ 3,000)$ to balances before refinancing. The solid blue lines report the distribution of actual LTV ratios for originated refinance mortgages. The bunching rate is the number of refinance mortgages with an LTV ratio between $79.5 \%$ and $80.5 \%$ at origination divided by the total number of loans with an imputed LTV ratio exceeding (below) 80\% that refinance. Reported average cash-in (cash-out) is the average amount borrowers refinancing an above (below) 80\%-LTV ratio mortgage provide at the closing of their new refinance mortgage. 
Figure 11. Conforming Loan Limit Bunching

Panel I. Distribution of Loan Size/CLL for Original Balances 100-140\% of CLL

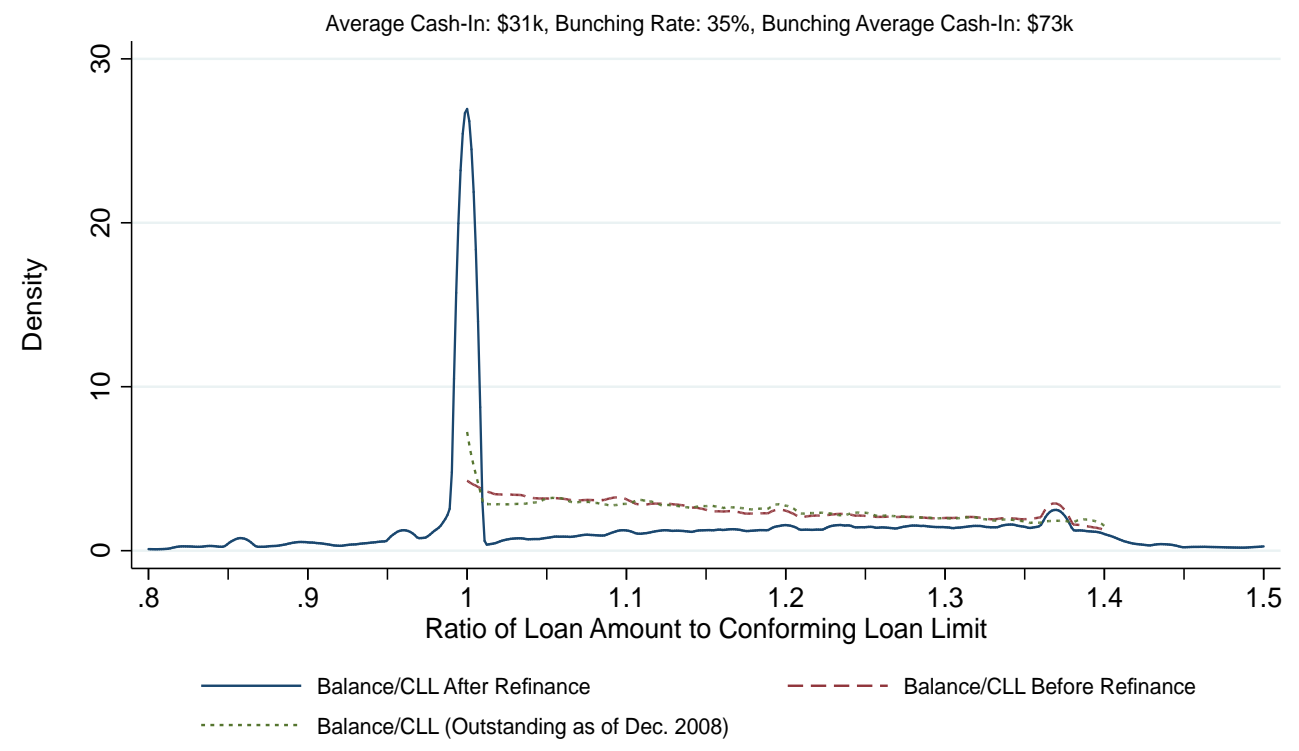

Panel II. Distribution of Loan Size/CLL for Original Balances 80-100\% of CLL

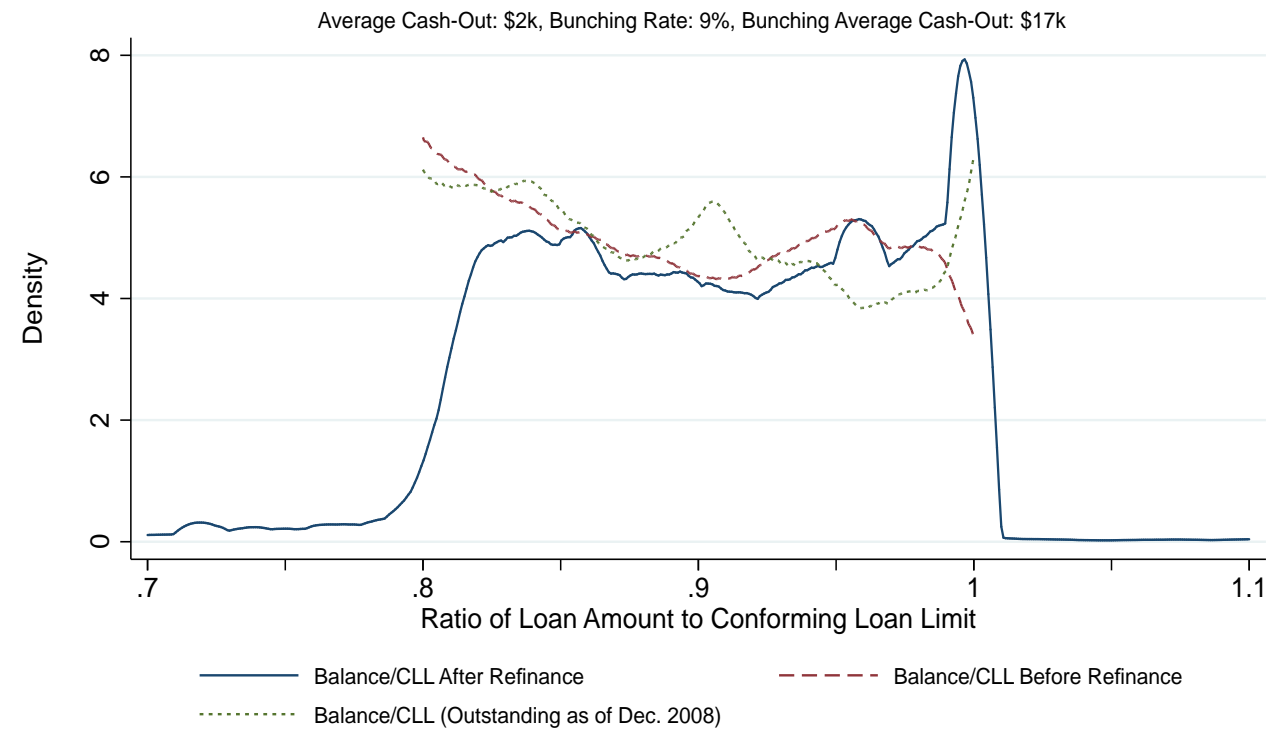

Notes: Figures plot distribution of loan sizes relative to the local conforming loan limit (CLL). Dashed lines plot the distribution of normalized predecessor loan sizes (measured three months before refinancing) for refinancing borrowers. Solid lines shows the distribution of normalized loan sizes for that group's new refinance mortgages. Dotted lines plot the LTV distribution of all outstanding mortgages in the given LTV range. Bunching rate is the number of refinance mortgages with relative CLL between $99.5 \%$ and $100.5 \%$ at origination divided by count of loans with a relative CLL ratio exceeding (below) $100 \%$ that refinance. Panel I includes loans for which we observe the predecessor loan with outstanding principal between 100 and $140 \%$ of the local CLL and loan whose outstanding balance (adjusted for expected refinancing costs) is between 80 and $100 \%$ of the CLL. Panel II includes loans for which we observe the predecessor loan with outstanding principal between 80 and $100 \%$ of the local CLL and loan whose outstanding balance (adjusted for expected refinancing costs) is between 70 and $110 \%$ of the CLL. 
Table 1. Summary Statistics

\begin{tabular}{|c|c|c|c|c|c|c|c|c|}
\hline & \multicolumn{8}{|c|}{$\underline{\text { Percentile }}$} \\
\hline & Count & Mean & Std. Dev. & $1 \mathrm{st}$ & 10 th & 50 th & $90 t h$ & 99 th \\
\hline & \multicolumn{8}{|c|}{ Panel I. Below-Conforming Loan Limit Loans } \\
\hline LTV & $7,308,119$ & 66.69 & 18.09 & 27.40 & 40.70 & 69.24 & 88.18 & 109.20 \\
\hline FICO & $7,308,076$ & 751.90 & 51 & 594 & 681 & 766 & 804 & 819 \\
\hline Interest Rate & $6,374,466$ & 4.56 & 0.96 & 2.75 & 3.38 & 4.50 & 5.75 & 7.13 \\
\hline \multirow[t]{2}{*}{ Balance } & $7,308,119$ & 211,335 & 117,725 & 44,000 & 83,000 & 185,000 & 388,000 & 590,000 \\
\hline & \multicolumn{8}{|c|}{ Panel II. Jumbo Loans } \\
\hline LTV & 172,212 & 64.73 & 14.70 & 28.50 & 43.22 & 67.23 & 80.00 & 95.80 \\
\hline FICO & 150,730 & 761.30 & 36.02 & 660 & 709 & 770 & 800 & 814 \\
\hline Interest Rate & 172,182 & 4.10 & 1.14 & 1.88 & 2.75 & 3.88 & 5.63 & 7.25 \\
\hline \multirow[t]{2}{*}{ Balance } & 172,212 & 959,771 & 693,231 & 440,000 & 536,000 & 813,000 & $1,475,000$ & $3,265,000$ \\
\hline & \multicolumn{8}{|c|}{ Panel III. Spreads and Yields } \\
\hline Guarantee fees & 72 & 34.05 & 11.03 & 23.80 & 25.70 & 28.92 & 56.07 & 61.20 \\
\hline Aaa Yields & 72 & 4.74 & 0.74 & 3.40 & 3.73 & 4.95 & 5.57 & 6.28 \\
\hline Baa Yields & 72 & 6.08 & 1.13 & 4.51 & 4.85 & 5.97 & 8.06 & 9.21 \\
\hline Baa-Aaa Spread & 72 & 1.34 & 0.62 & 0.75 & 0.84 & 1.18 & 2.52 & 3.38 \\
\hline CDS Spread & 72 & 177.29 & 231.84 & 13.48 & 37.07 & 89.91 & 166.61 & 1145.85 \\
\hline
\end{tabular}

Notes: Panel I \& Panel II report loan-level summary statistics on conforming and jumbo loans from Equifax's CRISM database which merges McDash Analytics mortgage servicing records from Lender Processing Services with Equifax credit bureau data. Panel III reports summary statistics for time series controls used in robustness checks, including guarantee fees from Fuster et al. (2013), bond yields from Federal Reserve Economic Data (FRED) at the Federal Reserve Bank of St. Louis, and CDS index from Markit. 
Table 2. Effect of QE Campaign Beginning on Interest Rates

\begin{tabular}{|c|c|c|c|c|c|c|c|c|c|c|}
\hline & $(1)$ & $(2)$ & $(3)$ & $(4)$ & $(5)$ & $(6)$ & $(7)$ & $(8)$ & $(9)$ & $(10)$ \\
\hline Program & \multicolumn{2}{|c|}{$\underline{\mathrm{QE} 1}$} & \multicolumn{2}{|c|}{$\underline{\mathrm{QE} 2}$} & \multicolumn{2}{|c|}{ MEP } & \multicolumn{2}{|c|}{$\underline{\mathrm{QE} 3}$} & \multicolumn{2}{|c|}{ Tapering } \\
\hline & \multicolumn{10}{|c|}{ Panel I. 3-month Window Around Program Start } \\
\hline Program Indicator & $\begin{array}{c}-117.053^{* * *} \\
(13.862)\end{array}$ & & $\begin{array}{c}-36.552^{* *} \\
(10.833)\end{array}$ & & $\begin{array}{c}-45.994^{* * *} \\
(7.296)\end{array}$ & & $\begin{array}{c}-17.863^{* *} \\
(5.913)\end{array}$ & & $\begin{array}{c}26.201 \\
(14.138)\end{array}$ & \\
\hline Program x Jumbo & $\begin{array}{c}53.069^{* * *} \\
(7.099)\end{array}$ & $\begin{array}{c}41.809^{* * *} \\
(7.485)\end{array}$ & $\begin{array}{l}-2.496 \\
(6.394)\end{array}$ & $\begin{array}{l}-1.800 \\
(5.964)\end{array}$ & $\begin{array}{c}6.559^{* * *} \\
(1.206)\end{array}$ & $\begin{array}{c}4.715 \\
(2.375)\end{array}$ & $\begin{array}{l}-0.417 \\
(1.465)\end{array}$ & $\begin{array}{l}-1.022 \\
(1.739)\end{array}$ & $\begin{array}{c}-22.445^{*} \\
(8.825)\end{array}$ & $\begin{array}{c}-24.829^{* *} \\
(8.216)\end{array}$ \\
\hline Jumbo Indicator & $\begin{array}{c}21.778^{* *} \\
(6.231)\end{array}$ & $\begin{array}{c}33.178^{* * *} \\
(5.516)\end{array}$ & $\begin{array}{c}46.188^{* * *} \\
(5.547)\end{array}$ & $\begin{array}{c}46.545^{* * *} \\
(5.034)\end{array}$ & $\begin{array}{c}17.795^{* * *} \\
(1.182)\end{array}$ & $\begin{array}{c}23.204^{* * *} \\
(2.019)\end{array}$ & $\begin{array}{c}23.307^{* * *} \\
(1.250)\end{array}$ & $\begin{array}{c}28.176^{* * *} \\
(1.258)\end{array}$ & $\begin{array}{l}-3.682 \\
(3.436)\end{array}$ & $\begin{array}{c}3.049 \\
(2.726)\end{array}$ \\
\hline Controls & & Yes & & Yes & & Yes & & Yes & & Yes \\
\hline County-Month FEs & & Yes & & Yes & & Yes & & Yes & & Yes \\
\hline Observations & 331,895 & 331,895 & 292,290 & 292,290 & 180,055 & 180,055 & 201,060 & 201,060 & 262,493 & 262,493 \\
\hline \multirow[t]{2}{*}{ R-squared } & 0.488 & 0.669 & 0.217 & 0.457 & 0.276 & 0.462 & 0.076 & 0.336 & 0.099 & 0.383 \\
\hline & \multicolumn{10}{|c|}{ Panel II. 6-month Window Around Program Start } \\
\hline Program Indicator & $\begin{array}{c}-139.649^{* * *} \\
(9.402)\end{array}$ & & $\begin{array}{c}-46.907^{* * *} \\
(8.795)\end{array}$ & & $\begin{array}{c}-63.073^{* * *} \\
(6.791)\end{array}$ & & $\begin{array}{c}-31.645^{* * *} \\
(5.887)\end{array}$ & & $\begin{array}{c}52.698^{* * *} \\
(15.017)\end{array}$ & \\
\hline Program x Jumbo & $\begin{array}{c}62.298^{* * *} \\
(6.778)\end{array}$ & $\begin{array}{c}52.780^{* * *} \\
(5.841)\end{array}$ & $\begin{array}{l}-0.775 \\
(5.740)\end{array}$ & $\begin{array}{l}-1.324 \\
(5.309)\end{array}$ & $\begin{array}{c}12.604^{* * *} \\
(2.269)\end{array}$ & $\begin{array}{c}10.058^{* * *} \\
(2.407)\end{array}$ & $\begin{array}{l}-5.038 \\
(3.545)\end{array}$ & $\begin{array}{l}-4.799 \\
(2.944)\end{array}$ & $\begin{array}{c}-35.385^{* * *} \\
(8.226)\end{array}$ & $\begin{array}{c}-35.631^{* * *} \\
(6.683)\end{array}$ \\
\hline Jumbo Indicator & $\begin{array}{c}8.473 \\
(5.985)\end{array}$ & $\begin{array}{c}20.154^{* * *} \\
(4.724)\end{array}$ & $\begin{array}{c}40.559^{* * *} \\
(4.988)\end{array}$ & $\begin{array}{c}41.886^{* * *} \\
(3.962)\end{array}$ & $\begin{array}{c}14.304^{* * *} \\
(1.808)\end{array}$ & $\begin{array}{c}19.849^{* * *} \\
(2.100)\end{array}$ & $\begin{array}{c}23.263^{* * *} \\
(1.366)\end{array}$ & $\begin{array}{c}27.578 * * * \\
(0.801)\end{array}$ & $\begin{array}{c}5.030 \\
(4.417)\end{array}$ & $\begin{array}{c}11.194^{* *} \\
(3.989)\end{array}$ \\
\hline Controls & & Yes & & Yes & & Yes & & Yes & & Yes \\
\hline County-Month FEs & & Yes & & Yes & & Yes & & Yes & & Yes \\
\hline Observations & 789,945 & 789,945 & 568,776 & 568,776 & 351,042 & 351,042 & 438,201 & 438,201 & 470,820 & 470,820 \\
\hline R-squared & 0.616 & 0.745 & 0.295 & 0.493 & 0.411 & 0.576 & 0.179 & 0.428 & 0.272 & 0.567 \\
\hline
\end{tabular}

Notes: The table reports regression coefficients relating loan-level mortgage interest rates (in basis points) to indicated unconventional monetary policy programs. QE, MEP ("Maturity Extension Program"), and Tapering Indicators are dummy variables equal to one after the introduction of each program (see Appendix Table 1). The sample includes single-family, first lien, 30-year term, fixed rate, non-interest only, non-balloon, and non-FHA refinance mortgages with no prepayment penalties and less than or equal to $80 \%$ LTV. Controls include binned original LTV and binned credit score. Jumbo Indicator is a dummy equal to one for jumbo loans. Program $\mathrm{x}$ Jumbo is the interaction between the program dummies and Jumbo Indicator. The event window includes the three (panel I) or six (panel II) months before/after the beginning month of each program period (e.g. QE1 sample in panel I is Sep2008Feb2009). All specifications control for 5-point LTV bins, 20-point FICO bins, and an indicator for missing FICO. Even columns control for county by month fixed effects. Standard errors are clustered at the month level. Asterisks denote significance levels $(* * *=1 \%, * *=5 \%, *=10 \%)$. 
Table 3. Effect of QE Campaign Beginning on Refinance Origination Volumes

\begin{tabular}{|c|c|c|c|c|c|c|c|c|c|c|}
\hline & $(1)$ & $(2)$ & $(3)$ & $(4)$ & $(5)$ & $(6)$ & $(7)$ & $(8)$ & $(9)$ & $(10)$ \\
\hline Program & \multicolumn{2}{|c|}{$\underline{\mathrm{QE} 1}$} & \multicolumn{2}{|c|}{$\underline{\mathrm{QE} 2}$} & \multicolumn{2}{|c|}{ MEP } & \multicolumn{2}{|c|}{$\underline{\mathrm{QE} 3}$} & \multicolumn{2}{|c|}{ Tapering } \\
\hline & \multicolumn{10}{|c|}{ Panel I. 3-month Window Around Program Start } \\
\hline Program Indicator & $\begin{array}{c}1.019^{* *} \\
(0.291)\end{array}$ & & $\begin{array}{c}0.487^{* *} \\
(0.152)\end{array}$ & & $\begin{array}{c}0.547 * * * \\
(0.079)\end{array}$ & & $\begin{array}{c}0.141 \\
(0.086)\end{array}$ & & $\begin{array}{c}-0.346^{*} \\
(0.148)\end{array}$ & \\
\hline Program x Jumbo & $\begin{array}{c}-0.824^{* *} \\
(0.236)\end{array}$ & $\begin{array}{c}-0.791^{*} \\
(0.319)\end{array}$ & $\begin{array}{c}0.153 \\
(0.118)\end{array}$ & $\begin{array}{c}0.170 \\
(0.141)\end{array}$ & $\begin{array}{l}-0.058 \\
(0.099)\end{array}$ & $\begin{array}{c}-0.008 \\
(0.109)\end{array}$ & $\begin{array}{c}0.041 \\
(0.034)\end{array}$ & $\begin{array}{c}0.029 \\
(0.063)\end{array}$ & $\begin{array}{c}0.414^{* *} \\
(0.151)\end{array}$ & $\begin{array}{c}0.372 \\
(0.196)\end{array}$ \\
\hline Jumbo Indicator & $\begin{array}{c}-2.141^{* * *} \\
(0.099)\end{array}$ & $\begin{array}{c}-2.128^{* * *} \\
(0.092)\end{array}$ & $\begin{array}{c}-2.294^{* * *} \\
(0.077)\end{array}$ & $\begin{array}{c}-2.240^{* * * *} \\
(0.076)\end{array}$ & $\begin{array}{c}-1.739 * * * \\
(0.043)\end{array}$ & $\begin{array}{c}-1.689^{* * *} \\
(0.071)\end{array}$ & $\begin{array}{c}-1.473^{* * *} \\
(0.006)\end{array}$ & $\begin{array}{c}-1.482^{* * *} \\
(0.015)\end{array}$ & $\begin{array}{c}-1.388^{* * *} \\
(0.019)\end{array}$ & $\begin{array}{c}-1.491^{* * *} \\
(0.028)\end{array}$ \\
\hline Controls & & Yes & & Yes & & Yes & & Yes & & Yes \\
\hline County-Month FEs & & Yes & & Yes & & Yes & & Yes & & Yes \\
\hline Observations & 492 & 492 & 492 & 492 & 492 & 492 & 492 & 492 & 492 & 492 \\
\hline \multirow[t]{2}{*}{ R-squared } & 0.637 & 0.925 & 0.586 & 0.946 & 0.463 & 0.941 & 0.338 & 0.919 & 0.279 & 0.916 \\
\hline & \multicolumn{10}{|c|}{ Panel II. 6-month Window Around Program Start } \\
\hline Program Indicator & $\begin{array}{c}1.153^{* * *} \\
(0.203)\end{array}$ & & $\begin{array}{c}0.456^{* *} \\
(0.166)\end{array}$ & & $\begin{array}{c}0.528^{* * *} \\
(0.092)\end{array}$ & & $\begin{array}{c}0.315^{* * *} \\
(0.082)\end{array}$ & & $\begin{array}{c}-0.745^{* * *} \\
(0.186)\end{array}$ & \\
\hline Program x Jumbo & $\begin{array}{c}-1.011^{* * *} \\
(0.148)\end{array}$ & $\begin{array}{c}-0.969 * * * \\
(0.209)\end{array}$ & $\begin{array}{l}0.283^{*} \\
(0.142)\end{array}$ & $\begin{array}{c}0.322 \\
(0.189)\end{array}$ & $\begin{array}{l}-0.012 \\
(0.079)\end{array}$ & $\begin{array}{c}0.034 \\
(0.113)\end{array}$ & $\begin{array}{l}-0.026 \\
(0.036)\end{array}$ & $\begin{array}{l}-0.043 \\
(0.066)\end{array}$ & $\begin{array}{c}0.570^{* * *} \\
(0.093)\end{array}$ & $\begin{array}{c}0.547^{* * *} \\
(0.147)\end{array}$ \\
\hline Jumbo Indicator & $\begin{array}{c}-1.921^{* * *} \\
(0.106)\end{array}$ & $\begin{array}{c}-1.932^{* * *} \\
(0.138)\end{array}$ & $\begin{array}{c}-2.164^{* * *} \\
(0.069)\end{array}$ & $\begin{array}{c}-2.161^{* * *} \\
(0.082)\end{array}$ & $\begin{array}{c}-1.694^{* * *} \\
(0.044)\end{array}$ & $\begin{array}{c}-1.683^{* * *} \\
(0.057)\end{array}$ & $\begin{array}{c}-1.445^{* * *} \\
(0.022)\end{array}$ & $\begin{array}{c}-1.454^{* * *} \\
(0.032)\end{array}$ & $\begin{array}{c}-1.449^{* * *} \\
(0.032)\end{array}$ & $\begin{array}{c}-1.477^{* * *} \\
(0.051)\end{array}$ \\
\hline Controls & & Yes & & Yes & & Yes & & Yes & & Yes \\
\hline County-Month FEs & & Yes & & Yes & & Yes & & Yes & & Yes \\
\hline Observations & 984 & 984 & 984 & 984 & 984 & 984 & 984 & 984 & 984 & 984 \\
\hline R-squared & 0.617 & 0.935 & 0.548 & 0.938 & 0.446 & 0.937 & 0.357 & 0.922 & 0.284 & 0.921 \\
\hline
\end{tabular}

Notes: Table reports regression coefficients relating county $\mathrm{x}$ month $\mathrm{x}$ mortgage segment log refinancing volumes to unconventional monetary policy programs. The left-hand side variable is the log dollar volume of refinanced mortgages at the county-month level as reported in the CRISM data. QE, MEP ("Maturity Extension Program"), and Tapering Indicators are dummy variables equal to one after the introduction of each program (see Appendix Table 1). Jumbo Indicator is a dummy equal to one for jumbo loans. Program x Jumbo is the interaction between the program dummies and Jumbo Indicator. Controls consist of average FICO and average LTV of all mortgages originated in that county-month segment. The sample includes single-family, first lien, non-FHA refinance mortgages between 25 and $120 \%$ original LTV. Counties are included in the sample if they have a positive number of jumbo originations in every sample month. The event window includes the three months (panel I) or six months (panel II) before/after each QE period (e.g. QE1 sample in panel I is Sep2008-Feb2009). Standard errors are clustered at the month level; asterisks denote conventional significance levels. 
Table 4. Robustness to Controlling for G-Fees, Credit Spreads and Banks CDS

\begin{tabular}{|c|c|c|c|c|c|}
\hline & (1) & $(2)$ & $(3)$ & (4) & $(5)$ \\
\hline \multirow[t]{2}{*}{ Program } & QE1 & QE2 & MEP & QE3 & Tapering \\
\hline & \multicolumn{5}{|c|}{ Panel I. Interest Rates } \\
\hline \multirow[t]{2}{*}{ Program x Jumbo } & $28.119^{* *}$ & -0.570 & -4.706 & 4.568 & $-22.925^{* *}$ \\
\hline & $(7.684)$ & $(5.197)$ & $(3.321)$ & $(2.410)$ & $(7.434)$ \\
\hline \multirow[t]{2}{*}{ Jumbo Indicator } & $-34.106^{* * *}$ & 9.232 & -4.266 & $13.154^{* * *}$ & $10.353^{* * *}$ \\
\hline & $(2.500)$ & $(4.593)$ & $(2.334)$ & $(0.732)$ & $(1.707)$ \\
\hline Controls & Yes & Yes & Yes & Yes & Yes \\
\hline County-Month FEs & Yes & Yes & Yes & Yes & Yes \\
\hline Observations & 331,895 & 292,290 & 180,055 & 201,060 & 262,493 \\
\hline \multirow[t]{2}{*}{ R-squared } & 0.668 & 0.450 & 0.462 & 0.327 & 0.381 \\
\hline & \multicolumn{5}{|c|}{ Panel II. Refinance Origination Volumes } \\
\hline \multirow[t]{2}{*}{ Program x Jumbo } & $-0.881^{* *}$ & 0.128 & 0.162 & -0.071 & 0.311 \\
\hline & $(0.339)$ & $(0.140)$ & $(0.147)$ & $(0.087)$ & $(0.180)$ \\
\hline \multirow[t]{2}{*}{ Jumbo Indicator } & $-2.641^{* * *}$ & $-2.525^{* * *}$ & $-2.322^{* * *}$ & $-2.165^{* * *}$ & $-3.140^{* * *}$ \\
\hline & $(0.079)$ & $(0.090)$ & $(0.091)$ & $(0.024)$ & $(0.020)$ \\
\hline County-Month FEs & Yes & Yes & Yes & Yes & Yes \\
\hline Observations & 492 & 492 & 492 & 492 & 492 \\
\hline R-squared & 0.941 & 0.954 & 0.955 & 0.943 & 0.964 \\
\hline
\end{tabular}

Notes: Panel I reports regression coefficients relating interest rates to the quantitative easing programs and to the other monetary policy programs. The sample includes single-family, first lien, 30-year term, fixed rate, noninterest only, non-balloon, and non-FHA refinance mortgages with no prepayment penalties and less than or equal to $80 \%$ LTV. Controls include binned original LTV and binned credit score. In all columns, we first subtract the contribution of the interaction of the Jumbo Indicator with a measure of Credit Spread (i.e. BBB to AAA spread from St. Louis Fed), with guarantee fees from Fuster et al. (2013), with banks' CDS, and county x month fixed effects as described in section 6.1.3. Panel II reports regression coefficients relating refinancing volume to the quantitative easing programs and to the other monetary policy programs. The left hand side variable is defined as the $\log$ of the dollar volume of refinanced mortgages as reported in the CRISM data. The sample includes single-family, first lien, non-FHA refinance mortgages. Counties are included in the quantity sample if they have greater than one jumbo origination in every month. We again subtract the contribution of the interaction of the jumbo indicator with credit spread and with guarantee fees as described in section 6.1.3. QE, MEP ("Maturity Extension Program"), and Tapering Indicators are dummy variables equal to one after the introduction of each program. MEP begins in Sept. 2011. Tapering begins in June 2013. Jumbo Indicator is a dummy equal to one for jumbo loans. QE $\mathrm{x}$ Jumbo is the interaction between the program dummies and Jumbo Indicator. The event window includes the three months prior to and after the beginning month of each QE period. For example, QE1 begins in December 2008, and the event window lasts from September 2008 through March 2009. Standard errors are clustered at the month level, and are reported in parentheses. Asterisks denote significance levels $(* * *=1 \%, * *=5 \%, *=10 \%)$. 
Table 5. Hazard Model Estimates of QE1 Effect on Refinancing

\begin{tabular}{|c|c|c|c|}
\hline & $(1)$ & $(2)$ & $(3)$ \\
\hline \multirow[t]{2}{*}{ December 2008 Indicator } & $0.151^{* * *}$ & $0.114^{* *}$ & $0.108^{*}$ \\
\hline & $(0.033)$ & $(0.057)$ & $(0.063)$ \\
\hline \multirow[t]{2}{*}{ January 2009 Indicator } & $0.812^{* * *}$ & $0.954^{* * *}$ & $0.950 * * *$ \\
\hline & $(0.027)$ & $(0.046)$ & $(0.051)$ \\
\hline \multirow[t]{2}{*}{ February 2009 Indicator } & $1.245^{* * *}$ & $1.367^{* * *}$ & $1.372^{* * *}$ \\
\hline & $(0.025)$ & $(0.043)$ & $(0.047)$ \\
\hline \multirow[t]{2}{*}{ Current LTV $>.9 \times$ December 2008} & & -0.064 & -0.063 \\
\hline & & $(0.086)$ & $(0.099)$ \\
\hline \multirow{2}{*}{ Current LTV > .9 x January 2009} & & $-0.447^{* * *}$ & $-0.379^{* * *}$ \\
\hline & & $(0.072)$ & $(0.081)$ \\
\hline \multirow[t]{2}{*}{ Current LTV $>.9 \times$ February 2009} & & $-0.429 * * *$ & $-0.376^{* * *}$ \\
\hline & & $(0.065)$ & $(0.073)$ \\
\hline \multirow[t]{2}{*}{ December 2008 x Jumbo } & & 0.120 & 0.017 \\
\hline & & $(0.086)$ & $(0.097)$ \\
\hline \multirow[t]{2}{*}{ January 2009 x Jumbo } & & $-0.190 * *$ & $-0.212^{* *}$ \\
\hline & & $(0.076)$ & $(0.083)$ \\
\hline \multirow[t]{2}{*}{ February 2009 x Jumbo } & & $-0.203^{* * *}$ & $-0.227 * * *$ \\
\hline & & $(0.069)$ & $(0.075)$ \\
\hline Loan Controls & Yes & Yes & Yes \\
\hline Borrower Controls & & & Yes \\
\hline Observations & $1,691,380$ & $1,691,380$ & $1,407,066$ \\
\hline
\end{tabular}

Notes: Table reports maximum-likelihood estimates of the prepayment hazard model described in Section 5.3. All specifications include a cubic function of loan age as a non-parametric baseline hazard. Loan-level controls include current LTV, loan size at origination, indicators for current LTV between 80 and $90 \%$, current LTV over $90 \%$, and current balance over the conforming loan limit. Borrower controls include DTI, a missing DTI indicator, and FICO bins. Jumbo is an indicator for loan amount at least $\$ 60,000$ above the CLL to account for cash-in refinancing. Robust standard errors in parentheses. Asterisks denote significance levels $(* * *=1 \%, * *=5 \%, *=10 \%)$. 
Table 6. Hazard Model Estimates of QE1 Effect on Refinancing Controlling for Coupon Gap

\begin{tabular}{|c|c|c|c|c|c|c|}
\hline & $(1)$ & $(2)$ & $(3)$ & $(4)$ & $(5)$ & $(6)$ \\
\hline QE1 Indicator & $\begin{array}{c}0.673^{* * *} \\
(0.018)\end{array}$ & $\begin{array}{c}0.725^{* * *} \\
(0.020)\end{array}$ & $\begin{array}{c}0.728^{* * *} \\
(0.020)\end{array}$ & $\begin{array}{c}0.501^{* * *} \\
(0.018)\end{array}$ & $\begin{array}{c}0.543^{* * *} \\
(0.020)\end{array}$ & $\begin{array}{c}0.493^{* * *} \\
(0.020)\end{array}$ \\
\hline Current LTV $>.9 \times$ QE1 & & $\begin{array}{c}-0.250 * * * \\
(0.059)\end{array}$ & $\begin{array}{c}-0.268^{* * *} \\
(0.059)\end{array}$ & & $\begin{array}{c}-0.255^{* * *} \\
(0.059)\end{array}$ & $\begin{array}{c}-0.274^{* * *} \\
(0.059)\end{array}$ \\
\hline QE1 Indicator x Jumbo & & $\begin{array}{c}-0.189^{* * *} \\
(0.047)\end{array}$ & $\begin{array}{c}-0.194^{* * *} \\
(0.047)\end{array}$ & & $\begin{array}{c}-0.123^{* * *} \\
(0.047)\end{array}$ & $\begin{array}{c}-0.108^{* *} \\
(0.047)\end{array}$ \\
\hline Out-of-Sample Coupon Gap & & & & $\begin{array}{c}0.002^{* * *} \\
(0.000)\end{array}$ & $\begin{array}{c}0.002^{* * *} \\
(0.000)\end{array}$ & $\begin{array}{c}0.002^{* * *} \\
(0.000)\end{array}$ \\
\hline $\begin{array}{l}\text { Loan Controls } \\
\text { Borrower Controls }\end{array}$ & yes & yes & $\begin{array}{l}\text { yes } \\
\text { yes }\end{array}$ & yes & yes & $\begin{array}{l}\text { yes } \\
\text { yes }\end{array}$ \\
\hline Observations & $2,053,902$ & $2,053,902$ & $2,053,902$ & $2,053,902$ & $2,053,902$ & $2,053,902$ \\
\hline
\end{tabular}

Notes: Table reports maximum-likelihood estimates of the prepayment hazard model described in Section 6.2.1. All specifications include a cubic function of loan age as a non-parametric baseline hazard. Loan-level controls include current LTV, loan size at origination, indicators for current LTV between 80 and 90\%, current LTV over 90\%, and current balance over the conforming loan limit. Borrower controls include DTI, a missing DTI indicator, and FICO bins. Jumbo is an indicator for loan amount at least $\$ 60,000$ above the CLL to account for cash-in refinancing. Robust standard errors in parentheses. Columns (4)-(6) offset using a coupon gap estimate calculated using the same model specifications on the time period May 2010 through Dec. 2012. 
Table 7. Higher LTV Cap Simulation during QE1 (Dec. 2008-May 2009)

\begin{tabular}{|c|c|c|c|c|c|c|c|}
\hline Current LTV Bin & $\begin{array}{c}\text { Number of } \\
\text { Mortgages } \\
\text { in Bin }\end{array}$ & $\begin{array}{l}\text { Baseline } \\
\text { Percent } \\
\text { Prepaid } \\
\end{array}$ & $\begin{array}{l}\frac{\text { out LTV }}{\text { lange }} \\
\text { Actual } \\
\text { Average } \\
\text { Cash-Out } \\
\text { (In) } \\
\end{array}$ & $\begin{array}{c}\text { Predicted } \\
\text { Prepaid } \\
\end{array}$ & $\begin{array}{l}\frac{\text { tual Higher }}{\text { Cap }} \\
\text { Predicted } \\
\text { Average } \\
\text { Cash-Out } \\
\text { (In) } \\
\end{array}$ & $\begin{array}{l}\text { Increase in } \\
\text { Number of } \\
\text { Refinances }\end{array}$ & $\begin{array}{c}\text { actual Increase } \\
\text { Increase in } \\
\text { Aggregate } \\
\text { Equity Cashed- } \\
\text { Out }\end{array}$ \\
\hline Current LTV $<=60 \%$ & $10,974,369$ & $7.9 \%$ & $\$ 39,176$ & $7.9 \%$ & $\$ 40,371$ & 0 & $\$ 1,029,490,968$ \\
\hline $60 \%<$ Current LTV $<=70 \%$ & $3,740,057$ & $7.3 \%$ & $\$ 17,752$ & $7.3 \%$ & $\$ 18,614$ & 0 & $\$ 236,462,571$ \\
\hline $70 \%<$ Current LTV $<=80 \%$ & $4,337,909$ & $6.7 \%$ & $\$ 9,316$ & $7.7 \%$ & $\$ 14,580$ & 40,222 & $\$ 2,125,432,102$ \\
\hline $80 \%<$ Current LTV $<=90 \%$ & $3,795,757$ & $4.3 \%$ & $\$ 2,700$ & $6.9 \%$ & $\$ 7,982$ & 101,469 & $\$ 1,663,184,733$ \\
\hline $90 \%<$ Current LTV $<=100 \%$ & $2,869,281$ & $2.4 \%$ & $\$ 2,170$ & $4.4 \%$ & $\$ 501$ & 56,148 & $(\$ 86,882,422)$ \\
\hline $100 \%<$ Current LTV $<=110 \%$ & $1,713,517$ & $1.2 \%$ & $(\$ 3,796)$ & $1.2 \%$ & $(\$ 3,338)$ & 0 & $\$ 9,328,061$ \\
\hline $110 \%<$ Current LTV $<=120 \%$ & 585,146 & $0.5 \%$ & $(\$ 89,126)$ & $0.5 \%$ & $(\$ 88,387)$ & 0 & $\$ 1,955,022$ \\
\hline $120 \%<$ Current LTV & 740,546 & $0.4 \%$ & $(\$ 144,764)$ & $0.4 \%$ & $(\$ 144,184)$ & 0 & $\$ 1,515,536$ \\
\hline Totals & $28,756,582$ & $5.9 \%$ & $\$ 13,470$ & $6.5 \%$ & $\$ 15,420$ & 197,839 & $\$ 4,980,486,570$ \\
\hline Total Adjusting for Data Coverage & $59,909,546$ & $5.6 \%$ & $\$ 15,459$ & $6.5 \%$ & $\$ 15,420$ & 412,165 & $\$ 10,376,013,687$ \\
\hline
\end{tabular}




\section{Appendix}

\section{A Additional TBA Market Details}

On the day a TBA contract is traded, the buyer and seller fix the basic characteristics of the MBS to be delivered, with a $0.01 \%$ allowed variance in the par value at delivery. Sellers in the TBA market are primarily mortgage originators seeking to lock in interest rates to hedge short-run interest-rate risk. Buyers in this market include MBS sponsors who are assembling Collateralized Mortgage Obligations for new securitizations. Generally, only six parameters of the mortgages to be delivered are specified: agency (Fannie, Freddie, or Ginnie), weighted-average maturity, weightedaverage coupon (in 50 basis-point increments), price, par amount, and settlement date. For example, a TBA contract might be simply specified FN3060, meaning that it represents a Fannie Maeguaranteed MBS whose weighted average maturity and coupon are 30 years and $6.0 \%$, respectively. A separate (much smaller) market exists called the Stipulated (STIP) market where CMOs with detailed information disclosures are traded. For this reason, when there is information to disclose about a MBS that enhances its value (e.g., predictors of lower early-termination risk), the STIP market is a more favorable trading platform. ${ }^{37}$ Two days prior to the TBA settlement date, the seller informs the buyer of the specific pools to be delivered and the trade is settled on an Agencydetermined settlement date. To deliver these pools, the seller has either acquired or originated Agency-eligible mortgages and paid the necessary upfront fees (known as g-fees) to have them assembled into an Agency-guaranteed pool.

For a variety of reasons, the vast majority of mortgages comprising TBAs are recent originations. Payment history information about seasoned mortgages can make them more valuable to trade on the STIP market (in the case of good news) or ineligible for TBA inclusion (in the case of missed payments, etc.). Adverse selection arising from the superior information set of the seller as to the termination risk of the mortgages to be delivered is mitigated by "cheapest-to-deliver" expectations and pricing by buyers and sellers (see Downing et al., 2009). This TBA contract standardization effectively commoditizes the MBS traded in TBAs, which, together with the government guarantee,

\footnotetext{
${ }^{37}$ In the Agency market, due to the default guarantees provided by Fannie, Freddie, and Ginnie, the value of MBS will primarily vary with the degree of termination risk borne by the investor since to the holder of a Agencyguaranteed mortgage, the cash flows from default and prepayment look identical. This risk may be a function of other features of the MBS not stipulated on the TBA forward contract, such as FICO, DTI, geographic location, etc.
} 
provides the TBA market with a degree of liquidity unmatched by any other secondary mortgage market. ${ }^{38}$

\section{B Robustness to Increasing Conforming Loan Limits}

In this appendix, we investigate the concern that the stronger response of GSE-eligible originations relative to jumbo originations around QE event dates simply reflects the establishment of high-cost area designations. The conforming loan limit increased from about $\$ 400,000$ to about $\$ 700,000$ for certain high-cost areas over time (see panel I of Appendix Figure 2). As mapped in panel II of Appendix Figure 2, areas with the high-cost designation are mainly counties on the coasts with higher land values. Although this increase occurred nearly a year before the beginning of QE1, expanding the size of the conforming market by increasing the CLL in certain areas should tilt originations from the jumbo segment to the GSE-eligible segment. To address this concern, we construct an estimation sample to non-high-cost counties whose conforming loan limits last changed in 2006, and even then only incrementally. Appendix Figure 3 shows that even when we restrict attention to these areas, we observe a significant and differential increase in the origination of conforming loans around QE1. As before, origination volumes in the jumbo and conforming segments track each other closely except during the QE1 period, justifying our parallel trends assumption.

\footnotetext{
${ }^{38}$ While each mortgage is a highly differentiated product, all mortgages in a given TBA contract are essentially behind a veil of ignorance and can thus be traded as a commodity. For market participants, the risk management and valuation exercises are simplified as they need consider only the risks associated with the main characteristics of the MBS. See Vickery and Wright (2013), who quantify the magnitude of the liquidity benefits of the TBA market, and Glaeser and Kallal (1997) and Vanasco (2014) for theoretical treatments of this benefit. This fungibility, however, is temporary. Upon settlement and delivery, the buyer observes the complete set of characteristics of each loan pool and the market value of delivered mortgage-backed securities will incorporate this information.
} 
Appendix Figure 1. Share of GSE Origination Owned by Federal Reserve, by Issuance Quarter

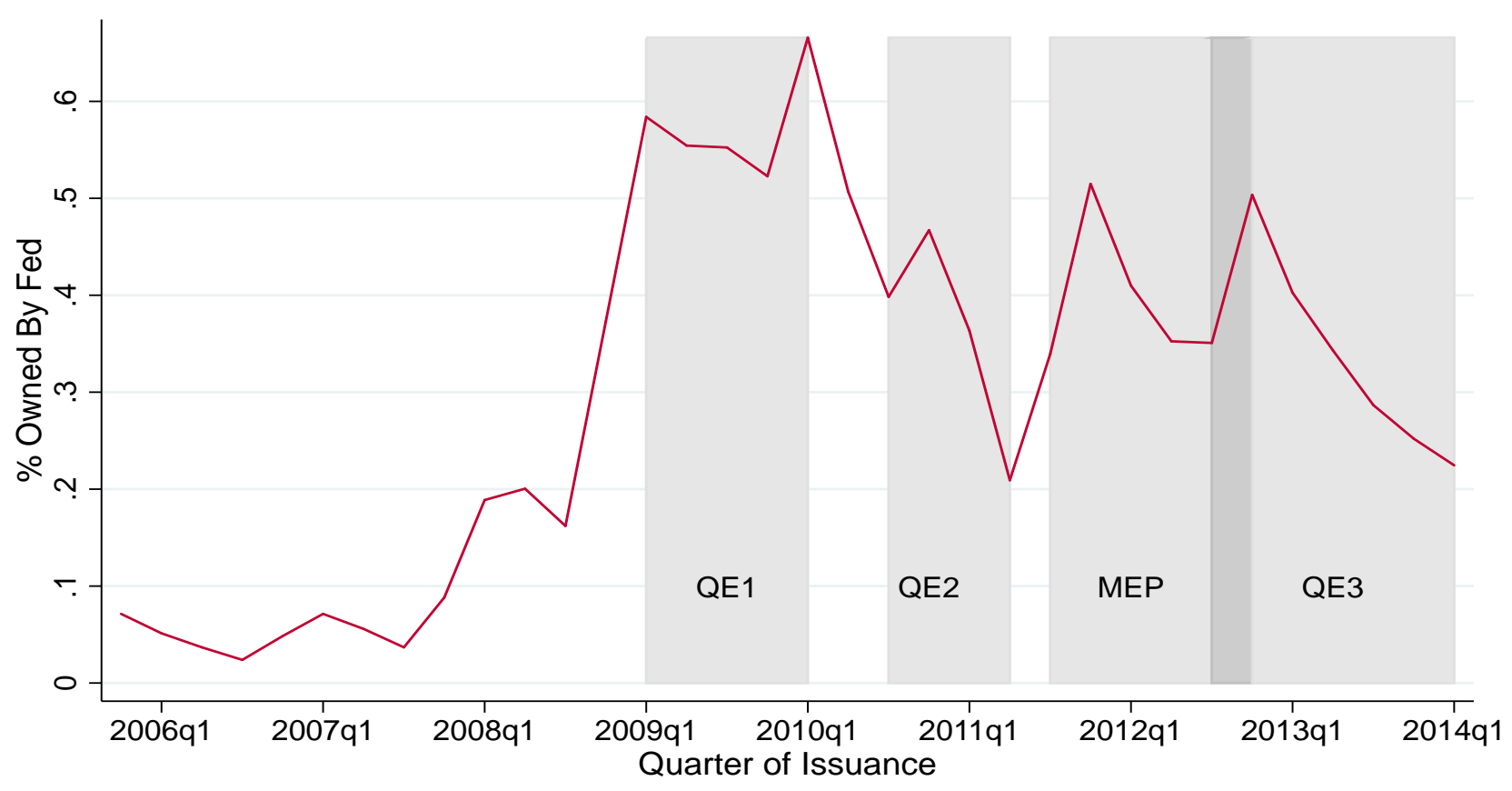

Notes: Figure plots the percentage of GSE MBS volume issued in each quarter that was ultimately owned by the Federal Reserve. Shaded regions indicate QE programs. Source: New York Federal Researve Open Market Operations data. 
Appendix Figure 2. Conforming Loan Limits

Panel I. National and Maximum High-Cost Area Conforming Loan Limits

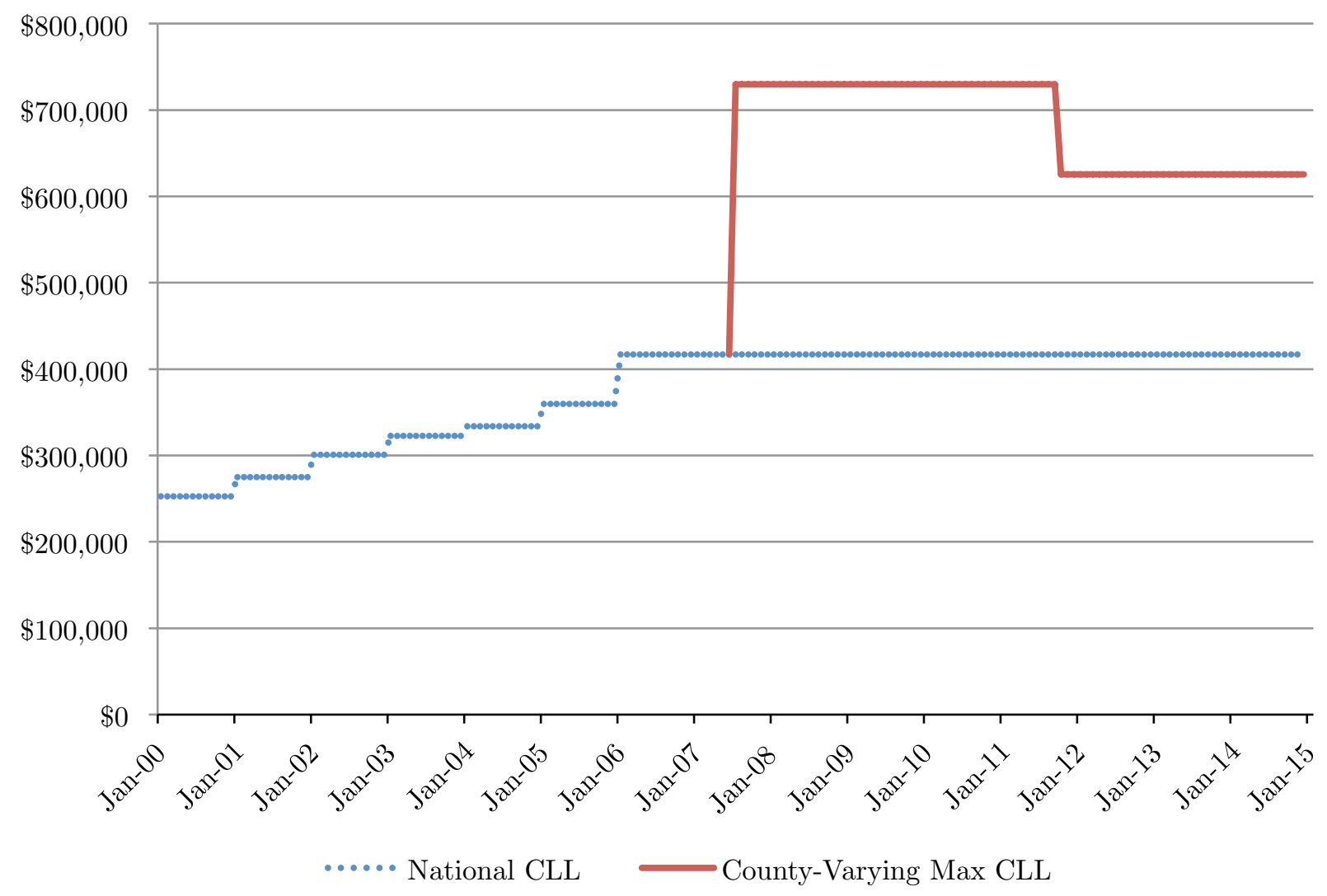

Panel II. The Geography of High-Cost County Designation

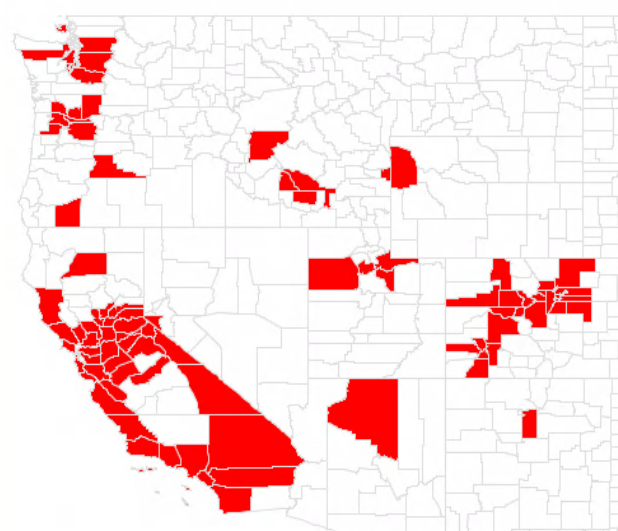

3 gat

High Cost $(\$ 417 \mathrm{k})$

Non-High Cost

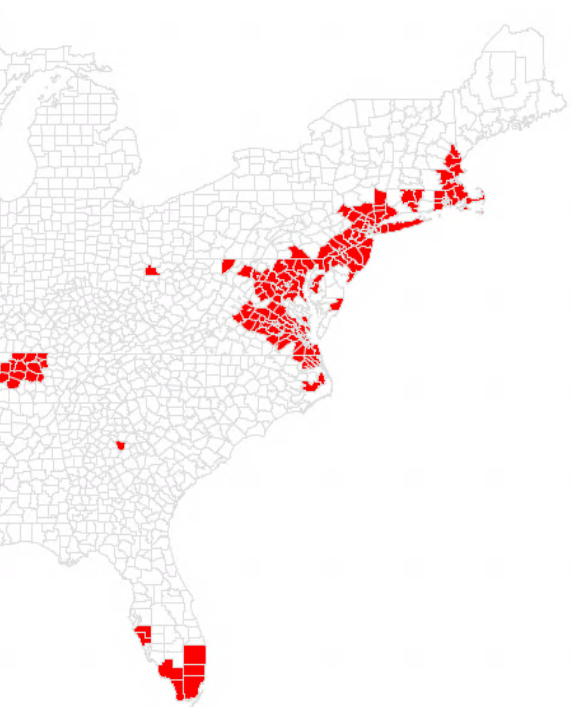

Notes: Panel I plots the national conforming loan limit over time and its maximal increase among certain high-cost counties in early 2008. Some of these temporary high-cost exemptions expired on October 1 , 2011. Panel II plots all counties in the contiguous state. Darkly shaded areas indicate counties designated as high cost, defined as counties with conforming loan limits greater than $\$ 417,000$. 


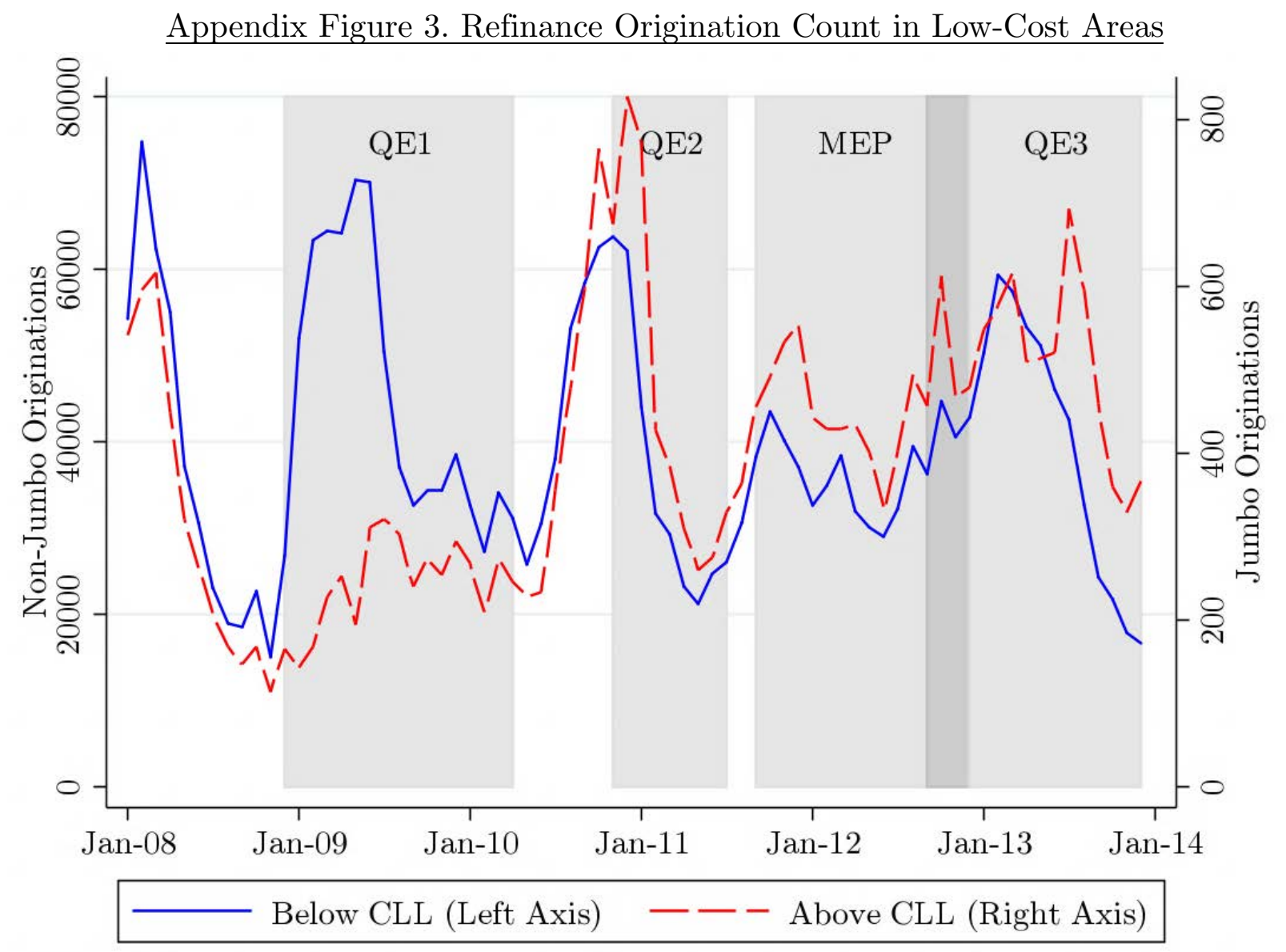

Notes: Figure plots the count of refinance mortgage originations in low-cost areas recorded by LPS for loans below and above the GSE conforming loan limit (CLL). See notes for Figure 6 . 
Appendix Figure 4. Refinance Volume around CLL

Panel I. Number of Originations

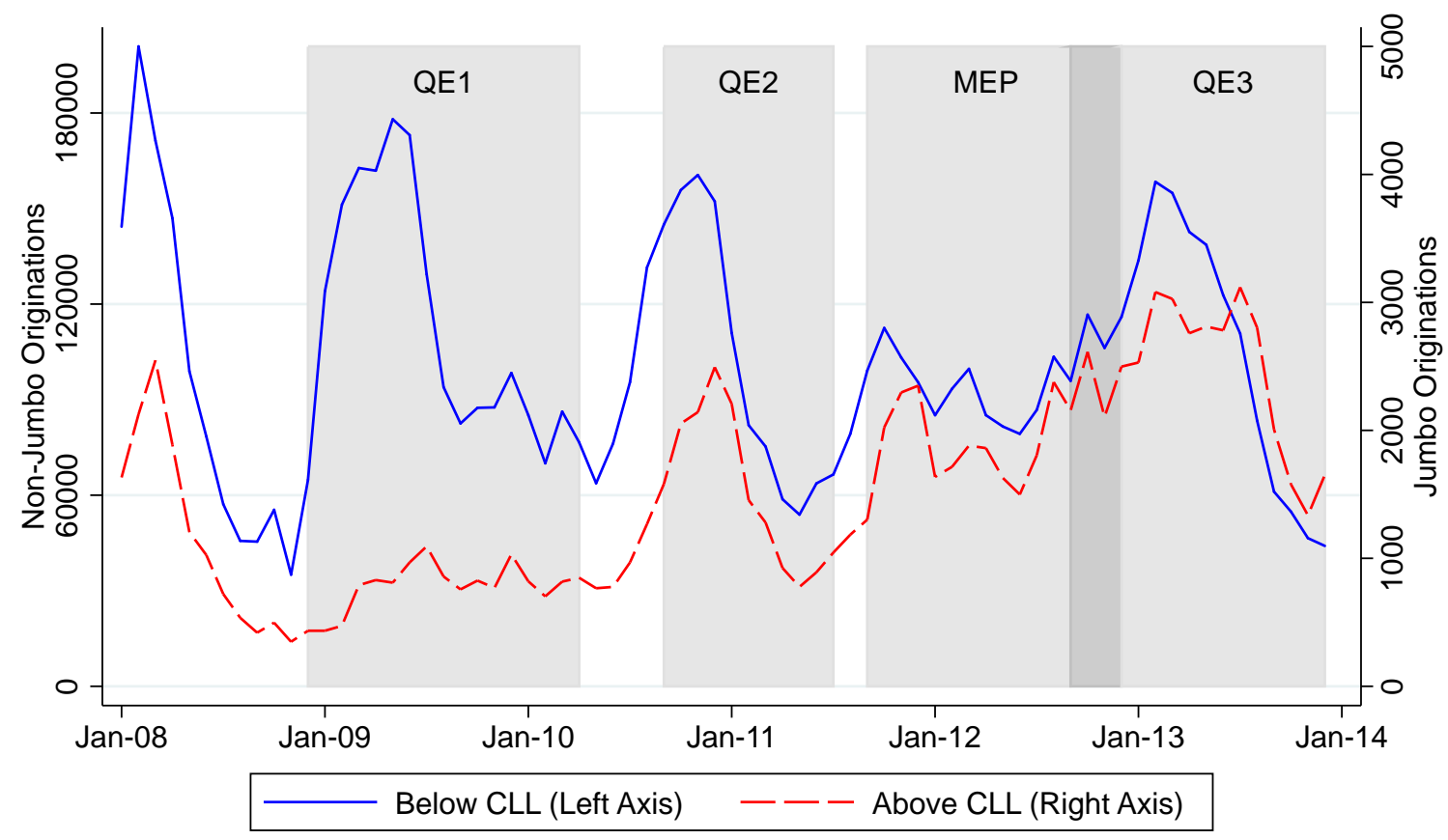

Panel II. Origination Volume

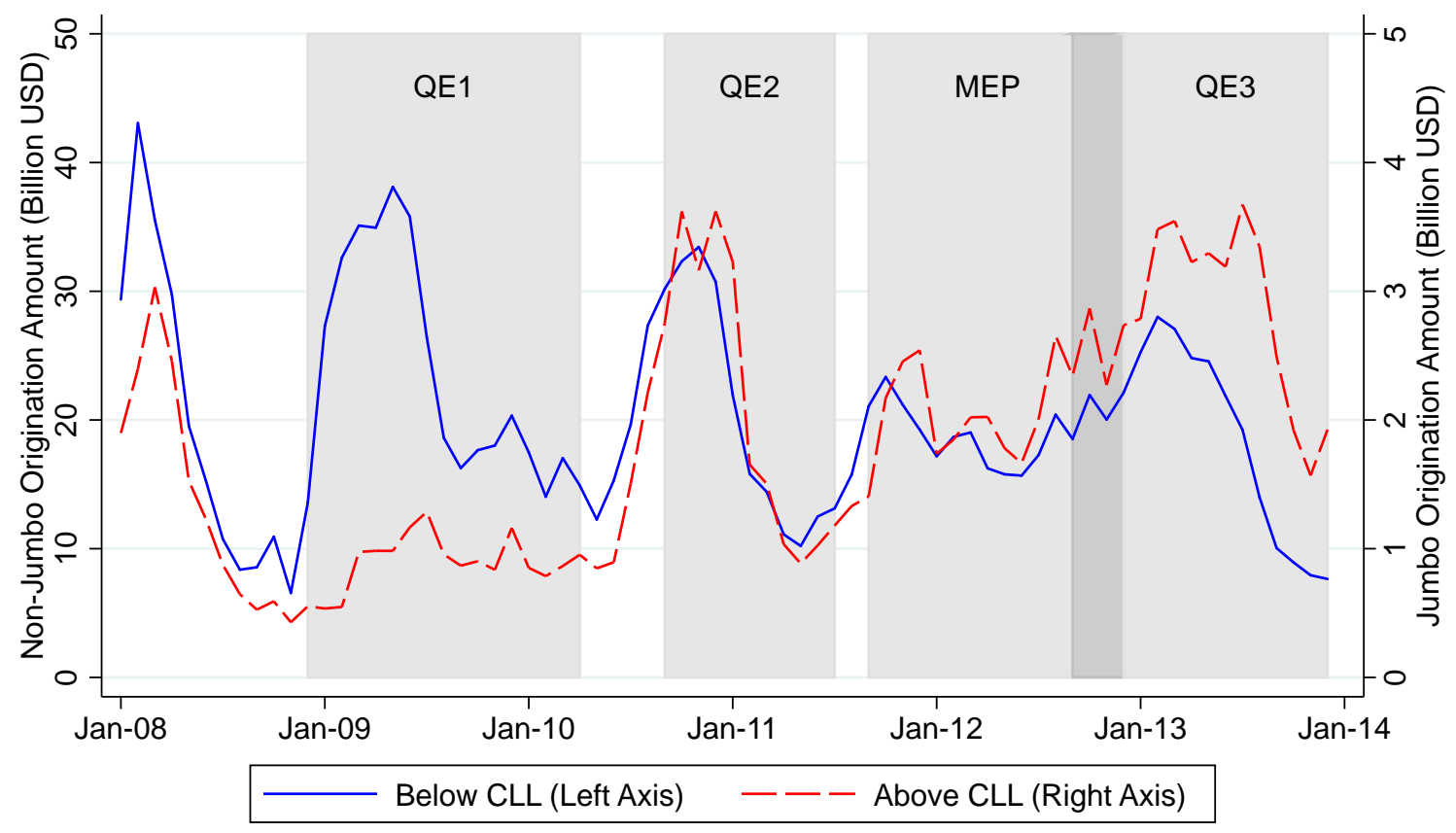

Notes: Figure plots the number of originations (top panel) and the origination volume (bottom panel) of refinance mortgages below the conforming loan limit and above the conforming loan limit as recorded by LPS. All the loans in the $[90 \%, 140 \%]$ interval have been dropped. FHA loans are excluded from the data. See notes for Figure 6. 


\section{Appendix Figure 5. Default Rates}

\section{Panel I. Delinquent within 1 year}

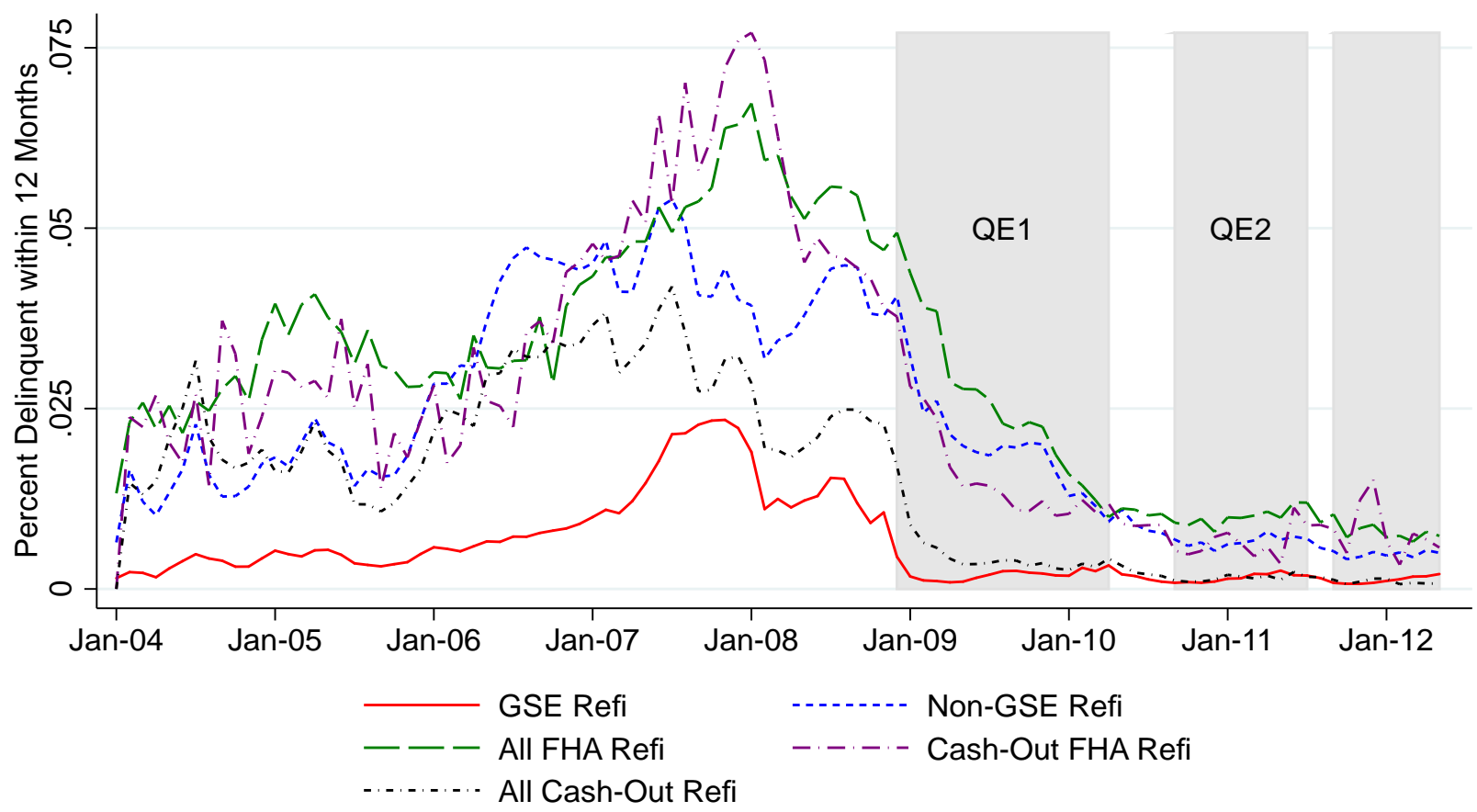

Panel II. Delinquent within 4 years

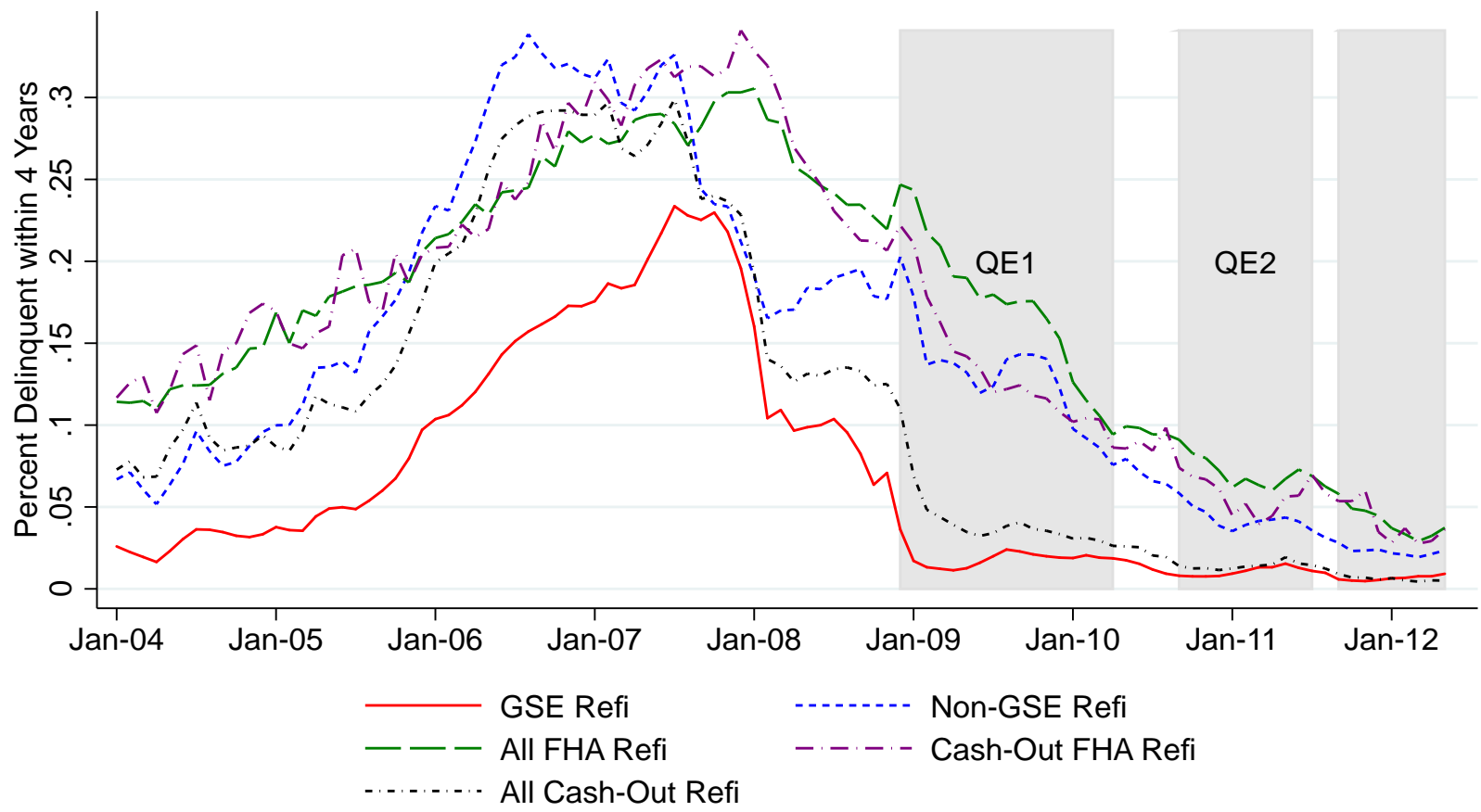

Notes: Figure plots the percent of loans delinquent within 1 year (top panel) and within four years (bottom panel) from refinancing for different types of refinances: GSE, FHA, cash-iout and non-GSE as recorded by LPS. 


\section{Appendix Figure 6. Loan-to-Value Ratio Bunching Pre-HARP}

for Original Loans Below $70 \%$

Panel I. Distribution of LTV for Original LTVs 0-60\%

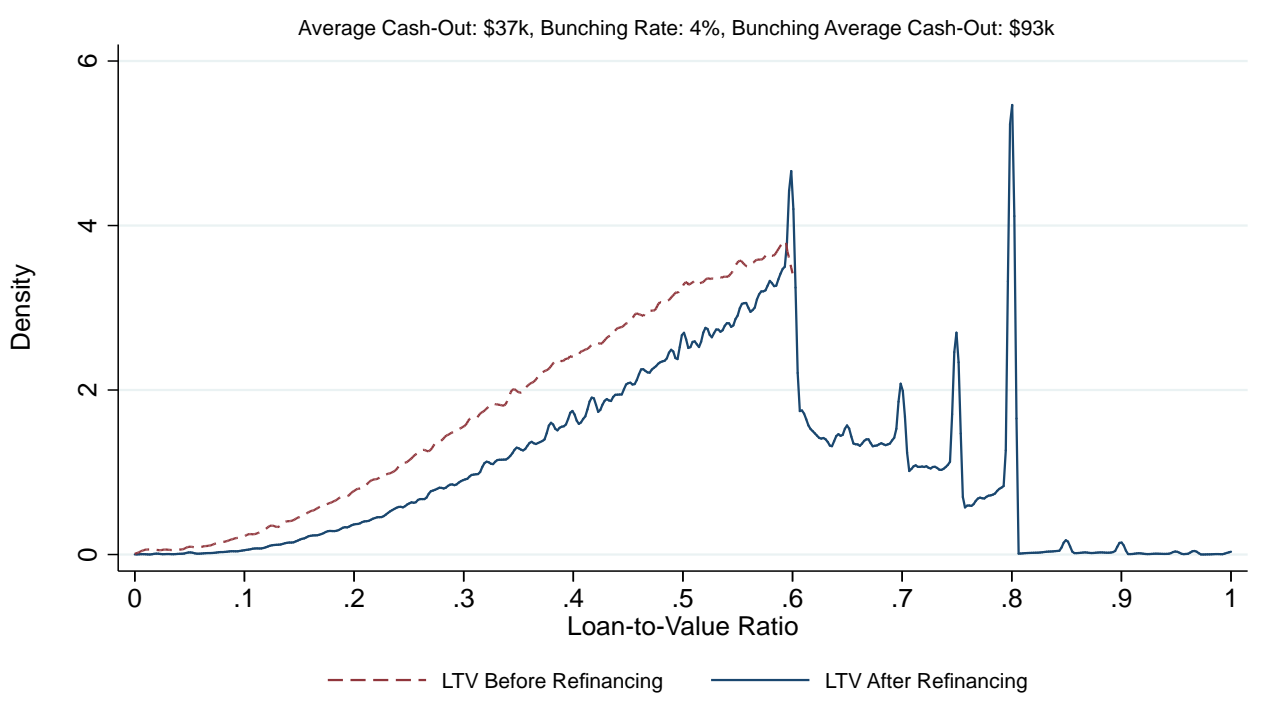

Panel II. Distribution of LTV for Original LTVs 60-70\%

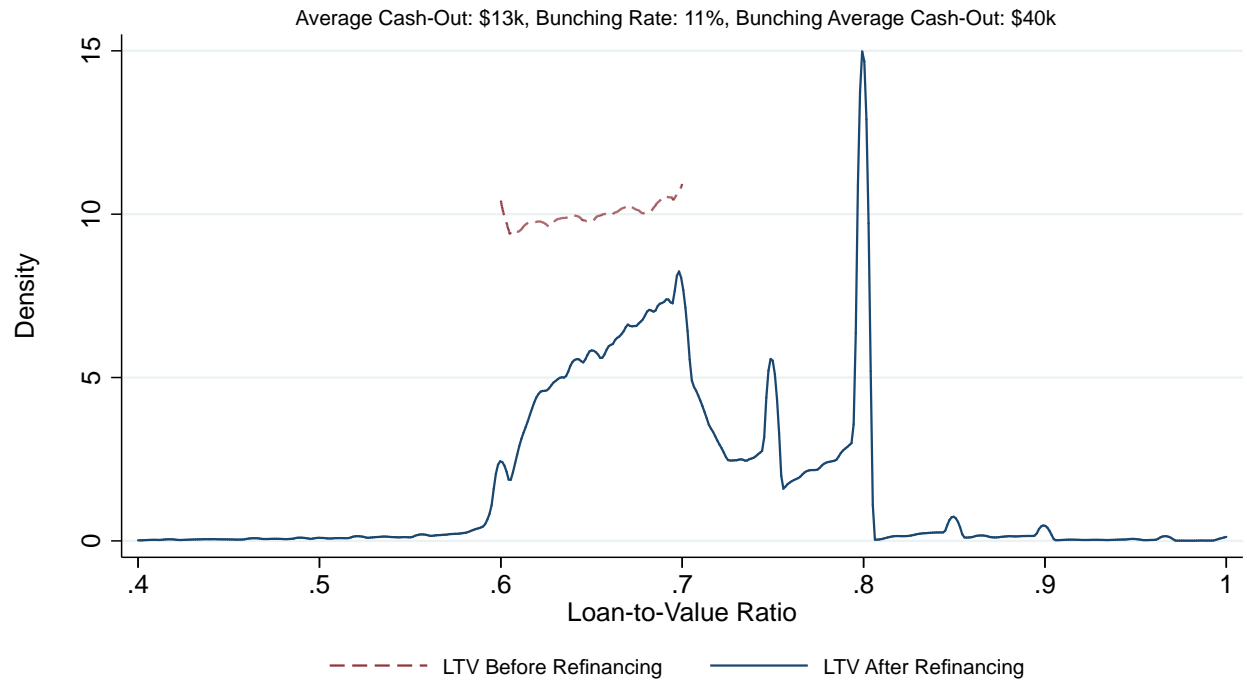

Notes: Figures report the distribution of borrower LTV ratios during QE1 but before the start of the Home Affordable Refinance Program (HARP) (Dec. 2008 to May 2009). Panel I includes loans for which we observe the predecessor loan with imputed LTV 0-60\%. Panel II includes loans for which we observe the predecessor loan with imputed LTV below 60-70\%. Dashed lines represent the imputed LTV distribution for mortgages that will be refinanced during the time period. To account for rolling closing costs into the balance of the new loan, we add average refinancing costs $(\$ 3,000)$ to the loan balance before the refinance. The solid blue lines report the distribution of actual LTV ratios for originated refinance mortgages. The bunching rate is the number of refinance mortgages with an LTV ratio between $79.5 \%$ and $80.5 \%$ at origination divided by the total number of loans in the givenoriginal LTV range that refinance. Bunching average cash-out is the average amount borrowers refinancing provide at the closing of their new refinance mortgage. 


\section{Appendix Figure 7. Durable Goods Consumption Event Studies}

Panel I. Effect of Refinancing on Mortgage Interest Payments

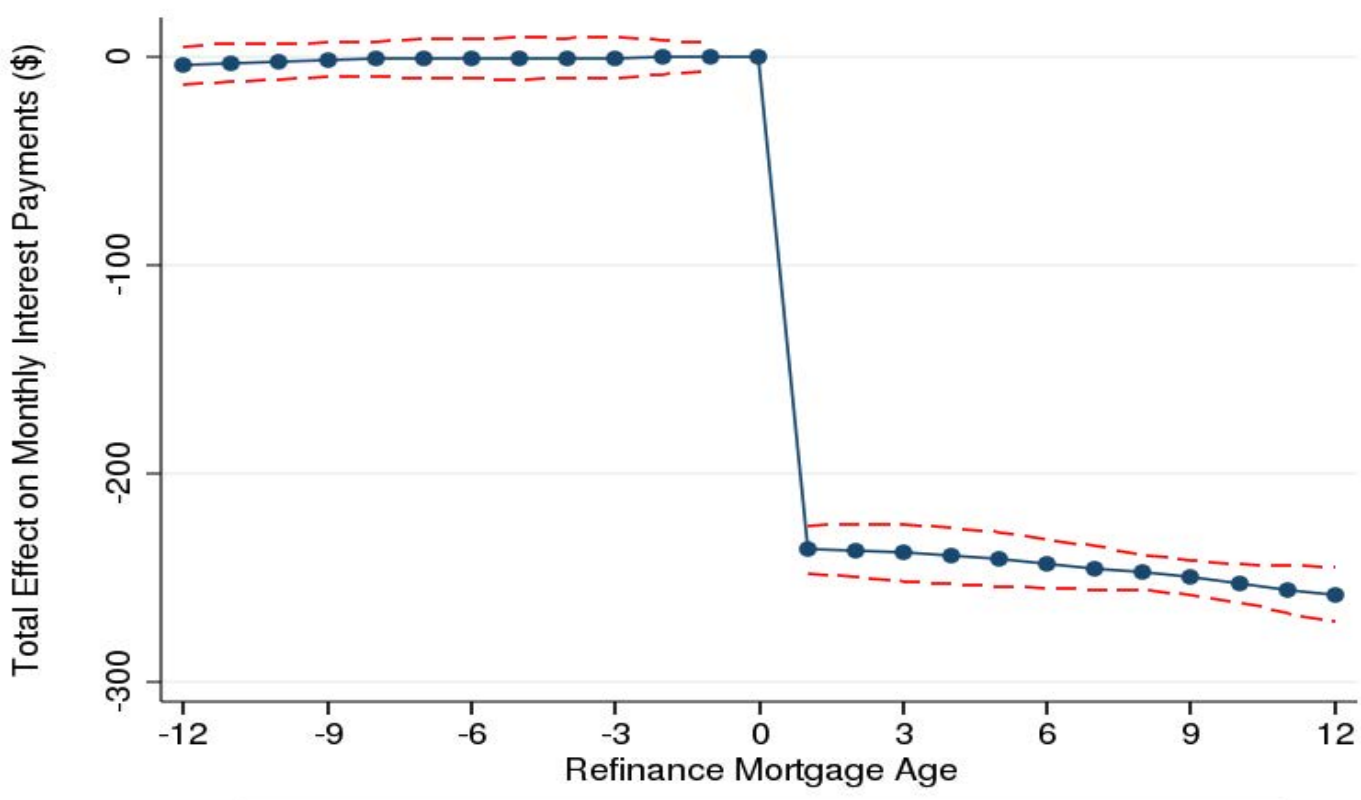

$\longrightarrow$ Point Estimate $\quad-----95 \%$ Confidence Interval

Panel II. Effect of Refinancing on Car Purchases

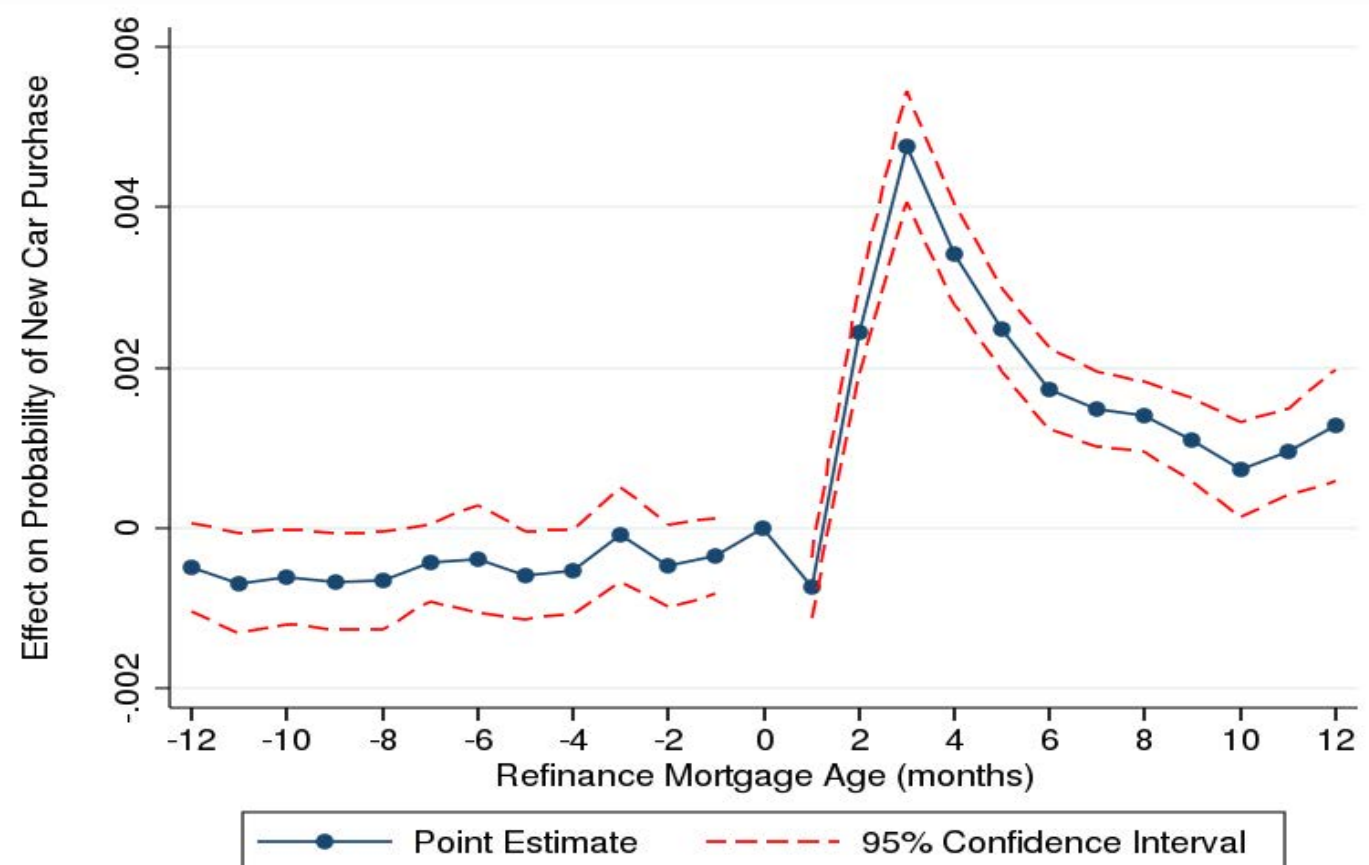

Notes: Figure plots event study coefficients on monthly mortgage interest payments (panel I) and on the likelihood of purchasing a car (panel II, measured as increasing outstanding auto-related debt by more than $\$ 5,000$ ) of time until (or since) refinancing. The sample is restricted to borrowers who refinanced during the QE1 period. See Section 6.1.4 for more details. 
Appendix Table 1. Fed Unconventional Monetary Policy Announcement Dates and Dates Used in Analysis

\begin{tabular}{cccc} 
Episode & Announcement Date & Event & Event Date \\
\hline QE1.1 & 25-Nov-08 & QE 1 Start & Dec-2008 \\
QE1.2 & 1-Dec-08 & & \\
QE1.3 & 16-Dec-08 & & \\
QE1.4 & 28-Jan-09 & & \\
QE1.5 & 18-Mar-09 & & \\
QE1.6 & 23-Sep-09 & QE 1 End & Apr-2010 \\
QE2.1 & 10-Aug-10 & QE 2 Start & Sep-2010 \\
QE2.2 & 21-Sep-10 & QE 2 End & Jul-2011 \\
FG.1 & 9-Aug-11 & MEP Start & Sep-2011 \\
FG.2 & 25-Jan-12 & & \\
QE3.1 & 13-Sep-12 & QE 3 Start & Sep-2012 \\
QE3.2 & 22-May-13 & & \\
QE3.3 & 19-Jun-13 & Tapering & Jun-2013 \\
QE3.4 & 10-Jul-13 & & \\
QE3.5 & 18-Sep-13 & QE 3 End & Oct-2014 \\
\hline Note: Table reports the timing of Federal Reserve Quantitative Easing announcements from \\
Krishnamurthy and Vissing-Jorgensen (2011) and Krishnamurthy and Vissing-Jorgensen (2013) as \\
well as the dates used in the paper for each LSAP program.
\end{tabular}


Appendix Table 2. Mortgage Product Refinancing Transition Matrix
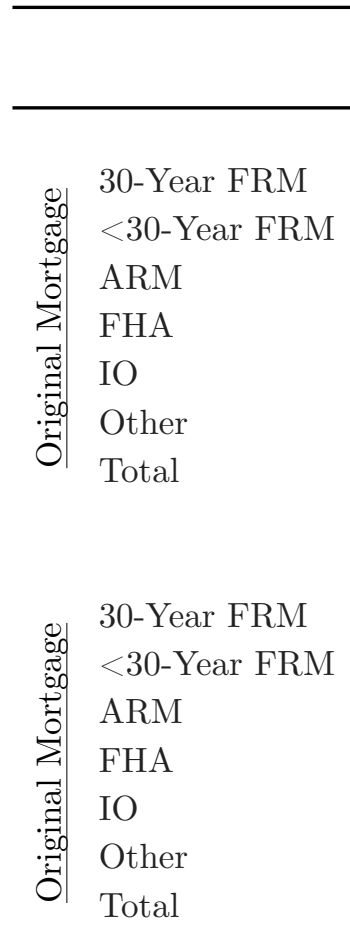

$\begin{array}{rr}20.20 \% & 3.66 \% \\ 6.52 \% & 5.95 \% \\ 13.45 \% & 1.59 \% \\ 3.04 \% & 0.83 \% \\ 3.32 \% & 0.30 \% \\ 0.22 \% & 0.22 \% \\ 46.75 \% & 12.56 \%\end{array}$

\begin{tabular}{c} 
Panel II. 2006 \\
\hline $4.45 \%$ \\
$1.03 \%$ \\
$8.14 \%$ \\
$1.01 \%$ \\
$2.46 \%$ \\
$0.07 \%$ \\
$17.15 \%$
\end{tabular}

$\begin{array}{rr}0.63 \% & 4.14 \% \\ 0.16 \% & 1.05 \% \\ 0.49 \% & 8.06 \% \\ 1.76 \% & 0.46 \% \\ 0.07 \% & 4.63 \% \\ 0.01 \% & 0.04 \% \\ 3.12 \% & 18.37 \%\end{array}$

$0.66 \%$
$0.10 \%$
$0.88 \%$
$0.12 \%$
$0.27 \%$
$0.02 \%$
$2.05 \%$

$33.75 \%$

$14.80 \%$ $32.61 \%$ $7.23 \%$ $11.04 \%$ $0.58 \%$ $100.00 \%$

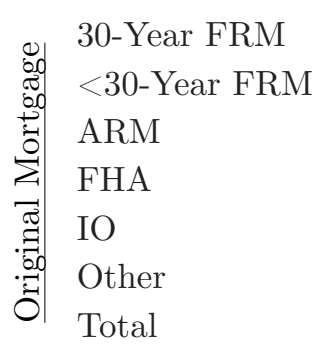

\section{$24.62 \%$ \\ $7.21 \%$ \\ $16.71 \%$ \\ $2.49 \%$ \\ $4.73 \%$ \\ $0.47 \%$ \\ $56.22 \%$}

$3.82 \%$
$6.24 \%$
$1.94 \%$
$0.73 \%$
$0.30 \%$
$0.15 \%$
$13.18 \%$

\section{Panel III. 2007}

$1.29 \%$
$0.27 \%$
$3.02 \%$
$0.18 \%$
$0.88 \%$
$0.06 \%$
$5.70 \%$

$1.38 \%$
$0.29 \%$
$1.49 \%$
$1.89 \%$
$0.30 \%$
$0.06 \%$
$5.41 \%$

$3.73 \%$
$0.85 \%$
$7.22 \%$
$0.22 \%$
$4.88 \%$
$0.12 \%$
$17.02 \%$

\section{$0.90 \%$ \\ $0.11 \%$ \\ $0.91 \%$ \\ $0.11 \%$ \\ $0.34 \%$ \\ $0.10 \%$ \\ $2.47 \%$}

$35.73 \%$

$14.98 \%$

$31.28 \%$

$5.62 \%$

$11.43 \%$

$0.95 \%$

Panel IV. 2008

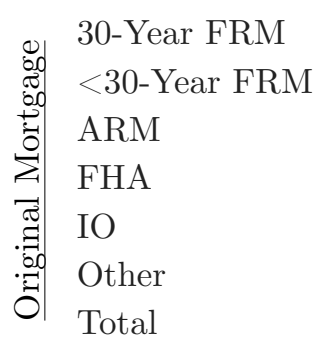

\section{$28.70 \%$ \\ $6.13 \%$ \\ $9.48 \%$ \\ $1.21 \%$ \\ $5.03 \%$ \\ $0.69 \%$ \\ $51.24 \%$}

$7.91 \%$
$9.29 \%$
$1.87 \%$
$0.75 \%$
$0.44 \%$
$0.19 \%$
$20.45 \%$

$0.78 \%$
$0.22 \%$
$1.24 \%$
$0.05 \%$
$0.42 \%$
$0.03 \%$
$2.74 \%$

\section{$7.46 \%$}

$1.57 \%$

$3.21 \%$

$5.68 \%$

$1.24 \%$

$0.35 \%$

$19.50 \%$

$1.01 \%$
$0.25 \%$
$1.59 \%$
$0.02 \%$
$2.72 \%$
$0.06 \%$
$5.65 \%$

$0.20 \%$

$0.04 \%$

$0.08 \%$

$0.02 \%$

$0.05 \%$

$0.03 \%$

$0.42 \%$

$100.00 \%$

\section{Panel V. 2009}

\begin{tabular}{|c|c|}
\hline & $\begin{array}{l}\text { 30-Year FRM } \\
<30-\text { Year FRN }\end{array}$ \\
\hline & ARM \\
\hline & FHA \\
\hline & IO \\
\hline & Other \\
\hline & Total \\
\hline
\end{tabular}

$39.53 \%$
$5.60 \%$
$3.59 \%$
$0.62 \%$
$3.63 \%$
$0.19 \%$
$53.17 \%$

\section{$9.26 \%$}

$8.91 \%$

$0.95 \%$

$6.44 \%$

$1.38 \%$

$0.71 \%$

$15.09 \%$

$0.68 \%$

$0.11 \%$

$0.04 \%$

$24.41 \%$

(continued on next page)

$0.05 \%$

$0.02 \%$

$0.02 \%$

$0.00 \%$

$0.01 \%$

$0.00 \%$

$0.11 \%$
$46.06 \%$

$17.49 \%$

$17.45 \%$

$7.73 \%$

$9.91 \%$

$1.35 \%$

$100.00 \%$

$56.38 \%$

$16.14 \%$

$5.61 \%$

$16.10 \%$

$5.43 \%$

$0.35 \%$

$100.00 \%$ 


\begin{tabular}{|c|c|c|c|c|c|c|c|c|}
\hline & \multicolumn{7}{|c|}{$\underline{\text { Refinance Mortgage }}$} \\
\hline & & 30-Yr FRM & $<30-$ Yr FRM & ARM & FHA & IO & Other & Total \\
\hline \multirow{8}{*}{ 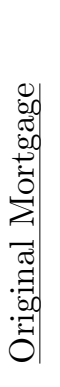 } & \multicolumn{8}{|c|}{ Panel VI. 2010} \\
\hline & 30-Year FRM & $35.07 \%$ & $17.71 \%$ & $3.06 \%$ & $4.48 \%$ & $0.21 \%$ & $0.07 \%$ & $60.60 \%$ \\
\hline & $<30$-Year FRM & $3.73 \%$ & $14.53 \%$ & $0.59 \%$ & $1.10 \%$ & $0.06 \%$ & $0.03 \%$ & $20.04 \%$ \\
\hline & $\mathrm{ARM}$ & $1.69 \%$ & $0.58 \%$ & $1.16 \%$ & $0.30 \%$ & $0.10 \%$ & $0.02 \%$ & $3.84 \%$ \\
\hline & FHA & $0.69 \%$ & $0.57 \%$ & $0.04 \%$ & $9.28 \%$ & $0.00 \%$ & $0.00 \%$ & $10.58 \%$ \\
\hline & IO & $2.63 \%$ & $0.29 \%$ & $0.55 \%$ & $0.44 \%$ & $0.74 \%$ & $0.01 \%$ & $4.68 \%$ \\
\hline & Other & $0.16 \%$ & $0.04 \%$ & $0.01 \%$ & $0.05 \%$ & $0.00 \%$ & $0.00 \%$ & $0.27 \%$ \\
\hline & Total & $43.98 \%$ & $33.72 \%$ & $5.40 \%$ & $15.65 \%$ & $1.12 \%$ & $0.14 \%$ & $100.00 \%$ \\
\hline \multirow{8}{*}{ 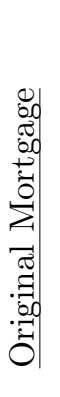 } & \multicolumn{8}{|c|}{ Panel VII. 2011} \\
\hline & 30-Year FRM & $33.29 \%$ & $20.38 \%$ & $4.88 \%$ & $2.72 \%$ & $0.29 \%$ & $0.10 \%$ & $61.66 \%$ \\
\hline & $<30$-Year FRM & $3.46 \%$ & $17.97 \%$ & $0.98 \%$ & $0.79 \%$ & $0.10 \%$ & $0.04 \%$ & $23.33 \%$ \\
\hline & $\mathrm{ARM}$ & $1.13 \%$ & $0.49 \%$ & $1.69 \%$ & $0.17 \%$ & $0.11 \%$ & $0.02 \%$ & $3.61 \%$ \\
\hline & FHA & $0.90 \%$ & $0.89 \%$ & $0.10 \%$ & $5.42 \%$ & $0.00 \%$ & $0.01 \%$ & $7.32 \%$ \\
\hline & IO & $1.86 \%$ & $0.26 \%$ & $0.76 \%$ & $0.19 \%$ & $0.77 \%$ & $0.02 \%$ & $3.85 \%$ \\
\hline & Other & $0.13 \%$ & $0.05 \%$ & $0.01 \%$ & $0.02 \%$ & $0.00 \%$ & $0.00 \%$ & $0.23 \%$ \\
\hline & Total & $40.78 \%$ & $40.04 \%$ & $8.43 \%$ & $9.30 \%$ & $1.27 \%$ & $0.18 \%$ & $100.00 \%$ \\
\hline \multirow{8}{*}{ 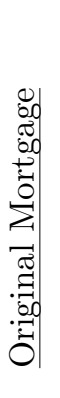 } & \multicolumn{8}{|c|}{ Panel VIII. 2012} \\
\hline & 30-Year FRM & $40.77 \%$ & $21.81 \%$ & $2.76 \%$ & $0.83 \%$ & $0.24 \%$ & $0.02 \%$ & $66.43 \%$ \\
\hline & $<30-$ Year FRM & $2.55 \%$ & $16.49 \%$ & $0.59 \%$ & $0.30 \%$ & $0.08 \%$ & $0.00 \%$ & $20.02 \%$ \\
\hline & $\mathrm{ARM}$ & $0.93 \%$ & $0.38 \%$ & $1.26 \%$ & $0.04 \%$ & $0.08 \%$ & $0.00 \%$ & $2.69 \%$ \\
\hline & FHA & $1.11 \%$ & $0.85 \%$ & $0.06 \%$ & $6.28 \%$ & $0.00 \%$ & $0.00 \%$ & $8.31 \%$ \\
\hline & $\mathrm{IO}$ & $1.29 \%$ & $0.18 \%$ & $0.27 \%$ & $0.03 \%$ & $0.53 \%$ & $0.00 \%$ & $2.30 \%$ \\
\hline & Other & $0.15 \%$ & $0.06 \%$ & $0.03 \%$ & $0.01 \%$ & $0.00 \%$ & $0.00 \%$ & $0.25 \%$ \\
\hline & Total & $46.81 \%$ & $39.77 \%$ & $4.98 \%$ & $7.49 \%$ & $0.93 \%$ & $0.03 \%$ & $100.00 \%$ \\
\hline \multirow{8}{*}{ 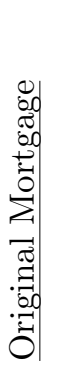 } & \multicolumn{8}{|c|}{ Panel IV. 2013} \\
\hline & 30-Year FRM & $36.26 \%$ & $24.16 \%$ & $1.47 \%$ & $0.56 \%$ & $0.17 \%$ & $0.00 \%$ & $62.62 \%$ \\
\hline & $<30$-Year FRM & $2.57 \%$ & $16.76 \%$ & $0.31 \%$ & $0.19 \%$ & $0.06 \%$ & $0.00 \%$ & $19.88 \%$ \\
\hline & $\mathrm{ARM}$ & $1.24 \%$ & $0.54 \%$ & $1.48 \%$ & $0.05 \%$ & $0.10 \%$ & $0.00 \%$ & $3.42 \%$ \\
\hline & FHA & $1.97 \%$ & $1.24 \%$ & $0.10 \%$ & $8.14 \%$ & $0.01 \%$ & $0.00 \%$ & $11.46 \%$ \\
\hline & IO & $1.32 \%$ & $0.20 \%$ & $0.26 \%$ & $0.03 \%$ & $0.53 \%$ & $0.00 \%$ & $2.34 \%$ \\
\hline & Other & $0.18 \%$ & $0.07 \%$ & $0.03 \%$ & $0.01 \%$ & $0.00 \%$ & $0.00 \%$ & $0.29 \%$ \\
\hline & Total & $43.53 \%$ & $42.98 \%$ & $3.65 \%$ & $8.97 \%$ & $0.86 \%$ & $0.00 \%$ & $100.00 \%$ \\
\hline
\end{tabular}

Notes: Table reports the percent of first-lien mortgages refinancing from a given original mortgage type (row) in a given year (panel) into the given refinance mortgage product type (column) from 2006 and 2013. Mortgage product categories are mutually exclusive. 30-Year FRM includes all non-FHA fixed-rate mortgages with original term of exactly 30 years. $<30$-Year FRM includes non-FHA fixed-rate mortgages with original terms under 30 years. ARM includes non-interest-only and nonFHA adjustable-rate mortgages. FHA includes all Federal Housing Administration loans, regardless of other product characteristics. IO includes all non-FHA interest only loans. Other includes various other product types including, for example, fixed-rate loans with an original term over 30 years. Source: LPS and Equifax. 
Appendix Table 3. Robustness to G-Fees and Credit Spreads: 6-Month Window

\begin{tabular}{|c|c|c|c|c|c|}
\hline & (1) & $(2)$ & $(3)$ & (4) & (5) \\
\hline \multirow[t]{2}{*}{ Program } & QE1 & $\mathrm{QE} 2$ & MEP & QE3 & Tapering \\
\hline & \multicolumn{5}{|c|}{ Panel I. Interest Rates } \\
\hline \multirow[t]{2}{*}{ Program x Jumbo } & $26.039^{* * *}$ & -1.594 & 2.015 & $12.839^{* * *}$ & $-25.011^{* * *}$ \\
\hline & $(4.124)$ & $(4.654)$ & $(3.865)$ & $(3.015)$ & $(5.065)$ \\
\hline \multirow[t]{2}{*}{ Jumbo Indicator } & $-32.950^{* * *}$ & $6.599^{*}$ & $-10.550^{* *}$ & $5.174^{*}$ & $12.100^{* * *}$ \\
\hline & $(2.718)$ & $(3.220)$ & $(3.661)$ & $(2.616)$ & $(1.138)$ \\
\hline Controls & Yes & Yes & Yes & Yes & Yes \\
\hline County x Month FEs & Yes & Yes & Yes & Yes & Yes \\
\hline Observations & 789,945 & 568,776 & 351,042 & 438,201 & 470,820 \\
\hline \multirow[t]{2}{*}{ R-squared } & 0.744 & 0.489 & 0.577 & 0.419 & 0.569 \\
\hline & \multicolumn{5}{|c|}{ Panel II. Refinance Origination Volumes } \\
\hline \multirow[t]{2}{*}{ Program x Jumbo } & -0.553 & 0.289 & 0.176 & $-0.296^{* *}$ & $0.291^{*}$ \\
\hline & $(0.323)$ & $(0.173)$ & $(0.142)$ & $(0.125)$ & $(0.142)$ \\
\hline \multirow[t]{2}{*}{ Jumbo Indicator } & $-2.558^{* * *}$ & $-2.476^{* * *}$ & $-2.285^{* * *}$ & $-2.052^{* * *}$ & $-2.947^{* * *}$ \\
\hline & $(0.074)$ & $(0.079)$ & $(0.084)$ & $(0.074)$ & $(0.116)$ \\
\hline County x Month FEs & Yes & Yes & Yes & Yes & Yes \\
\hline Observations & 984 & 984 & 984 & 984 & 984 \\
\hline R-squared & 0.942 & 0.948 & 0.951 & 0.943 & 0.963 \\
\hline
\end{tabular}

Notes: Panel I reports regression coefficients relating interest rates to the quantitative easing programs and to the other monetary policy programs. The sample includes single-family, first lien, 30-year term, fixed rate, non-interest only, non-balloon, and non-FHA refinance mortgages with no prepayment penalties with less than or equal to $80 \%$ LTV. Controls include binned original LTV and credit score. In all columns, we subtract the contribution of an interaction of the Jumbo Indicator with a measure of Credit Spread (i.e. BBB to AAA spread) and with guarantee fees as described in section 6.1.3 as well as county by month fixed effects. Panel II reports regression coefficients relating refinancing volume to the quantitative easing programs and to the other monetary policy programs. The left hand side variable is defined as the log of the dollar volume of refinanced mortgages as reported in the CRISM data. The sample includes single-family, first lien, non-FHA refinance mortgages. Counties are included in the sample that have positive jumbo originations every month. In both Panel I \& II for all columns, we control for the interaction of the jumbo indicator with a measure of Credit Spread (i.e. BBB to AAA spread), with guarantee fees, and with average bank CDS spreads. QE, MEP ("Maturity Extension Program"), and Tapering Indicators are dummy variables equal to one after the introduction of each program. MEP begins in Sept. 2011. Tapering begins in July 2013. Jumbo Indicator is a dummy equal to one for jumbo loans. QE x Jumbo is the interaction between the program dummies and Jumbo Indicator. The event window includes the six months prior to and after the beginning month of each QE period. For example, QE1 begins in December 2008, and the event window lasts from June 2008 through June 2009. Standard errors are clustered at the month level, and are reported in parentheses. Asterisks denote significance levels $(* * *=1 \%, * *=5 \%, *=10 \%)$. 
Appendix Table 4. Coefficients on Time-Series Controls

\begin{tabular}{|c|c|c|c|c|c|}
\hline & $\begin{array}{c}(1) \\
\text { QE1 }\end{array}$ & $\begin{array}{c}(2) \\
\mathrm{QE} 2\end{array}$ & $\begin{array}{c}(3) \\
\mathrm{MEP}\end{array}$ & $\begin{array}{c}(4) \\
\text { QE3 }\end{array}$ & $\begin{array}{c}(5) \\
\text { Tapering }\end{array}$ \\
\hline & \multicolumn{5}{|c|}{ Panel I. Interest Rates } \\
\hline AB Spread $\times$ Jumbo & $\begin{array}{c}0.276^{* * *} \\
(0.063)\end{array}$ & $\begin{array}{c}0.206^{* * *} \\
(0.049)\end{array}$ & $\begin{array}{c}0.187^{* * *} \\
(0.048)\end{array}$ & $\begin{array}{c}0.130^{* *} \\
(0.057)\end{array}$ & $\begin{array}{c}0.189^{* * *} \\
(0.060)\end{array}$ \\
\hline G-Fee $\times$ Jumbo & $\begin{array}{c}-1.497^{* * *} \\
(0.173)\end{array}$ & $\begin{array}{c}-1.429^{* * *} \\
(0.190)\end{array}$ & $\begin{array}{c}-1.614^{* * *} \\
(0.172)\end{array}$ & $\begin{array}{c}-1.613^{* * *} \\
(0.172)\end{array}$ & $\begin{array}{c}-1.305^{* * *} \\
(0.356)\end{array}$ \\
\hline CDS $\times$ Jumbo & $\begin{array}{l}-0.011 \\
(0.014)\end{array}$ & $\begin{array}{l}-0.000 \\
(0.010)\end{array}$ & $\begin{array}{l}-0.003 \\
(0.010)\end{array}$ & $\begin{array}{c}0.018 \\
(0.011)\end{array}$ & $\begin{array}{c}0.004 \\
(0.012)\end{array}$ \\
\hline Controls & Yes & Yes & Yes & Yes & Yes \\
\hline County-Month FEs & Yes & Yes & Yes & Yes & Yes \\
\hline Observations & $2,618,508$ & $2,839,677$ & $3,057,411$ & $2,970,252$ & $2,937,633$ \\
\hline \multirow[t]{2}{*}{ R-squared } & 0.781 & 0.799 & 0.788 & 0.740 & 0.748 \\
\hline & \multicolumn{5}{|c|}{ Panel II. Refinance Origination Volume } \\
\hline AB Spread $\times$ Jumbo & $\begin{array}{c}0.002 \\
(0.002)\end{array}$ & $\begin{array}{l}-0.001 \\
(0.002)\end{array}$ & $\begin{array}{l}-0.001 \\
(0.002)\end{array}$ & $\begin{array}{l}-0.002 \\
(0.002)\end{array}$ & $\begin{array}{l}-0.002 \\
(0.002)\end{array}$ \\
\hline G-Fee $\times$ Jumbo & $\begin{array}{c}0.025^{* * *} \\
(0.004)\end{array}$ & $\begin{array}{c}0.022^{* * *} \\
(0.004)\end{array}$ & $\begin{array}{c}0.026^{* * *} \\
(0.004)\end{array}$ & $\begin{array}{c}0.025^{* * *} \\
(0.004)\end{array}$ & $\begin{array}{c}0.033^{* * *} \\
(0.005)\end{array}$ \\
\hline CDS $\times$ Jumbo & $\begin{array}{c}-0.001^{* * *} \\
(0.000)\end{array}$ & $\begin{array}{c}-0.001^{* *} \\
(0.000)\end{array}$ & $\begin{array}{c}-0.001^{*} \\
(0.000)\end{array}$ & $\begin{array}{l}-0.001 \\
(0.000)\end{array}$ & $\begin{array}{c}-0.001^{*} \\
(0.000)\end{array}$ \\
\hline Controls & Yes & Yes & Yes & Yes & Yes \\
\hline County-Month FEs & Yes & Yes & Yes & Yes & Yes \\
\hline Observations & 4,920 & 4,920 & 4,920 & 4,920 & 4,920 \\
\hline R-squared & 0.930 & 0.930 & 0.930 & 0.932 & 0.932 \\
\hline
\end{tabular}

Notes: Each column estimates the relationship between interest rates (panel I) and origination volumes (panel II) to credit spreads and guarantee fees for all months between 2008-2013 except for the six months before/after the indicated program. The sample for panel I includes loans with LTV less than or equal to $80 \%$, controlling for county by month fixed effects. The sample for panel II has two observations for each county-month: log of total refinance origination below the conforming loan limit and above the conforming loan limit for counties that had non-zero refinancing activity in both the jumbo and non-jumbo segments throughout the sample period. We control for county by month fixed effects. QE1 begins in December 2008, QE2 begins in September 2010, MEP begins in September 2011, QE3 begins in September 2012, and Tapering begins in June 2013. Clustered standard errors are reported in parentheses. Asterisks denote significance levels $(* * *=1 \%, * *=5 \%, *=10 \%)$. 
Appendix Table 5. OLS Estimation of Treasury Rates and Predicted Mortgage Rates

(1)

(3)

(4)

$(5)$

(6)

Predicted

Predicted

Predicted

Predicted Conforming Predicted Conforming Predicted Conforming

Jumbo Rate

Rate Jumbo Rate

Rate

Jumbo Rate

Rate

5-year Treasury Yield

$0.631^{* * *} \quad 0.635^{* * *}$

(0.018)

(0.025)

10-year Treasury Yield

(0.018)

$\begin{array}{cccc} & & 0.063 & 0.199^{* * *} \\ & & (0.087) & (0.070) \\ 0.841^{* * *} & 0.836^{* * *} & 0.762^{* * *} & 0.585^{* * *} \\ (0.030) & (0.019) & (0.120) & (0.093) \\ 0.026^{* * *} & 0.024^{* * *} & 0.027^{* * *} & 0.028^{* * *} \\ (0.001) & (0.001) & (0.002) & (0.001)\end{array}$

Constant

$0.038^{* * *}$

$0.037^{* * *}$

(0.001)

(0.001)

(0.001)

(0.001)

(0.002)

(0.001)

Observations

156

156

156

156

156

156

R-squared

0.763

0.862

0.802

0.883

0.803

0.888

Notes: Each column estimates the relationship between interest rates to constant maturity treasury yields. The odd columns consider the jumbo rates, while the even columns analyze the conforming rates. Columns 1 and 2 consider the relation between mortgage rates and the treasury rate with 5 year maturity, while Columns 3 and 4 investigate the relation to the 10 year maturity. Columns 5 and 6 consider include both treasury rates in the specification. Clustered standard errors are reported in parentheses. Asterisks denote significance levels $(* * *=1 \%, * *=5 \%, *=10 \%)$. 
Appendix Table 6. Prepayment Probability during QE1 (Dec. 2008-May 2009)

$(1)$

$(2)$

(3)

$(4)$

$(5)$

Prediction Prediction for Prediction for

Prediction (Loan \& LTV Cap LTV Cap

Current LTV Actual Percent (Loan Borrower Increase to $90 \%$ Increase to $90 \%$

Bin Prepaid Controls) Controls)

(Col. 2)

(Col. 3)

$\begin{array}{llllll}{[0 \%, 60 \%]} & 7.4 \% & 7.9 \% & 7.9 \% & 7.9 \% & 7.9 \% \\ (60 \%, 70 \%] & 7.1 \% & 7.3 \% & 7.3 \% & 7.3 \% & 7.3 \% \\ (70 \%, 80 \%] & 6.7 \% & 6.8 \% & 6.7 \% & 7.7 \% & 7.7 \% \\ (80 \%, 90 \%] & 4.1 \% & 4.4 \% & 4.3 \% & 7.3 \% & 6.9 \% \\ (90 \%, 100 \%] & 2.4 \% & 2.5 \% & 2.4 \% & 4.9 \% & 4.4 \% \\ (100 \%, 110 \%] & 1.2 \% & 1.4 \% & 1.2 \% & 1.4 \% & 1.2 \% \\ (110 \%, 120 \%] & 0.7 \% & 0.7 \% & 0.5 \% & 0.7 \% & 0.5 \% \\ \text { Above } 120 \% & 0.8 \% & 0.7 \% & 0.4 \% & 0.7 \% & 0.4 \%\end{array}$

Note: Table reports the actual percent of loans prepaying over Dec. 2008-May 2009 in column 1, the predicted probability of prepayment using the hazard model with loan characteristic controls in column 2, and the predicted probability of prepayment using the hazard model with loan and borrower characteristic controls in column 3. Columns $4 \& 5$ predict prepayment probability by shifting the LTV bins down by one bin for loans with current LTV between $70 \%$ and $100 \%$. 
Appendix Table 7. Cash-Out Estimate during QE1 (Dec. 2008-May 2009)

$(1)$

(2)

(3)

Cash-Out Model Prediction for LTV

Current LTV Actual Average Cash- (Loan \& Equity Increase \& Equity

\begin{tabular}{lccc}
\multicolumn{1}{c}{ Bin } & Out & Controls) & Decrease (Col. 3) \\
\hline$[0 \%, 60 \%]$ & & & \\
$(60 \%, 70 \%]$ & $\$ 39,176$ & $\$ 39,176$ & $\$ 40,371$ \\
$(70 \%, 80 \%]$ & $\$ 17,752$ & $\$ 17,752$ & $\$ 18,614$ \\
$(80 \%, 90 \%]$ & $\$ 9,316$ & $\$ 9,316$ & $\$ 14,580$ \\
$(90 \%, 100 \%]$ & $\$ 2,700$ & $\$ 2,700$ & $\$ 7,982$ \\
$(100 \%, 110 \%]$ & $\$ 2,170$ & $\$ 2,170$ & $\$ 501$ \\
$(110 \%, 120 \%]$ & $(\$ 3,796)$ & $(\$ 3,796)$ & $(\$ 3,338)$ \\
Above $120 \%$ & $(\$ 89,126)$ & $(\$ 89,126)$ & $(\$ 88,387)$ \\
\hline
\end{tabular}

Note: Table reports the actual cash-out amounts over Dec. 2008-May 2009 in column 1, and the predicted cash-out amounts using an OLS model with loan and equity characteristic controls in column 2. Column 3 predicts cash-out amounts by shifting the LTV bins down by one bin for loans with current LTV between $70 \%$ and $100 \%$, and changing the equity calculation from $20 \%$ to $10 \%$. Equity calculated as property value minus unpaid balance on original loan minus $20 \%$ of property value. 
Appendix Table 8. Prepayment Probability during QE1 using Refinance Hazard Model Results

\begin{tabular}{|c|c|c|}
\hline & $(1)$ & $(2)$ \\
\hline \multirow[t]{2}{*}{ Ln(Original Loan Amount) } & $0.319^{* * *}$ & $0.251^{* * *}$ \\
\hline & $(0.009)$ & $(0.010)$ \\
\hline \multirow[t]{2}{*}{ CLL $+60000<$ Current Balance } & $-1.066^{* * *}$ & $-1.067 * * *$ \\
\hline & (0.023) & $(0.025)$ \\
\hline \multirow[t]{2}{*}{$\mathrm{LTV}<=60 \%$} & $-7.015^{* * *}$ & $-6.154^{* * *}$ \\
\hline & $(0.116)$ & $(0.133)$ \\
\hline \multirow[t]{2}{*}{$60 \%<\mathrm{LTV}<=70 \%$} & $-7.088^{* * *}$ & $-6.175^{* * *}$ \\
\hline & $(0.117)$ & $(0.135)$ \\
\hline \multirow[t]{2}{*}{$70 \%<\mathrm{LTV}<=80 \%$} & $-7.200 * * *$ & $-6.291^{* * *}$ \\
\hline & $(0.117)$ & $(0.134)$ \\
\hline \multirow[t]{2}{*}{$80 \%<\mathrm{LTV}<=90 \%$} & $-7.714^{* * *}$ & $-6.800 * * *$ \\
\hline & $(0.118)$ & $(0.136)$ \\
\hline \multirow[t]{2}{*}{$90 \%<\mathrm{LTV}<=100 \%$} & $-8.320^{* * *}$ & $-7.366^{* * *}$ \\
\hline & $(0.120)$ & $(0.139)$ \\
\hline \multirow[t]{2}{*}{$100 \%<\mathrm{LTV}<=110 \%$} & $-8.984^{* * *}$ & $-8.106^{* * *}$ \\
\hline & $(0.134)$ & $(0.155)$ \\
\hline \multirow[t]{2}{*}{$110 \%<\mathrm{LTV}<=120 \%$} & $-9.671^{* * *}$ & $-9.051^{* * *}$ \\
\hline & $(0.187)$ & $(0.235)$ \\
\hline \multirow[t]{2}{*}{$120 \%<\mathrm{LTV}$} & $-9.779 * * *$ & $-9.348^{* * *}$ \\
\hline & $(0.206)$ & $(0.285)$ \\
\hline Loan Controls & Yes & Yes \\
\hline Borrower Controls & & Yes \\
\hline Observations & $2,468,905$ & $2,035,027$ \\
\hline
\end{tabular}

Notes: Table reports the results of a hazard model estimating the propensity to refinance. All specifications include a cubic function of loan age as a non-parametric baseline hazard. Loanlevel controls include current LTV bin, loan size at origination, and current balance over the conforming loan limit. Borrower controls include DTI, a missing DTI indicator, and FICO bins. Jumbo is an indicator for loan amount at least $\$ 60,000$ above the CLL to account for cash-in refinancing. Robust standard errors in parentheses. 
Appendix Table 9. Cash-Out Regression Estimates during QE1

\begin{tabular}{|c|c|c|c|}
\hline & $(1)$ & $(2)$ & $(3)$ \\
\hline \multirow[t]{2}{*}{ Equity Available (20\%) } & & $0.025^{* * *}$ & $0.023^{* * *}$ \\
\hline & & $(0.006)$ & $(0.006)$ \\
\hline \multirow[t]{2}{*}{ Unpaid Balance $>80 \%$ LTV X Equity Available (20\%) } & & & $0.451^{* * *}$ \\
\hline & & & (0.098) \\
\hline \multirow[t]{2}{*}{ Log Unpaid Balance } & $-5,942.455^{* * *}$ & $-7,736.501 * * *$ & $-5,584.112^{* * *}$ \\
\hline & $(293.676)$ & $(526.326)$ & $(699.385)$ \\
\hline \multirow[t]{2}{*}{ Unpaid Balance $>$ CLL $+\$ 60,000$} & $-89,972.064^{* * *}$ & $-94,673.259^{* * *}$ & $-89,991.239^{* * *}$ \\
\hline & $(2,765.606)$ & $(2,889.990)$ & $(2,808.333)$ \\
\hline \multirow[t]{2}{*}{$60 \%<\mathrm{LTV}<=70 \%$} & $-17,270.706^{* * *}$ & $-13,462.585^{* * *}$ & $-14,157.241^{* * *}$ \\
\hline & $(404.527)$ & $(1,017.086)$ & $(968.142)$ \\
\hline \multirow[t]{2}{*}{$70 \%<\mathrm{LTV}<=80 \%$} & $-22,716.783^{* * *}$ & $-17,938.175^{* * *}$ & $-18,871.462^{* * *}$ \\
\hline & $(412.408)$ & $(1,246.156)$ & $(1,186.598)$ \\
\hline \multirow[t]{2}{*}{$80 \%<\mathrm{LTV}<=90 \%$} & $-27,876.773^{* * *}$ & $-22,551.291^{* * *}$ & $-19,801.435^{* * *}$ \\
\hline & $(353.535)$ & $(1,361.538)$ & $(1,341.236)$ \\
\hline \multirow[t]{2}{*}{$90 \%<\mathrm{LTV}<=100 \%$} & $-26,181.303^{* * *}$ & $-20,318 \cdot 167^{* * *}$ & $-6,619.607^{* *}$ \\
\hline & $(328.689)$ & $(1,487.384)$ & $(3,150.314)$ \\
\hline \multirow[t]{2}{*}{$100 \%<\mathrm{LTV}<=110 \%$} & $-31,690.277^{* * *}$ & $-26,046.732^{* * *}$ & $-10,656.271^{* * *}$ \\
\hline & $(353.255)$ & $(1,439.077)$ & $(3,467.823)$ \\
\hline \multirow[t]{2}{*}{$110 \%<\mathrm{LTV}<=120 \%$} & $-110,364.624^{* * *}$ & $-101,578.779^{* * *}$ & $-60,053.387^{* * *}$ \\
\hline & $(3,989.665)$ & $(4,443.665)$ & $(9,589.823)$ \\
\hline \multirow[t]{2}{*}{$120 \%<\mathrm{LTV}$} & $-166,534.843^{* * *}$ & $-156,179.071^{* * *}$ & $-86,735.836^{* * *}$ \\
\hline & $(5,896.883)$ & $(6,131.483)$ & $(12,833.365)$ \\
\hline R-squared & 0.035 & 0.038 & 0.040 \\
\hline Observations & 820,653 & 820,653 & 820,653 \\
\hline
\end{tabular}

Notes: Table reports regression estimates of cash-out refinances. Left-hand side variable is cash-out amount. To account for rolling closing costs into the balance of the new loan, we add average refinancing costs $(\$ 3,000)$ to the loan balance before the refinance. All specifications include a cubic function of loan age as a nonparametric baseline hazard. Equity Available is calculated as property value minus unpaid balance on the borrower's previous mortgage, minus a $20 \%$ down payment (calculated as $20 \%$ of the original loan amount). Loan-level controls include current LTV bin, and loan size at origination. Jumbo is an indicator for loan amount at least $\$ 60,000$ above the CLL to account for cash-in refinancing. Robust standard errors in parentheses. 